Utah State University

DigitalCommons@USU

\title{
8-2013
}

\section{Acceptance and Commitment Therapy for the Treatment of Posttraumatic Stress Among Adolescents}

Michelle R. Woidneck

Utah State University

Follow this and additional works at: https://digitalcommons.usu.edu/etd

Part of the Psychology Commons

\section{Recommended Citation}

Woidneck, Michelle R., "Acceptance and Commitment Therapy for the Treatment of Posttraumatic Stress Among Adolescents" (2013). All Graduate Theses and Dissertations. 1385.

https://digitalcommons.usu.edu/etd/1385

This Dissertation is brought to you for free and open access by the Graduate Studies at DigitalCommons@USU. It has been accepted for inclusion in All Graduate Theses and Dissertations by an authorized administrator of DigitalCommons@USU. For more information, please contact digitalcommons@usu.edu.

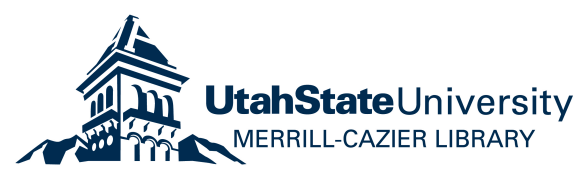




\title{
ACCEPTANCE AND COMMITMENT THERAPY FOR THE TREATMENT OF POSTTRAUMATIC STRESS AMONG ADOLESCENTS
}

\author{
by
}

Michelle R. Woidneck

A dissertation submitted in partial fulfillment

of the requirements for the degree

of

DOCTOR OF PHILOSOPHY

in

Psychology

Approved:

Michael P. Twohig, Ph.D.

Major Professor

Clinton E. Field, Ph.D.

Committee Member

Timothy Slocum, Ph.D.

Committee Member
Donna Gilbertson, Ph.D.

Committee Member

Gretchen Gimpel Peacock, Ph.D.

Committee Member

Mark R. McLellan, Ph.D.

Vice President for Research and

Dean of the School of Graduate Studies

UTAH STATE UNIVERSITY

Logan, Utah 
Copyright (C Michelle Woidneck 2012

All Rights Reserved 


\author{
ABSTRACT \\ Acceptance and Commitment Therapy for the Treatment of \\ Posttraumatic Stress Among Adolescents \\ by \\ Michelle R. Woidneck, Doctor of Philosophy \\ Utah State University, 2012
}

Major Professor: Michael P. Twohig, Ph.D.

Department: Psychology

Trauma exposure among youth in the United States is a common event. Although the number of individuals who meet criteria for a diagnosis of posttraumatic stress disorder (PTSD) is only a small percentage of those exposed to trauma, many individuals who do not meet full criteria for PTSD continue to experience problematic posttraumatic stress symptomology. Acceptance and commitment therapy (ACT) is an empiricallybased psychological intervention that has shown effectiveness in the treatment of a number of concerns among both adults and adolescents. ACT has shown preliminary effectiveness in the treatment of adult PTSD, but its effectiveness in treating adolescent posttraumatic stress is currently unknown. Using a multiple-baseline design, the present study investigated the effectiveness of a 10-week ACT protocol to treat adolescents experiencing posttraumatic stress. Seven individuals between the ages of 12 and 17 participated in the treatment, four of who were from a community sample and three who 
were in residential care to treat comorbid eating disorders. Structured interviews were completed at pretreatment and individuals reported baseline data for anywhere from 7 to 66 days before engaging in treatment. Symptom and process measures were completed at each session. Postassessment was completed one week following the final session.

Results revealed a decrease in posttraumatic stress symptomology across both samples, with a $73.7 \%$ mean reduction in self-reported posttraumatic stress symptomology and a mean reduction of $58.8 \%$ on clinician-rated measures of PTSD. Overall results provide preliminary support for ACT as an effective treatment for adolescent posttraumatic stress. Empirical and clinical implications of results as well as limitations and future directions are discussed. 
PUBLIC ABSTRACT

\author{
Acceptance and Commitment Therapy for the Treatment of \\ Posttraumatic Stress Among Adolescents \\ by \\ Michelle R. Woidneck, Doctor of Philosophy \\ Utah State University, 2012
}

The prevalence of exposure to traumatic events among youth in the United States is alarmingly high. Trauma exposure has been linked to numerous negative outcomes, including the development of posttraumatic stress disorder (PTSD) and problematic posttraumatic stress symptomology. Effective trauma-focused treatments for children and adolescents have been identified; however, these treatments also possess various limitations, including a substantial number of individuals who do not respond, show minimal responsiveness, or drop out before completing treatment. Such limitations indicate that investigation into alternative treatment modalities is warranted.

In collaboration with Utah State University (USU), a psychology professor, Dr. Michael Twohig, and a USU doctoral student, Michelle Woidneck, conducted a study examining the utility of Acceptance and Commitment Therapy (ACT) as a treatment for adolescents with posttraumatic stress. The project's main purpose was to explore the effectiveness of a 10-week ACT protocol to treat posttraumatic stress among adolescents 
from two samples. Another important aim was to evaluate the treatment acceptability of the selected intervention.

Findings from the project showed a decrease in posttraumatic stress symptomology on multiple measures. Positive changes on measures of depression, general distress, and quality of life were also observed. The overall treatment acceptability among participants was high. Taken together, these results provide preliminary support for ACT as an effective treatment for adolescent posttraumatic stress. 


\section{ACKNOWLEDGMENTS}

I first want to express my gratitude to my advisor and mentor, Dr. Michael Twohig, who believed in my ability to take on this project and for his ongoing guidance, advice, and encouragement. I would also like to thank my committee members, Drs. Donna Gilbertson, Gretchen Peacock, Clinton Field, and Timothy Slocum, for helpful suggestions, support, and time dedicated to this project. Thanks to my senior lab mates and colleagues, Jesse Crosby and Andrew Armstrong, for helping to pave the way and for sharing materials and insights throughout the dissertation process. Many thanks go to Kate Morrison, as well, for assistance with the treatment adherence evaluation process. Benson Munyan was also an asset who helped with recruitment and data entry.

This project also would not have been possible without the collaboration and support of Dr. Tera Lensegrav-Benson, Dr. Benita Quakenbush-Roberts, Gary Roberts, and the associated Treatment and Executive Teams - thank you. To my parents and family, I will be forever grateful for your ongoing love and encouragement; I would not be where I am today without your support. Finally, I thank the participants of this study for their time and for trusting me enough to engage in this journey together. The courage and willingness of these individuals and families is admirable and inspirational, and it was an honor to be a part of the healing process.

Michelle R. Woidneck 


\section{CONTENTS}

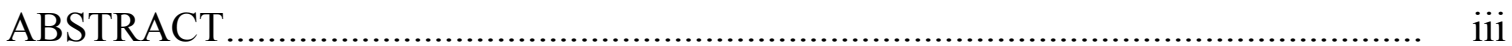

PUBLIC ABSTRACT ….............................................................................

ACKNOWLEDGMENTS ................................................................................. vii

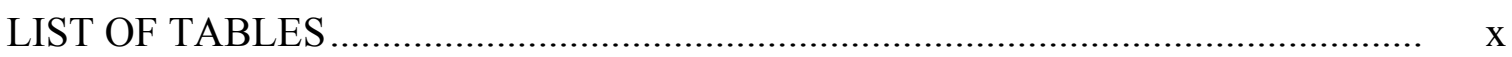

LIST OF FIGURES ............................................................................... xi

\section{CHAPTER}

I. INTRODUCTION ....................................................................... 1

II. REVIEW OF LITERATURE …........................................................... 5

PTSD Diagnostic Criteria and Considerations ........................................ 5

Prevalence and Comorbidity Among Adults .............................................. 7

Adolescents and Trauma............................................................................. 9

Current Treatments .......................................................................... 13

Limitations of Existing Outcome Research .......................................... 15

Acceptance and Commitment Therapy................................................ 19

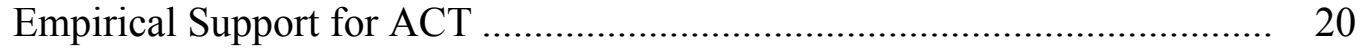

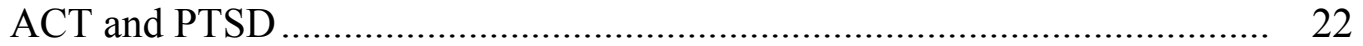

III. METHOD …................................................................................. 25

Participants and Setting....................................................................... 25

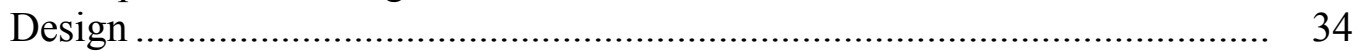

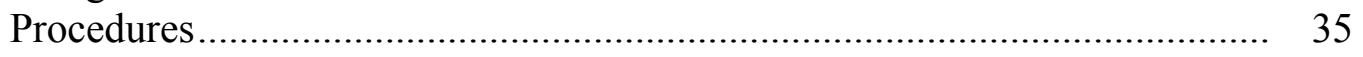

Measures ............................................................................. 36

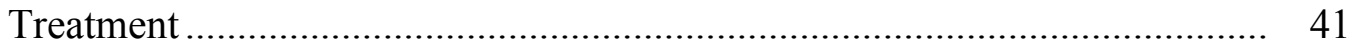

Treatment Adherence .......................................................................... 41

IV. $\quad$ RESULTS ................................................................................ 46

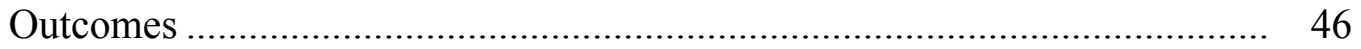

Summary of Outcome Results ......................................................... 60

Psychological Process of Change Results............................................... 61 


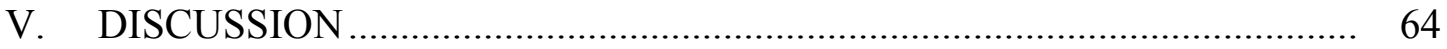

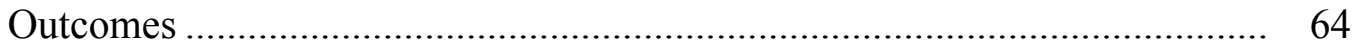

Empirical and Clinical Implications ..................................................... 68

Limitations and Future Directions ..................................................... 72

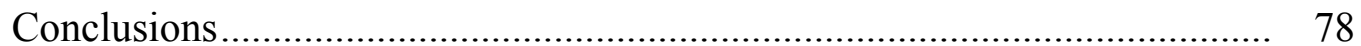

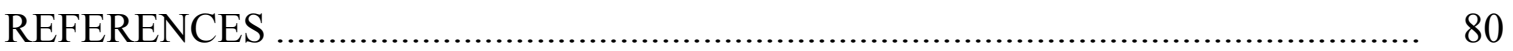

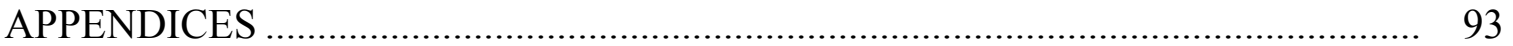

Appendix A: Recruiting Materials ........................................................... 94

Appendix B: Informed Consent/Assent ................................................. 98

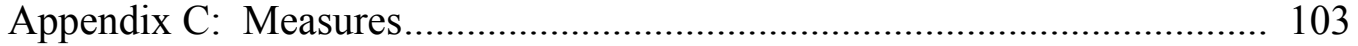

Appendix D: Treatment Adherence ........................................................... 115

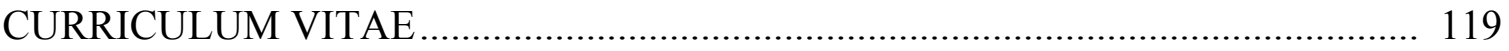




\section{LIST OF TABLES}

Table $\quad$ Page

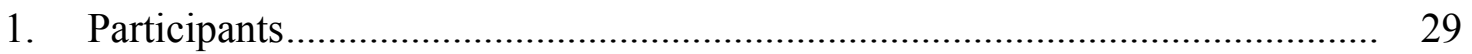

2. Summary of Treatment Sessions ...................................................... 43

3. Means and Standard Deviations from Pretreatment to Posttreatment .............. 61 


\section{LIST OF FIGURES}

Figure $\quad$ Page

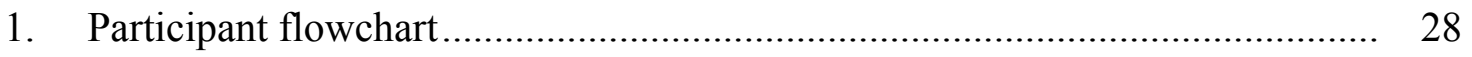

2. Daily trauma ratings and weekly ACT process data................................... 47

3. Clinician Administered PTSD Scale ............................................................ 48

4. Child PTSD Symptom Scale................................................................... 48

5. Children's Depression Inventory ....................................................... 48

6. Brief Symptom Inventory Global Severity Index ...................................... 48

7. Comprehensive Quality of Life-Objective Scores .................................. 48

8. Comprehensive Quality of Life-Subjective Scores ................................ 48

9. Lag correlations: Weekly PTS and process ratings across participants............ 63 


\section{CHAPTER I}

\section{INTRODUCTION}

More than $25 \%$ of youth in the United States are exposed to at least one traumatic event by the age of 16 (Costello, Erkanali, Fairbanks, \& Angold, 2002). The prevalence of posttraumatic stress disorder (PTSD) among youth, however, has been found to be lower, with 6-month prevalence estimates around 3.7\% for boys and $6.3 \%$ for girls (Kilpatrick et al., 2003). The Diagnostic and Statistical Manual of Mental Disorders-TR (DSM-IV-TR) diagnostic criteria for PTSD do not currently differ between adolescents and adults; however, the applicability of the DSM's criteria to youth is questionable (American Academy of Child and Adolescent Psychiatry [AACAP], 2010). Many children and adolescents who are exposed to trauma develop clinically significant posttraumatic stress (PTS) symptomology, but do not meet the full diagnostic criteria for PTSD. Nevertheless, research indicates that these individuals experience functional impairments comparable to those who do meet diagnostic criteria for PTSD (Carrion, Weems, Ray, \& Reiss, 2002).

Empirical evidence demonstrates that exposure to trauma is strongly related to a number of negative outcomes. Youth who experience a traumatic event have significantly higher rates of depression, poor academic achievement, substance abuse, disrupted interpersonal relationships, poor health, suicidal ideation, and other internalizing and externalizing problems compared to youth with no history of trauma exposure (e.g., Berman, Kurtines, Silverman, \& Serafini, 1996; Flannery, Wester, \& Singer, 2004; Giaconia et al., 1995; Gorman-Smith \& Tolan, 1998; Nader, Pynoos, Fairbanks, \& 
Frederick, 1990; Osofsky, Wewers, Hann, \& Fick, 1993; Schwab-Stone et al., 1999; Schwartz \& Gorman, 2003; Singer, Anglin, Song, \& Lunghofer, 1995). Additionally, youth who have been exposed to violence and/or abuse are at greater risk for later revictimization (Classen, Palesh, \& Aggarwal, 2005), and the risk of developing more severe problems, such as PTSD, becomes higher following every exposure to a traumatic event (e.g., Cougle, Resnick, \& Kilpatrick, 2009; Dohrenwend et al., 2006; Kilpatrick \& Saunders, 1999). Further, individuals who were exposed to trauma in childhood/adolescence often continue to experience problematic PTS symptoms into their college years (e.g., Brady, 2006; Scarpa et al., 2002).

Trauma-Focused Cognitive Behavioral Therapy (TF-CBT) is the recommended fist-line of therapy of PTS and PTSD among youth (AACAP, 2010). TF-CBT has shown effectiveness in reducing PTS symptomology among youth (Silverman et al., 2008); however, there are a number of limitations with the existing research in this area. The content and emphasis of individual interventions classified as TF-CBT varies considerably. The differences across interventions make it difficult to draw general conclusions about the effectiveness of TF-CBT and also make it impossible to discern what treatment components are responsible for change. Additionally, many youth do not respond, show minimal responsiveness, or drop out before completing treatment (Stallard, 2006). Further, the majority of research has focused on a specific type of trauma rather than PTS following exposure to trauma generally. In sum, at this time it is unknown what specific treatment strategies are effective with which trauma populations in alleviating which symptoms. While these limitations do not negate the value of TF-CBT, they do 
suggest that additional research regarding the treatment of youth with PTS and PTSD is needed.

Acceptance and commitment therapy (ACT; Hayes, Strosahl, \& Wilson, 1999) is an empirically based psychological intervention that has shown effectiveness in the treatment of a number of concerns among adults and may be beneficial in the treatment of PTS and PTSD among young people. Unlike traditional CBT approaches, ACT does not directly focus on symptom reduction, but rather targets the utility and function of psychological experiences such as thoughts, feelings, memories, and physiological sensations, and pursuing meaningful life activities regardless of their presence. ACT uses various behavioral and experiential techniques to target six core processes with the aim of creating change that will allow individuals to function with their traumatic memories in a way that is more personally meaningful and values driven.

ACT has been shown to effectively treat a number of concerns among adults and adolescents (Murrell \& Scherbarth, 2006; Ruiz, 2010), but no large studies investigating the effectiveness of ACT as a treatment for PTS or PTSD currently exist. Four case studies have shown preliminary support for the use of ACT as a treatment of PTSD in adults (Codd, Twohig, Crosby, \& Enno, 2011; Orsillo \& Batten, 2005; Twohig, 2009) and late-adolescence/young-adulthood (Batten \& Hayes, 2005). Further, given the central role of emotional avoidance in individuals with PTS and PTSD, ACT theoretically makes sense as a treatment for PTS (Walser \& Hayes, 2006). Research suggests individuals who attempt to avoid or suppress distressing trauma-related thoughts experience both an increase in the frequency of these thoughts (Shipherd \& Beck, 2005) and greater PTS 
symptom severity generally (Cameron, Palm, \& Follette, 2010); thus, providing further support for the use of ACT as a treatment for PTS.

Given the limitations of standard PTS/PTSD treatment approaches with adolescents and the potential promise of ACT as a treatment for PTS, the evaluation of ACT for PTS is warranted. The purpose of this study is to provide preliminary data on the effectiveness of ACT for PTS among adolescents between the ages of 12 and 17. This study aimed to answer the following questions:

1. Does ACT positively influence behavior change, general functioning, quality of life, general distress, depression, and severity of PTS and PTSD related symptoms among youth with posttraumatic stress?

2. How does ACT affect its presumed processes of change?

3. How acceptable is ACT as treatment for youth with posttraumatic stress? 


\section{CHAPTER II}

\section{REVIEW OF LITERATURE}

\section{PTSD Diagnostic Criteria and Considerations}

The DSM-IV-TR defines PTSD as an Axis I anxiety disorder characterized by four main components: (1) exposure to a traumatic event; (2) persistent psychological and/or physiological re-experiences of the event; (3) persistent avoidance of reminders of the trauma and numbing of general responsiveness; and (4) persistent symptoms of increased arousal that were not present prior to the event. According to the DSM-IV-TR, in order for a situation to be considered traumatic, the individual must have experienced or witnessed an event that involved or threatened death or serious injury and/or threatened the physical integrity of that individual or others. Additionally, at the time of the traumatic event, the individual must have responded with intense fear, helplessness, and/or horror. For children, this response may have alternatively consisted of disorganized or agitated behavior (American Psychiatric Association [APA], 2000). Examples of these traumas include sexual or physical assault, child physical or sexual abuse, natural disasters, sudden loss of a loved one, domestic violence, war combat, motor vehicle accidents, and others. To meet the diagnostic criteria for PTSD, an individual must also display at least one re-experiencing symptom, three or more avoidance/numbing symptoms, and two or more increased arousal symptoms that persist longer than one month following exposure to the traumatic event, and these symptoms 
must cause clinically significant distress or impairment to the individual's life (APA, 2000).

The DSM-IV-TR diagnostic criteria for PTSD do not currently differ for adolescents and adults; and it should be noted that these criteria were developed from research conducted with primarily adult samples without inclusion of any individuals under the age of 16 (Kilpatrick et al., 1998). Thus, the applicability of the current DSM's criteria to children and adolescents has been debated, and factor analytic studies have found notable differences in posttraumatic stress symptomology in adolescents compared to adults (e.g., Anthony, Lonigan, \& Hecht, 1999; Anthony et al., 2005; Sack, Seeley, \& Gregory, 1997; Saul, Grant, \& Carter, 2008). These studies support different models of PTSD that better match adolescents' symptomology, including a three-cluster model consisting of intrusion/avoidance symptoms, arousal symptoms, and numbing/passive avoidance symptoms (Anthony et al., 1999, 2005), or a four-factor model consisting of arousal, avoidance, intrusion, and numbing symptoms (Sack et al., 1997; Saul et al., 2008). In general, there is clinical agreement that PTSD in youth may manifest with dysregulation of physical, affective, behavioral, cognitive, and/or interpersonal functioning that is not adequately depicted in the current PTSD diagnostic criteria (AACAP, 2010). In fact, a number of potential revisions for the DSM-V have been suggested for preschool and school-age children as well as for adolescents, including broadening the range of reactions to trauma exposure (DSM-IV criterion A), adding alternative behavioral manifestations for a number of existing avoidance and arousal 
criteria, and reducing the number of avoidance symptoms required for a PTSD diagnosis (Scheeringa, Zeanah, \& Cohen, 2010).

The specific PTSD criteria changes are presently under development; however, the current draft of the DSM-V to be released in May 2013 includes the addition of developmentally appropriate criteria for PTSD to better fit the differences in the expression of posttraumatic stress across the lifespan (APA, 2012). Specifically, the proposed changes include a broadened definition of criterion A, including the removal of any specific emotional response at the time of the traumatic event and separation of the DSM-IV-TR's current criterion C (avoidance/numbing symptoms) into two separate categories: avoidance and negative alterations in cognitions and mood. The proposed diagnostic criteria will require only one avoidance symptom and two or more negative alterations in cognitions and mood symptoms. The number of re-experiencing and hyperarousal symptoms is proposed to remain the same as the current diagnositic criteria; however, additional behavioral manifestations have been added to the list of hyperarousal symptons. A specific subtype of PTSD (PTSD in Preschool Children) has also been proposed, and a separate set of diagnostic criteria are presented for this group (APA, 2012).

\section{Prevalence and Comorbidity Among Adults}

Epidemiological research has found that the majority of the United States population will be exposed to a traumatic event at some point during their lifetimes (e.g., Breslau et al., 1998; Kessler, Sonnega, Bromet, Hughes, \& Nelson, 1995; Sledjeski, 
Speisman, \& Dierker, 2008). Data from the National Comorbidity Survey-Replication (NCS-R), a large-scale, nationally representative household survey of mental illness conducted between February 2001 and April 2003, found that 81.7\% of respondents reported a lifetime exposure to a stressor that met the diagnostic criteria within PTSD. The lifetime prevalence of PTSD in the United States, however, has been found to be much lower, with estimates ranging between $6.8 \%$ to $7.8 \%$ (Cox, Clara, \& Enns, 2002; Kessler, Berglund, Demler, Jin, \& Walters, 2005). Although the majority of individuals exposed to traumatic events never go on to meet the diagnostic criteria for PTSD, empirical evidence suggests PTSD is not the only clinically significant consequence of exposure to trauma. Individuals exposed to trauma may subsequently experience depression, other anxiety disorders, and/or drug abuse or dependency (Galea et al., 2002; Shalev et al., 1998). Further, the risk of developing PTSD becomes increasingly higher following each exposure to a traumatic event (e.g., Cougle et al., 2009; Dohrenwend et al., 2006; Kilpatrick \& Saunders, 1999).

Comorbidity and associated problems among adults with PTSD is high. Physical illness has been found to be associated with PTSD, such that individuals with PTSD report higher rates of chronic pain and general physical complaints (e.g., Asmundson, Coons, Taylor, \& Katz, 2002; Roy-Byrne, Noonan, Afari, Buchwald, \& Goldberg, 2006; Roy-Byrne, Smith, Goldberg, Afari, \& Buchwald, 2004) as well as have a higher rate of cardiovascular/circulatory, autoimmune, musculoskeletal, digestive, and respiratory disorders (e.g., Boscarino, 2004; Kang, Bullman, \& Taylor, 2006; Sareen et al., 2007). Additionally, lifetime comorbidity of psychiatric diagnoses among those with PTSD is up 
to $80 \%$, which is significantly higher than individuals without PTSD or individuals with other diagnoses (Fairbanks, Ebert, \& Caddell, 2001). PTSD is also associated with disruptions in work, social functioning, and physical health (e.g., Alonso et al., 2004; Galovski \& Lyons, 2004; Smith, Schnurr, \& Rosenheck, 2005). Such problems can be costly, and in fact, PTSD has been suggested to be the most costly anxiety disorder in terms of per person health care expenditures (Greenberg et al., 1999).

\section{Adolescents and Trauma}

More than $25 \%$ of youth in the United States are exposed to at least one traumatic event by the age of 16 (Costello et al., 2002). Over the past few decades, concern regarding youth violence has gained increasing attention in the media and schools. According to the Office of the Surgeon General, "violence is the greatest threat to the lives of America's children and adolescents" (United States Department of Health and Human Services, 2001, pp. 51-52). In a survey of 12- to 17-year-olds, $8 \%$ reported a history of at least one sexual assault, 17\% reported a past physical assault, and 39\% reported witnessing violence (Kilpatrick \& Saunders, 1999). A telephone survey of a nationally representative sample of 2,000 individuals between 10 and 16 years of age found that $40 \%$ of the sample reported being victims of at least one physical or sexual assault (Boney-McCoy \& Finkelhor, 1995). Additionally, those who were victims of violence reported significantly more problematic psychological and behavioral symptomology, such as PTSD, increased sadness, and more school difficulties compared to non-victimized participants. These findings are consistent with prior and subsequent 
research regarding the positive relationship between youth exposed to violence and emotional and behavioral difficulties, including PTSD, depression, academic achievement, interpersonal relationships, substance abuse, and other internalizing and externalizing problems (e.g., Berman et al., 1996; Flannery et al., 2004; Gorman-Smith \& Tolan, 1998; Nader et al., 1990; Osofsky et al., 1993; Schwab-Stone et al., 1999; Schwartz \& Gorman, 2003; Singer et al., 1995). Further, the negative impact of trauma can be long term. For example, one longitudinal study of abused and neglected youth found that only $22 \%$ of the sample were resilient, defined as meeting a success criterion for six of eight measured domains: employment, homelessness, education, social activity, psychiatric disorder, substance abuse, and two domains assessing criminal behavior: official arrest and self-reports of violence (McGloin \& Widom, 2001).

A 10-year longitudinal study in North Carolina conducted with 1,420 individuals between the ages of 9 and 16 found that $68 \%$ of youth had experienced a potentially traumatic event (e.g., victim and/or witness of violence, sexual abuse, natural disaster, death of a loved one, serious illness or accident, etc.) by the age of 16. Additionally, results revealed that $20.4 \%$ of youth exposed to one traumatic event and $49.6 \%$ of youth exposed to two or more events reported impairment of some kind, including disruption of relationships, school problems, physical problems, and/or increased emotional problems. Further, individuals who had been exposed to trauma had almost double the rates of psychiatric disorders compared to those who had never been exposed to trauma. The lifetime occurrence of anxiety, depressive, and disruptive behavior disorders for this sample was $9.6 \%, 12.1 \%$, and $19.2 \%$, respectively. Results also supported the presence of 
a dose-dependent relationship between trauma and psychiatric disorders, with higher rates of psychiatric disorders among individuals with higher incidents of trauma exposure (Copeland, Keeler, Angold, \& Costello, 2007).

While empirical evidence clearly supports the negative impact of exposure to traumatic events, no population-based epidemiological studies examining the prevalence of PTSD among youth currently exist. However, research investigating the prevalence of PTSD among at-risk populations has been conducted. In general, among victims of childhood neglect and/or childhood physical, sexual, and/or emotional abuse, an estimated $20 \%$ to $63 \%$ of these individuals develop PTSD. Between $14 \%$ and $35 \%$ of youth involved in motor vehicle accidents, $12 \%$ to $53 \%$ of youth with chronic medical illness (e.g., cancer, leukemia), and 5\% to 95\% of disaster survivors (e.g., earthquakes, floods, bombings, shootings) develop PTSD (Gabbay, Oatis, Silva, \& Hirsch, 2004). Using data from the National Survey of Adolescents, which included a sample of 4,023 adolescents between the ages of 12 and 17, the 6-month prevalence rate of PTSD for adolescents was estimated to be $3.7 \%$ for boys and $6.3 \%$ for girls (Kilpatrick et al., 2003). In another study with 384 adolescents, Giaconia et al. (1995) found that $43 \%$ of youth had experienced one or more traumatic events throughout their lifetimes and $14.5 \%$ of these youth subsequently met the diagnostic criteria for PTSD. In this study, the lifetime prevalence rate for PTSD among youth was 6.3\%. Consistent with aforementioned findings, the individuals who were exposed to traumas but never developed diagnosable PTSD still exhibited significantly greater emotional and behavioral problems compared to peers with no trauma exposure. For example, trauma 
exposed youth were roughly four times as likely to score in the clinical range on externalizing problems on the Youth Self Report (YSR) and were at higher risk for poor academic performance, suicidal ideation, suicide attempts, and poorer health than the controls.

Additionally, empirical evidence suggests that children and adolescents who have been exposed to violence and/or abuse are at risk for later revictimization. For instance, individuals who have been severely maltreated as children have an elevated statistical risk of being assaulted later in life (Classen et al., 2005). Similarly, a longitudinal study conducted with 1,569 college students found that childhood sexual abuse predicted revictimization in adolescence, which subsequently predicted sexual assault in college (Humphrey \& White, 2000). Results of this study also revealed that individuals who experienced sexual victimization in adolescence were at greatest risk for revictimization in adulthood. Victims' increased risk for revictimization may be related to maladaptive attempts to cope with and reduce posttraumatic distress (e.g., substance abuse, dysfunctional sexual behavior, or aggression), which subsequently lead to additional victimization and possibly even more self-endangering behavior (Classen et al., 2005).

In addition to increased risk for revictimization, exposure to trauma is related to multiple negative outcomes in young adulthood. For example, one study of college students revealed greater PTS symptoms were related to increased health problems, greater health-related functional impairment, and increased alcohol, cigarette, and drug use (Flood, McDevitt-Murphy, Weathers, Eakin, \& Benson, 2009). In a sample of 319 university students, lifetime community violence exposure was associated with greater 
substance use, risky sexual behavior, and risky driving practices regardless of gender, ethnicity, personality characteristics, family socioeconomic status, family support, or neighborhood collective efficacy (Brady, 2006). Finally, another study found that $93.2 \%$ of college-age young adults reported being a witness to violence and $76.4 \%$ reported a lifetime victimization of violence, with individuals with higher rates of traumatic exposure reporting higher levels of depression, aggression, interpersonal problems, and PTSD symptomology (Scarpa et al., 2002).

\section{Current Treatments}

For adults, several evidence-based treatments for PTSD exist, including pharmacotherapy, eye movement desensitization and reprocessing (EMDR), and cognitive behavioral therapies (CBT) such as prolonged exposure, stress inoculation therapy, and cognitive processing therapy (APA, 2004; Foa, Keane, Friedman, \& Cohen 2009; Hamblen, Schnurr, Rosenberg, \& Eftekhari, 2009). Of these treatments, there is particularly strong evidence for exposure-based therapies in the treatment of PTSD (Hamblen et al., 2009). Research regarding the treatment of PTS symptoms and PTSD in youth is relatively recent; however, much investigation has recently been done in this area. A review of the literature conducted in August 2010 revealed 28 randomized controlled trials (RCT) targeting PTS/PTSD among youth; three studies evaluated the efficacy of pharmacotherapy interventions and 25 evaluated psychosocial treatments.

In general, CBT currently possesses the most empirical support for treatment of childhood/adolescent PTS and PTSD (AACAP, 2010). In a recent meta-analysis, 
Silverman et al. (2008) evaluated the effectiveness of 21 methodologically rigorous RCTs investigating the efficacy of various treatments for youth exposed to traumatic events. Results revealed that Trauma-Focused CBT (TF-CBT) met Chambless and colleagues' (1998) criteria for classification as a well-established treatment, and School-Based Group CBT was identified as a probably efficacious treatment. The eight studies that possessed treatments referred to as TF-CBT were sometimes called by different names (e.g., Child Cognitive-Behavioral Therapy; Individual Child and Parent Cognitive-Behavioral Treatment); however, all treatments considered TF-CBT shared the following components: working with children in an individual format; providing training in cognitive and behavioral procedures, such as cognitive challenging and reframing, thought replacement, and problem-solving; and using exposure, which may have been in the form of narratives, imagery, drawings, or other techniques. Other components commonly used in TF-CBT include: psychoeducation, parenting skills, relaxation skills, affective modulation skills, cognitive coping and processing, trauma narration, in vivo exposure to trauma reminders, conjoint child-parent sessions, and enhancing future safety and development (Cohen, Mannarino, \& Deblinger, 2006). TF-CBT was designed to treat children with PTSD, depression, anxiety, and other trauma-related difficulties such as shame, guilt, and self-blame and is typically conducted individually with the child but has also been conducted in group formats and with parents (AACAP, 2010).

A meta-analysis of the 21 aforementioned RCTs revealed trauma-related therapies possessed an overall effect size of $d=0.43$ on PTS symptoms (Silverman et al., 2008). Additionally, the type of treatment and type of trauma targeted were both found to 
moderate the treatment effect. CBT interventions possessed a greater overall effect size $(d=0.50)$ than non-CBT interventions $(d=0.19)$, and treatments that targeted sexual abuse had a greater effect $(d=0.46)$ on PTS symptoms than treatments that targeted other types of traumas (e.g., physical abuse, neglect, motor vehicle accidents; $d=0.38$ ). Parental involvement was also investigated, and the authors found that a parent's involvement in the child's therapy did not significantly impact the treatment effect on PTS symptom reduction. However, some have found that parental involvement resulted in greater decreases in children's externalizing behaviors compared to treatments without parental involvement (e.g., Deblinger, Lippmann, \& Steer, 1996). Although there is limited evidence describing the impact of parent involvement on child outcomes, it is generally accepted that involving parents in treatment is good practice (AACAP, 2010).

\section{Limitations of Existing Outcome Research}

CBT, particularly TF-CBT, currently possesses substantial support for its utility in the treatment of youth with PTS and PTSD symptoms. While the success of TF-CBT is well established, the existing research is not without limitations. First, a number of treatments fall under the label of TF-CBT, and although some purport that there are certain core components to treatments considered TF-CBT (e.g., Amaya-Jackson \& DeRosa, 2007; Cohen et al., 2006), the content and emphasis of individual interventions show considerable variations. For example, a TF-CBT program used by King et al. (2000) placed a large emphasis on exposure, with $70 \%$ of the sessions dedicated to graded exposure, while another TF-CBT program used by Cohen and Mannarino (1996) 
placed a larger emphasis on cognitive reframing, contingency reinforcement, and problem solving. Similarly, the way in which specific techniques are used across programs varies. For example, to target emotional regulation, Cohen and Mannarino (1998) used thought replacement, positive imagery, and relaxation; King et al. (2000) trained the children/adolescents in cue-controlled and differential relaxation and provided them with personalized relaxation tapes to practice with outside of sessions; and Deblinger et al. (1996) taught children to express their emotions more appropriately through verbal, written, or artistic methods. The differences across interventions make it difficult to draw general conclusions about the effectiveness of TF-CBT and also make it impossible to discern what treatment components are responsible for change and which components do not provide any additional benefit.

Additionally, the length of CBT interventions has also varied greatly, ranging from a single 30-minute intervention (Zehnder, Meuli, \& Landolt, 2010) to 25 hours over the course of 30 weeks (30 50-minute weekly sessions; Trowell et al., 2002); thus, the necessary amount of time required to create optimal change is also unknown. The majority of RCTs have also focused on a specific type of trauma rather than PTS following exposure to trauma generally. Roughly half of the RCTs to date have focused on children who had been sexually abused. Youth who have been sexually abused may be a unique population for a number of reasons. Sexual abuse is likely to occur in the context of the family, is purposeful, and there is a high likelihood of repeated incidents of abuse (Ramchandani \& Jones, 2003). Additionally, other factors have been shown to be related to sexual abuse, including high rates of parental conflict, parental 
psychopathology, and poor parent-child relationships that are not necessarily related to other types of trauma (Fergusson, Lynskey, \& Horwood, 1996). Factors such as these make sexual abuse victims a unique population, and therefore the generalizability of treatments effective with this population to individuals exposed to other types of traumas cannot be assumed. At this time, it is difficult to identify what specific treatment strategies are effective with which trauma populations in alleviating which symptoms. In numerous cases, attrition was also problematic. Multiple studies had between $20 \%$ to $40 \%$ attrition (Ahmad \& Sundelin-Wahlsten, 2008; Celano, Hazzard, Webb, \& McCall, 1996; Cohen \& Mannarino, 1998; King et al., 2000). In some instances treatment refusal was also problematic. For example, in one study $26 \%$ of eligible families refused to consent to a TF-CBT school intervention (Stein et al., 2003) and in another study $12.5 \%$ of initial participants refused consent after learning about the EMDR intervention (Chemtob, Nakashima, \& Carlson, 2002). Many studies also experienced difficulty attaining follow-up data, with some studies reporting follow-up data for fewer than $50 \%$ of treatment completers (e.g., Cohen \& Mannarino, 1997; Cohen, Mannarino, \& Knudsen, 2005), making it difficult to determine the long-term efficacy of treatments.

Finally, although TF-CBT is efficacious in the treatment of PTS and PTSD for most children and adolescents, between $16 \%$ to $40 \%$ of youth diagnosed with PTSD at pretreatment continued to meet the diagnostic criteria for PTSD at posttreatment (e.g., Cohen, Deblinger, Mannarino, \& Steer, 2004; Cohen et al., 2005; Deblinger et al., 1996; King et al., 2000). Further, diagnostic status alone does not provide sufficient evidence of clinically significant improvement. For instance, Carrion et al. (2002) found no 
significant differences in impairment or distress in youth who met full diagnostic criteria for PTSD and those who met criteria for only two of the three diagnostic clusters.

While these limitations do not negate the value of existing trauma therapies, they do suggest that additional research regarding the treatment of youth PTS and PTSD is needed. Given problematic rates of attrition, refusal, and treatment non-responders, alternative treatment modalities are worthy of investigation. Acceptance- and mindfulness-based interventions provide an alternative approach to treatment that may prove to be beneficial in the treatment of youth PTS and PTSD.

Acceptance- and mindfulness-based treatments have been referred to as "third wave" cognitive behavioral treatments and are fundamentally different from traditional behavioral and cognitive behavioral interventions. Traditional CBT approaches purport that by directly targeting and learning to alter problematic thoughts, feelings, and/or bodily sensations, these negative symptoms will decrease; and as a result, individuals will experience lower levels of distress and increases in overall functioning (Leichsenring, Hiller, Weissberg, \& Leibing, 2006). Acceptance- and mindfulness-based approaches, on the other hand, do not directly target symptom reduction or the content of thoughts, feelings, and bodily sensations. Rather, these interventions focus on an individual's awareness of and relationship to thoughts, feelings, and bodily sensations, with the aim of altering the function of these inner experiences to promote quality of life (Hayes, 2004). ACT (Hayes et al., 1999) is an example of one such treatment and was the intervention focus for this study. 


\section{Acceptance and Commitment Therapy}

As previously mentioned, ACT is more concerned with quality of life than symptom reduction, per se. ACT focuses on how individuals relate to their inner experiences and how these relationships function within different areas of their lives. Instinctually, individuals often respond to unwanted thoughts, feelings, and/or bodily sensations by attempting to reduce the intensity or frequency of these experiences (Hayes et al., 2004). Paradoxically, these attempts to avoid or alter uncomfortable internal experiences often lead to further personal distress or harm. ACT refers to this phenomenon as experiential avoidance, and claims that experiential avoidance is central to human suffering and psychopathology (Hayes, Luoma, Bond, Masuda, \& Lillis, 2006). Individuals' experiential avoidance strategies often interfere with their ability to live a meaningful and fulfilling life. Thus, ACT targets experiential avoidance by helping individuals broaden their possible responses to unwanted inner experiences. This broadening of responses is referred to as psychological flexibility (Hayes et al., 2006).

ACT has identified six interrelated processes connected to psychological flexibility, and various behavioral and experiential techniques are used in therapy to directly target these core processes. Techniques that target acceptance help an individual learn to willingly experience uncomfortable inner events rather than attempting to control or fight them. Defusion techniques aim to decrease the literal impact of language so thoughts have less influence over one's actions. Self-as-context involves learning to view

one's self as the context where these inner experiences occur, rather than defining oneself by the content of these thoughts, feelings, and so forth. Strategies that aid in present 
moment awareness help an individual to learn to selectively attend to existing internal and external experiences as they occur. ACT also emphasizes the identification of values, as personal values provide a life direction and serve to motivate change. Finally, committed action is targeted and involves taking effective, value-consistent action regardless of the presence of negatively evaluated inner experiences (Hayes et al., 2006).

\section{Empirical Support for ACT}

A large and continually growing number of studies support the ACT model and its processes (Ruiz, 2010). The specific processes are supported on their own in dozens of component studies (Hayes et al., 2006; Ruiz, 2010). Recent meta-analyses of RCTs also showed ACT was superior to control conditions $(g=0.68)$ and treatment as usual (TAU; $g=0.42 ;$ Powers, Zum Vorde Sive Vording, \& Emmelkamp, 2009), and possibly better than established treatments such as CBT ( $g=0.27$; Levin \& Hayes, 2009). ACT is also deemed to have strong research support for the treatment of depression and modest research support for the treatment of chronic pain, obsessive compulsive disorder, mixed anxiety, and psychosis by the APA Division 12 Taskforce: Society of Clinical Psychology (n.d.) to determine empirically supported treatments. Surprisingly, ACT is quite well supported in the treatment of adult disorders, but there is limited evidence of its utility with children and adolescents even though there has been considerable theoretical accounts of the work (e.g., Greco, Blackledge, Coyne \& Ehrenreich, 2005; Greco \& Hayes, 2008; Murrell, Coyne \& Wilson, 2005; Twohig, Field, Armstrong, \& Dahl, 2010; Twohig, Hayes, \& Berens, 2007; Twohig, Hayes, \& Berlin, 2008). To date 
only two published RCTs on ACT with youth exist: a pilot study for adolescents with depression (Hayes, Boyd, \& Sewell, 2011) and one for adolescents with chronic pain (Wicksell, Melin, Lekander, \& Olsson, 2009).

In a RCT with individuals between the ages of 10 and 18 with chronic pain (Wicksell et al., 2009), 32 youth were randomly assigned to 10 weeks of ACT or to a multidisciplinary treatment approach (MDT) that included the use of the medication amitriptyline. Results revealed significant improvements within both groups; however, those in the ACT group reported significantly greater improvements in functioning and quality of life compared to those in the MDT group. These results provide support for the utility of ACT in the treatment of adolescent chronic pain.

In a pilot study conducted with adolescents who were referred for outpatient services for the treatment of depression (Hayes et al., 2011), 30 individuals were randomly assigned to receive ACT or TAU. At posttreatment and follow-up, individuals in the ACT condition showed significantly greater reductions in depression compared to those in the TAU group. At posttreatment, $58 \%$ of individuals in the ACT group exhibited reliable change on measures of depression, while only $36 \%$ of individuals in the TAU group showed reliable change. Individuals in the ACT group exhibited an average reduction in depression of $16.3 \%$ at posttreatment, while individuals in the TAU group showed an average reduction of $12.3 \%$. Interestingly, at 3-month follow-up, those in the ACT group showed an even greater reduction in depression, with an average reduction of $27.9 \%$ compared to pretreatment, while those in the TAU exhibited a $5.7 \%$ increase in depressive symptomology compared to pretreatment. Similarly, within the ACT group 
adolescents exhibited reliable improvement on measures of global functioning at posttreatment ( $26 \%$ of adolescents) and follow-up (38\% of adolescents), while no individuals in the TAU group exhibited reliable improvement in global functioning at either time point.

Multiple case studies and case series have revealed that ACT has also been used successfully with adolescents with anxiety-based school refusal (Heffner, Sperry, \& Eifert, 2002; Wilson \& Coyne, 2003), anorexia nervosa (Heffner et al., 2002), social phobia and generalized anxiety disorder (Greco, 2002), schizophrenia (García-Montes \& Pérez-Álvarez, 2001), and obsessive compulsive disorder (Armstrong, Morrison, \& Twohig, in press).

\section{ACT and PTSD}

To date, no large studies have been conducted on ACT to treat PTSD, but four case studies have shown preliminary support for the use of ACT as a treatment for PTSD in adults (Codd et al., 2011; Orsillo \& Batten, 2005; Twohig, 2009) and in late adolescence/early adulthood (Batten \& Hayes, 2005). Further, a substantial amount of data supports the relationship between ACT processes and PTSD symptoms. Experiential avoidance has been shown to be related to the exacerbation and maintenance of PTSD symptoms over time (Tull, Gratz, Salters, \& Roemer, 2004). In a thorough functionalcontextual conceptualization of PTSD, Blackledge (2004) suggests a number of reasons why experiential avoidance may maintain PTSD symptomology, including: avoidance strategies decrease opportunities for positive reinforcement for appropriate, more useful 
behaviors; avoidance behaviors may increase exposure to aversive experiences (e.g., suppression, substance abuse); and avoidance prevents new learning from occurring, thus allowing for continued fusion with negative evaluations of one's self and environment, problematic behavioral rules, and recollections of the traumatic event.

There is a particularly strong positive relationship between specific types of experiential avoidance and PTSD symptomology. Alexithymia, or difficulty experiencing and describing emotions (Frewen et al., 2008; Fukunishi, Tsuruta, Hirabayashi, \& Asukai, 2001), the use of thought suppression (Aaron, Zaglul, \& Emery, 1999; Mayou, Ehlers, \& Bryant, 2002), and avoidant coping (Dempsey, 2002; Scarpa, Haden, \& Hurley, 2006) have all been found to be strongly predictive of PTSD symptomology and severity among both children and adults. Interestingly, one recent study found no significant difference in overall PTS symptom severity among college students exposed to a traumatic event as defined by the DSM-IV-TR and those who were exposed to an upsetting event that did not meet this criteria. However, thought suppression did significantly predict PTS symptom severity regardless of the classification of the initial trauma exposure (Cameron et al., 2010). These results suggest criterion A of the PTSD diagnosis is not sufficient in predicting PTS symptom severity, but rather psychological processes such as experiential avoidance, particularly thought suppression, play a much larger role in the development and maintenance of PTS and PTSD. Additionally, some data have started to emerge supporting a negative relationship between mindfulness and PTSD symptom severity (Thompson \& Waltz, 2010). Specifically, in a sample of 191 college students with PTS symptomology, mindfulness, particularly the facet nonjudgment or acceptance of 
everyday experiences, predicted variance in PTS symptomology above and beyond experiential avoidance (Thompson \& Waltz, 2010).

Taken together, experiential avoidance, mindfulness, and acceptance appear to play important roles in the severity and maintenance of PTSD symptomology, providing promising support for the potential utility of acceptance- and mindfulness-based interventions in the treatment of PTSD. For these and other reasons, ACT as a treatment for PTS and PTSD is worthy of investigation. 


\section{CHAPTER III}

\section{METHOD}

\section{Participants and Setting}

Adolescents between the ages of 12 and 17 who were experiencing clinically significant levels of PTS were sought as participants. Potential participants were recruited using multiple methods. Flyers were placed throughout Utah State University's campus and the local community (see Appendix A). Paid newspaper advertisements appeared in local newspapers and paid announcements were aired on a local radio station. Stories were published in the community newspaper and campus newspaper based on interviews conducted by writers from both papers. Referral materials were mailed to local mental health and medical providers as well as to school counselors and school psychologists at local middle and high schools. Due to an initial low response rate to recruitment efforts within the community, recruitment extended to a local residential treatment facility for adolescent girls with eating disorders. Thus, the final sample for this study consisted of individuals from two distinct groups: four participants from the community and three participants with comorbid eating disorders who were residing within a residential treatment facility.

Participants were eligible to enroll in the study if they had experienced a traumatic event and continued to experience significant distress and/or interference within their lives. Specifically, the inclusion criteria were as follows: (1) the individual must have been between 12 and 17 years of age; (2) the individual must have experienced 
a traumatic event, and (3) the individual must have been experiencing significant distress and/or functional impairment in his/her life, as indicated by a rating of 2 or higher on the global severity rating on the Clinician Administered PTSD Scale for Children and Adolescents. Participants were excluded if they: (1) were currently experiencing ongoing trauma (e.g., physical abuse, witness domestic violence); (2) were not capable of participating in research due to physical/medical complications and/or could not receive parental consent; (3) had been diagnosed with mental retardation or a developmental disability; or (4) were currently receiving individual psychotherapy for trauma related concerns. Participants within the residential facility were receiving multifaceted treatments for their eating disorder pathology. Individuals with other comorbid conditions not included in the exclusion criteria were allowed to participate. Appropriate referral information to local mental health resources were provided to individuals who did not qualify for or who did not complete the study. All assessment and treatment procedures were conducted by a trained graduate student therapist. The community participants completed all assessment and treatment procedures in therapy rooms within a research laboratory at Utah State University. The residential participants completed all assessment and treatment procedures within the residential treatment facility.

Twenty-nine individuals contacted the research assistant to express interest in the research study. Six were either too old or too young to participate, three emailed to request more information but did not leave a phone number and did not contact the researcher again after additional information was provided, four were referred by a school counselor but denied interest in participating, one had concerns other than PTS, 
and one was currently receiving individual therapy and was uninterested in discontinuing this treatment. Fourteen prospective participants passed the initial telephone screening and were scheduled for intake sessions. Of these, 10 youth met criteria and were enrolled. For those not enrolled, two did not meet the eligibility criteria for PTS, one was invited to enroll but the guardian opted for a higher level of care (i.e. residential treatment), and one withdrew partway through the initial intake because of concerns regarding the limits of confidentiality. Of the 10 enrolled, seven were from the community and three were simultaneously receiving residential treatment for comorbid eating disorders. All three residential participants completed treatment. Of the seven youth from the community, three completed the entire treatment, one was an early responder and opted to discontinue treatment after three sessions but agreed to complete post and follow-up assessments, and three dropped out of treatment prematurely. Of these participants who dropped out, two completed only one treatment session and one completed two sessions. Their reported reasons for dropping out were as follows: the participant who attended two sessions said she was "too busy" to continue treatment after she was selected for participation on a school sports team; the second participant, who was the younger sister of the aforementioned participant, said she was unwilling to participate if her sister did not participate, and subsequently both siblings dropped out simultaneously; the third participant refused to return after the first session because she said she "did not want to think about [her trauma]." Also of note, all three of these participants experienced complex sexual trauma and all three expressed ambivalence about participating at the time of intake but ultimately provided assent following encouragement from their 
guardians. All who did not qualify, chose not to participate, or discontinued treatment prematurely were given referrals for other services. See Figure 1 for the participant flowchart.

A summary of participants is provided in Table 1 and each participant is described in more detail below. In order to better protect confidentiality, only necessary information about participants' traumas and symptomology are provided.

\section{Community Participants}

Community Participant 1. Community Participant 1 (C1) reported two traumatic events to which he continued to experience posttraumatic stress symptomology. He experienced a trauma at the age of 4 in which he observed police unexpectedly raid his

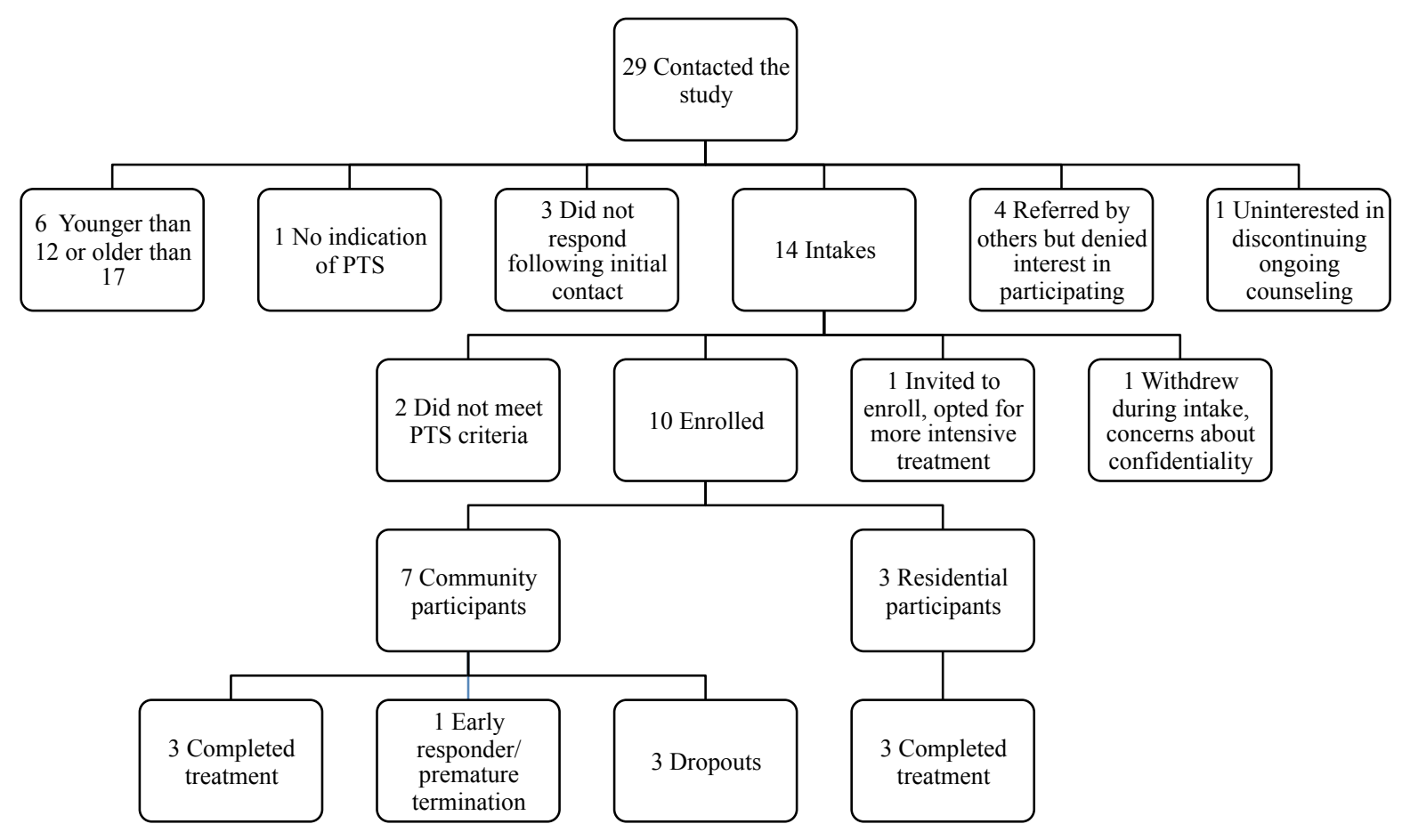

Figure 1. Participant flowchart. 
Table 1

Participants

\begin{tabular}{|c|c|c|c|c|c|c|}
\hline Participant & Sex & Age & Trauma Type(s) & $\begin{array}{l}\text { Age Trauma(s) } \\
\text { Occurred }\end{array}$ & Medication(s) & $\begin{array}{c}\text { Comorbid } \\
\text { Condition(s) }\end{array}$ \\
\hline R1 & $\mathrm{F}$ & 15 & $\begin{array}{c}\text { Death of a Primary } \\
\text { Caregiver; Exposure } \\
\text { to Violence }\end{array}$ & $8 ; 8-12$ & $\begin{array}{l}\text { Fluoxetine; } \\
\text { Olanzapine }\end{array}$ & $\begin{array}{l}\text { ED NOS; } \\
\text { GAD }\end{array}$ \\
\hline R2 & $\mathrm{F}$ & 15 & $\begin{array}{l}\text { Sexual Abuse; } \\
\text { Physical Abuse }\end{array}$ & 7-9; 4-9 & $\begin{array}{l}\text { Concerta; } \\
\text { Strattera }\end{array}$ & $\begin{array}{l}\text { Diabetes; } \\
\text { Bulimia } \\
\text { Nervosa; } \\
\text { ADHD }\end{array}$ \\
\hline R3 & $\mathrm{F}$ & 15 & $\begin{array}{l}\text { Death of a Primary } \\
\text { Caregiver }\end{array}$ & 14 & $\begin{array}{l}\text { Effexor; } \\
\text { Abilify }\end{array}$ & $\begin{array}{l}\text { Anorexia } \\
\text { Nervosa; } \\
\text { MDD; GAD }\end{array}$ \\
\hline $\mathrm{C} 1$ & M & 12 & $\begin{array}{c}\text { Witnessed father's } \\
\text { arrest \& } \\
\text { imprisonment; } \\
\text { Physical Abuse }\end{array}$ & $4 ; 8$ & None & $\begin{array}{l}\text { GAD; Celiac } \\
\text { Disease }\end{array}$ \\
\hline $\mathrm{C} 2$ & $\mathrm{~F}$ & 17 & Sexual Abuse & $5-8$ & Effexor & MDD \\
\hline $\mathrm{C} 3$ & M & 13 & Natural Disaster & 10 & None & None \\
\hline $\mathrm{C} 4$ & $\mathrm{~F}$ & 15 & Sexual Abuse & 14 & Celexa & MDD \\
\hline
\end{tabular}

Note. All participants self-identified as Caucasian. $\mathrm{M}=$ Male; $\mathrm{F}=$ Female; $\mathrm{ADHD}=$ Attention Deficit Hyperactivity Disorder; ED NOS = Eating Disorder Not Otherwise Specified; GAD = Generalized Anxiety Disorder; MDD = Major Depressive Disorder

house and arrest his father. At the age of 8 his father became violent toward $\mathrm{C} 1$ and roughly grabbed C1's neck, and C1 feared his father was going to choke him. C1 reported the event at the age of 4 as the more traumatic of the two events. At the time of intake, $\mathrm{C} 1$ endorsed psychological distress and physiological reactivity in response to trauma reminders and intrusive recollections of the events. He attempted to avoid 
reminders of the trauma, including thoughts, feelings, conversations, people, and places, and expressed a restricted range of affect. He endorsed numerous hyperarousal symptoms, including difficulty falling asleep, hypervigilance, and an exaggerated startle response. These symptoms caused C1 high levels of distress and interfered with his social and scholastic functioning. At the time of intake, C1 met diagnostic criteria for PTSD.

Community Participant 2. Community Participant 2 (C2) experienced several sexual abuse encounters between the ages of 5 and 8 by an older, male extended relative whom she visited regularly. At the time of intake, C2 experienced psychological distress at exposure cues; avoidance of thoughts, feelings, and conversations related to trauma reminders; inability to recall much of what happened at the time of the trauma; feelings of detachment from others; and a sense of a foreshortened future. Additionally, she experienced significant sleeping problems, irritability and anger outbursts, difficulty concentrating and an exaggerated startle response. She expressed high levels of selfblame, depression, and confusion in response to her trauma history and also endorsed much difficulty trusting others and reported high efforts to avoid feelings of intimacy and vulnerability. She endorsed a delayed onset of these symptoms, beginning around the onset of puberty. These symptoms caused C2 significant distress and interfered with her social functioning. At the time of intake, $\mathrm{C} 2$ met diagnostic criteria for delayed onset PTSD.

Community Participant 3. At the age of 10, Community Participant 3 (C3) experienced a Class 5 tornado that completely destroyed his family's house and killed multiple individuals living in the city where the tornado occurred. C3 experienced 
intrusive recollections of the event and high levels of psychological and physiological distress in response to trauma reminders. He worked hard to avoid thoughts and feelings associated with the event as well as certain activities and places. He was unable to remember many important aspects of the traumatic event, exhibited a restricted range in affect and diminished interest in activities he once enjoyed, felt detached from others, and endorsed a sense of a foreshortened future. He reported high levels of hypervigilance and attempted to avoid feeling "out of control" by engaging in a number of safety checking behaviors. He described near constantly scanning his environment for danger, experiencing intrusive thoughts about "worst case scenarios" that may occur in any given situation, and taking many precautions to ensure his physical safety. These symptoms caused C3 significant distress. At the time of intake, C3 did not meet diagnostic criteria for PTSD because he did not experience enough hyperarousal symptoms to support a diagnosis.

Community Participant 4. Community Participant 4 (C4) experienced an incident of sexual abuse by her biological father at the age of 14 . At the time of intake she endorsed numerous reexperiencing symptoms, including intrusive memories, nightmares, and physiological reactivity and psychological distress in response to trauma reminders. She avoided thoughts, feelings, conversations, activities, places, and people that reminded her of her father or of the event, including high efforts to avoid looking at father-daughter dyads in the community and avoiding certain songs, movies, and social events she previously enjoyed with her father. She reported high levels of distress and feelings of nausea in response to these trauma cues. C4 also reported diminished interest 
in activities she previously enjoyed, significant feelings of detachment from others, and often felt emotionally “numb.” Additionally, C4 experienced much difficulty concentrating and reported high levels of irritability and emotional reactivity, indicating she experienced anger that could go from "zero to sixty" in a matter of seconds. She also endorsed depression and experienced problematic "trust issues" since the traumatic encounter, and made high efforts to avoid feeling vulnerable or becoming "too close" to others. These symptoms caused her significant distress and interfered with her social, scholastic, and developmental functioning. At the time of intake, $\mathrm{C} 4$ met diagnostic criteria for PTSD.

\section{Residential Participants}

Residential Participant 1. When Residential Participant 1 (R1) was 8 years old, her grandfather, who was a primary caregiver, became ill and passed away. Between the ages of 8 and 12, R1 was also exposed to violence within the home. R1 was never directly injured nor witnessed significant injury to another as a result of the violence; however, the violence exhibited by R1's sister was severe enough to warrant her removal from the home by Child Protective Services. R1 reported the loss of her caregiver as the trauma that caused her the most significant distress and impairment. At the time of intake, R1 reported reexperiencing symptoms, including intrusive recollections of her grandfather's death and psychological distress and physiological reactivity in response to trauma reminders. She exhibited both avoidance and numbing symptoms, including avoidance of thoughts, feelings, conversations, activities, and places; and feelings of detachment and estrangement from others as well as emotional numbness. She 
experienced difficulty concentrating that may or may not have been a result of trauma. R1 also expressed much difficulty allowing herself to become close to others for fear they may leave her, which began after the loss of her grandfather. She attempted to avoid feelings of intimacy and vulnerability. These symptoms interfered with R1's social functioning and caused her significant distress; however, she did not experience enough hyperarousal symptoms to meet diagnostic criteria of PTSD at the time of intake.

Residential Participant 2. Residential Participant 2 (R2) experienced repeated exposure to violence and physical abuse exhibited by her biological father between the ages of 4 and 9 , and multiple incidents of sexual abuse by her father between the ages of 7 and 9. At the time of intake R2 endorsed numerous reexperiencing symptoms, including intrusive recollections, nightmares, and psychological and physiological reactivity in response to trauma reminders. She avoided thoughts, feeling, conversations, activities, places, and people that reminded her of her father and/or of the abuse. She endorsed feelings of numbness and detachment from others, as well as difficulty falling and staying asleep, difficulty concentrating, irritability, and exaggerated startle. These symptoms interfered with R2's social and scholastic functioning and caused her significant distress. At the time of intake, R2 met diagnostic criteria for PTSD.

Residential Participant 3. Residential Participant 3 (R3) experienced traumatic grief in response to the loss of a primary caregiver. R3's mother was diagnosed with breast cancer when R3 was 7 years old and passed away when R3 was 14 years old. At the time of intake, R3 experienced intrusive recollections of her mother, distressing dreams/nightmares, psychological distress in response to reminders of her mother, 
difficulty sleeping, irritability, and difficulty concentrating. She avoided thoughts, feelings, and conversations related to her mother or to reminders of her mother. She experienced depression, high levels of guilt and survivor's guilt, diminished interest in activities she previously enjoyed, feelings of numbness, and detachment from others. These symptoms caused her significant distress and impairment in her social and scholastic functioning. R3's traumatic event does not technically meet criterion A diagnostic criteria for PTSD; however, R3's symptomology met all other diagnostic criteria for PTSD.

\section{Design}

This study utilized two (community and residential) nonconcurrent multiple baseline across participants designs to examine the effect of 10 weeks of ACT on the frequency and severity of posttraumatic stress symptomology and to control for the effects of the passage of time, testing, and contact with the clinic (Cooper, Heron, \& Heward, 2007; Kazdin, 1992). All participants began collecting baseline data on posttraumatic stress related symptoms after completion of an initial pretreatment session. The specific symptoms that were tracked are described in detail in the measures section. A minimum of five, stable baseline data points were required before a participant could enter the treatment phase of this study. Two cohorts of participants were combined under two multiple baselines in order to reduce the length of the baseline phase before beginning treatment and to account for the two settings between the cohorts. $\mathrm{C} 1$ (participant 1 from the community sample) and R1 (participant 1 from the residential 
sample) began treatment after 8 and 7 days of baseline, respectively. Treatment began for C2 and R2 after 20 and 35 days of baseline, respectively, and corresponding to a reduction in C1's and R1's PTS symptomology, as measured by the daily self-monitoring measure. Treatment began for C3, C4, and R3 after 62, 66, and 43 days of baseline, respectively, and corresponding to a reduction in C2's and R2's PTS symptomology.

\section{Procedures}

Parents and children attended an initial, 2-hour pretreatment session where interested individuals signed an informed consent and assent (see Appendix B). Confidentiality and reporting obligations outlined within the informed consent/assent forms were also explicitly covered at this time. The initial session included a structured interview with the adolescent using the Clinician Administered PTSD Scale for Children and Adolescents (CAPS-CA; Newman et al., 2004) to assess for eligibility and to determine background information and present difficulties. Participants also completed all assessments listed in the measures section at the time of intake (pretreatment) and after the final session (posttreatment; see Appendix C). The background information was only delivered at pretreatment and the measure of treatment acceptability was only administered at posttreatment. At the pretreatment assessment, participants were also given daily tracking forms and/or online login information to record daily avoidance, reexperiencing, and arousal symptoms, as well as daily distress and interference associated with these symptoms. Brief training on what was and was not to be recorded 
was covered at the end of the initial intake session. Self-monitoring began at the time of the initial intake and continued through all phases of the experiment.

Following an initial pretreatment assessment and baseline period, participants completed a 10-week ACT protocol for treating adolescent posttraumatic stress. The Avoidance and Fusion Questionnaire for Youth (AFQ-Y; Greco, Murrell, \& Coyne, 2005) and Child PTSD Symptom Scale (CPSS; Foa, Johnson, Feeny, \& Treadwell, 2001) were given at each treatment session. One week after completion of the 10-week intervention, the participants returned for a postassessment. Three months after completion of the intervention, participants completed a follow-up assessment; however, the follow-up data will not be included for this project, as not all participants have yet completed follow-up.

\section{Measures}

\section{Daily Self-Monitoring}

The primary outcome was based on the diagnostic criteria for PTSD and the amount of distress and interference associated with PTS symptomology. Self-reported frequencies of daily avoidance, reexperiencing, and arousal symptoms as well as ratings of how distressing these symptoms were and how much they interfered with daily functioning were reported to the researcher via the Internet using individual online login IDs or using a paper tracking form that was returned to the experimenter each week. Participants recorded their daily subjective rating in each of these areas on a scale from 0 to 10 , with 10 indicating higher frequencies, distress, and/or interference. The scores 
from these five questions were summed (for a total score of 0-50), and the total scores were plotted and used to make treatment decisions.

\section{Background Information}

Participants completed questions about age, sex, education, ethnicity/race, age in which trauma occurred, how long trauma-related symptoms have been problematic, previous treatment attempts, other psychological diagnoses, and current psychotropic medications.

\section{Clinician Administered PTSD Scale for Children and Adolescents}

The Clinician Administered PTSD Scale for Children and Adolescents (CAPS-

CA; Newman et al., 2004) is a 33-item structured interview used to assess PTSD

diagnostic status and symptom frequency and intensity for youth aged 8 to 18 years. The CAPS-CA is a modified version of the Clinician Administered PTSD Scale (CAPS) used with adults, which is considered to be the gold-standard assessment of PTSD and severity of PTSD symptomology. The CAPS-CA can be used to make a current or lifetime diagnoses of PTSD or to assesses PTS symptoms over the past week. Questions also target the impact of symptoms on various areas of functioning, including overall distress, coping skills, and impairment. Items also assess overall severity, validity of ratings, associated symptoms, and coping strategies. The Life Events Checklist (LEC) is a part of the CAPS-CA and is used to identify traumatic stressors experienced. The LEC has demonstrated adequate psychometric properties as a stand-alone assessment of traumatic exposure (Gray et al., 2004). The CAPS-CA is a valid and reliable measure of childhood 
PTSD, evidenced by strong internal consistency, convergent validity indicators, intraclass correlations, and Kappa coefficients (Harrington, 2009).

\section{Brief Symptom Inventory}

The Brief Symptom Inventory (BSI; Derogatis, 1993) is a 53-item self-report measure of psychological symptoms for individuals 13 years of age and older. The BSI measures nine primary symptom dimensions (somatization, obsessive compulsive behavior, interpersonal sensitivity, depression, anxiety, hostility, phobic anxiety, paranoid ideation, and psychoticism) and three global indices: the Global Severity Index (GSI) which measures overall distress level, Positive Symptom Distress Index (PSDI) which measures the intensity of symptoms, and Positive Symptom Total (PST) which indicates the number of self-reported symptoms. The BSI is a shorter version of the Symptom Checklist-90 Revised (SCL-90-R), and shows good internal consistency reliability for all nine symptom dimensions ( $\alpha$ s between .71 and .85). Factor analysis revealed excellent construct validity. With factor loadings between .35 and .66 for all the questions according to the nine factors (Derogatis, 1993).

\section{Child PTSD Symptom Scale}

The Child PTSD Symptom Scale (CPSS; Foa et al., 2001) is a 24-item self-report measure that assesses PTSD related symptoms and symptom severity in individuals between 8 and 18 years of age. It includes 17 symptom items and 7 functional impairment items. Symptom items are rated on a 4-point frequency scale $(0=$ "not at all" to $3=$ "5 or more times a week"). Functional impairment items are scored as $0=$ "absent" 
or $1=$ "present." The CPSS yields a total symptom severity scale score (ranging from 051) and a total severity-of-impairment score (ranging from 0-7). The CPSS has adequate internal consistency on the total symptom scale $(\alpha=.89)$ and on each of the subscales $(\alpha$ s between .80 to .91$)$ and high convergent validity $(r=.80)$.

\section{Children's Depression Inventory}

The Children's Depression Inventory (CDI; Kovacs, 1985) is a 27-item self-report measure that assesses cognitive, affective, and behavioral symptoms of depression in youth. Items are given a severity rating of 0,1 , or 2 , which are summed to a total score. A cutoff score of 19 has been found to identify children who are depressed (Doerfler, Felner, Rawlinson, Raley, \& Evans, 1988). Adequate test-retest reliability has been demonstrated $(\mathrm{ICC}=.82 ;$ Finch, Saylor, Edwards, \& McIntosh, 1987).

\section{Comprehensive Quality of Life Scale-Student Version}

The Comprehensive Quality of Life Scale—Student Version (ComQol—S5; Cummins, 1997) is a self-report measure that assesses subjective and objective quality of life on seven life domains. These seven domains are material well-being, health, productivity, intimacy, safety, community, and emotional well-being. An objective and a subjective quality of life (Qol) score is obtained. The objective domains comprise culturally-relevant measures of objective well-being. The subjective domains comprise domain satisfaction weighted by their importance to the individual. The objective and subjective scales have been validated independent of one another, and thus it is psychometrically acceptable to administer either one or both of the scales. The 
ComQol—S5 has adequate test-retest reliability $(r>.73)$ and good content and construct validity (Cummins, 1997). The ComQol-S5 has been validated with individuals ages 1218. A parallel adult version is also available.

\section{Avoidance and Fusion Questionnaire for Youth}

The Avoidance and Fusion Questionnaire for Youth (AFQ-Y; Greco, Murrell, et al., 2005) is a 17-item self-report measure modeled after the Acceptance and Action Questionnaire (AAQ; Hayes et al., 2004). The AFQ-Y assesses experiential avoidance and cognitive fusion in youth. Scores range from $0-68$, with higher scores indicating higher levels of experiential avoidance and lower levels of psychological flexibility. Internal consistency of the AFQ-Y is high $(\alpha=.90$; Greco, Lambert, \& Baer, 2008), and moderate correlations in expected directions were found between the AFQ-Y and measures of related constructs such as acceptance and mindfulness, thought suppression, anxiety, problem behavior, and quality of life. Although change with treatment in AFQ-Y scores has not been assessed, available findings support convergent and construct validity of the measure (Greco et al., 2008).

\section{Treatment Evaluation Inventory-Short Form}

The Treatment Evaluation Inventory-Short Form (TEI-SF; Kelley, Heffer, Gresham, \& Elliot, 1989) is a 9-item self-report measure of treatment acceptability. Two items do not apply to the population in question and were omitted. The 7-item modified version has been used previously (e.g., Twohig, Hayes, et al., 2010). The original TEI-SF instrument has high internal consistency $(\alpha=.85)$ and a reliable factor structure (Kelly et 
al., 1989). Participants rate each item on a 5-point likert scale; total scores over 21 indicate greater acceptability than unacceptability of the intervention.

\section{Treatment}

The protocol in the present study was a modified protocol created from preexisting treatment manuals for a different childhood (Armstrong et al., in press) and adult anxiety disorder (Twohig, Hayes, et al., 2010), and supplemented from a manual specifically developed for PTSD in adults (Walser \& Westrup, 2007). Treatment consisted of 10 individual weekly 1-hour sessions of ACT. The goals of this treatment protocol were: (1) to decrease the use of experiential avoidance strategies, (2) to help the client determine effective strategies for responding to trauma related symptoms, (3) to practice using these strategies outside of session, (4) to gradually decrease distress associated with trauma related symptoms, and (5) increase occurrence of identified, meaningful life activities. Table 2 provides an overview of the treatment components and specific interventions used at each session.

\section{Treatment Adherence}

All treatment sessions were either video or audio recorded to monitor treatment integrity. Twenty percent of the tapes were viewed and scored for treatment integrity by an independent graduate student researcher who was trained to competence in coding procedures and ACT processes. Treatment adherence was assessed using a standardized treatment integrity scoring system that has been used in previous ACT research (Twohig, 
Hayes, et al., 2010). The sessions reviewed were selected randomly but systematically so that of the ten total sessions, two sessions from each participant (only one session for C2 since she attended only three sessions) and at least one of each session number were reviewed. As sessions were viewed, operational definitions of ACT processes guided the coder's assessment of therapist verbalizations (see Appendix D). Sessions were scored in 1-minute intervals, and processes were coded according to a partial-interval recording procedure. A process was endorsed for a given interval if the therapist targeted that process at any time within the minute. "General assessment" was coded when the therapist asked about participants' PTS symptomology, assessed progress, or inquired about participants' implementation of treatment components. Non-adherent items were also coded, including challenging cognitions, use of a cognitive therapy rationale, supporting the idea that thoughts and feelings lead to action, using avoidant change strategies, or using traditional exposure and response prevention within session or suggesting its use outside of session. At the end of each viewed session, the coder gave the therapist a score for "adherence to the ACT model" and "overall therapist competency" using a scale from 1 to 5 , with 5 indicating the highest level.

Thirteen total sessions were reviewed. Two recordings of sessions 1, 2, and 3, and one incident of sessions 4 through 10 were reviewed. Across all intervals coded, processes were targeted as follows, demonstrating adherence to ACT processes: acceptance $/$ willingness $=43 \%$, defusion $=7 \%$, self-as-context $=1.5 \%$, present moment awareness $=10 \%$, values $=13 \%$, and committed action $=14 \%$. General assessment was coded in $37 \%$ of intervals. ACT-inconsistent elements were not endorsed in any session; 


\section{Table 2}

\section{Summary of Treatment Sessions}

\begin{tabular}{|c|c|c|}
\hline Session & Treatment components & Exercises/Content \\
\hline \multirow[t]{4}{*}{1} & Informed Consent & $\begin{array}{l}\text { - Warning that therapy may result in emotional discomfort } \\
\text { - Commitment to complete all } 10 \text { sessions }\end{array}$ \\
\hline & Limits to Confidentiality & $\begin{array}{l}\text { - Suicide, homicide, and abuse of children or disabled adults } \\
\text { - Physical or sexual abuse that has not been previously reported to } \\
\text { authorities was reported } \\
\text { - Any reportable information was also reported to the legal guardian }\end{array}$ \\
\hline & General Assessment & $\begin{array}{l}\text { - Asking client to describe PTS symptoms (PTSS) \& how they } \\
\text { interfere with their life } \\
\text { - Find out why they seek treatment, what they hope and expect }\end{array}$ \\
\hline & Psychoeducation & $\begin{array}{l}\text { - Discuss fight, flight, or freeze response } \\
\text { - Discuss PTS \& PTSD, including three primary symptom clusters } \\
\text { and contexts in which symptoms occur for client }\end{array}$ \\
\hline 2 & Creative Hopelessness & $\begin{array}{l}\text { - Brainstorm strategies used to control PTSS and explore short-term } \\
\text { vs. long-term effectiveness of these strategies } \\
\text { - Identify the negative impact of attempts to control PTSS } \\
\text { - Highlight paradoxical nature of attempts to control PTSS using the } \\
\text { Tug of War metaphor }\end{array}$ \\
\hline \multirow[t]{3}{*}{3} & Control as the Problem & $\begin{array}{l}\text { - Reinforce the futility of attempts to control PTSS } \\
\text { - Identify attempts to control PTSS as part of the problem using the } \\
\text { Polygraph, Chocolate Cake, and Falling in Love exercises }\end{array}$ \\
\hline & Defusion & $\begin{array}{l}\text { - Help foster defusion by using the Physicalizing exercise and having } \\
\text { client draw a picture of this object }\end{array}$ \\
\hline & Acceptance & $\begin{array}{l}\text { - Introduce acceptance as an alternative to control using the Two } \\
\text { Scales metaphor \& Trauma on Paper exercise using the picture } \\
\text { created during the Physicalizing exercise }\end{array}$ \\
\hline \multirow[t]{3}{*}{4} & Acceptance & $\begin{array}{l}\text { - Review acceptance by demonstrating that the willingness to } \\
\text { experience PTSS is a chosen behavior and alternative to control } \\
\text { - Identify the decrease in effort required to willingly experience } \\
\text { PTSS }\end{array}$ \\
\hline & Defusion & $\begin{array}{l}\text { - Teach the limits of language and its role in suffering using Kid in a } \\
\text { Grocery Store metaphor and What are the Numbers exercise } \\
\text { - Tichener's Milk, Milk, Milk exercise }\end{array}$ \\
\hline & Committed Action & - Behavioral commitments to practice defusion strategies this week \\
\hline \multirow[t]{3}{*}{5} & Acceptance \& Defusion & - Passengers on the Bus metaphor/exercise \\
\hline & Values & $\begin{array}{l}\text { - Introduce values through use of the Passengers on the Bus metaphor } \\
\text { by asking client to begin to think about the direction s/he wants the } \\
\text { bus to travel }\end{array}$ \\
\hline & Committed Action & - Behavioral commitment \\
\hline
\end{tabular}

(continued) 


\begin{tabular}{|c|c|c|}
\hline Session & Treatment Components & Exercises/Content \\
\hline \multirow[t]{3}{*}{$6-7$} & Values & $\begin{array}{l}\text { - Define the concept of values using Compass metaphor } \\
\text { - Clarify the client's values using the Heart Shaped Box exercise and } \\
\text { assess the consistency of his/her behavior with those values using } \\
\text { Bull's Eye exercise }\end{array}$ \\
\hline & Acceptance & $\begin{array}{l}\text { - Continue to encourage acceptance of any problematic inner } \\
\text { experiences by revisiting the Passengers on the Bus metaphor and } \\
\text { through the use of the Annoying Party Guest metaphor } \\
\text { - Identify opportunities for acceptance from out of session practice }\end{array}$ \\
\hline & Committed Action & - Behavioral commitments to engage in value-based activities \\
\hline \multirow[t]{3}{*}{8} & $\begin{array}{l}\text { Contact with Present } \\
\text { Moment }\end{array}$ & $\begin{array}{l}\text { - Help the client be present with their inner experiences using the } \\
\text { Awareness of Inner Experiences and Leaves on a Stream exercise } \\
\text { - Identify the importance of being present while not being heavily } \\
\text { attached to inner experiences using Kindergarten Teacher metaphor }\end{array}$ \\
\hline & Defusion & - Having a Thought versus Buying a Thought activity \\
\hline & Committed Action & - Behavioral commitments to engage in value-based activities \\
\hline \multirow[t]{3}{*}{9} & Self-as-Context & $\begin{array}{l}\text { - Identify the self as the context where inner experiences occur using } \\
\text { the Chessboard \& TV Set metaphors } \\
\text { - Explain that the client does not choose what inner experiences occur, } \\
\text { but that they can choose what to do with them }\end{array}$ \\
\hline & $\begin{array}{l}\text { Contact with Present } \\
\text { Moment }\end{array}$ & - Watching Thoughts on a Screen \\
\hline & Committed Action & $\begin{array}{l}\text { - Increased behavioral commitments to engage in valued living based } \\
\text { on recent values work } \\
\text { - Foster committed action by reviewing any processes that still need } \\
\text { attention }\end{array}$ \\
\hline 10 & Review \& Termination & $\begin{array}{l}\text { - Summarize the treatment by revisiting the Passengers on a Bus } \\
\text { metaphor } \\
\text { - Discuss end of treatment and apply ACT processes to termination } \\
\text { - Suggest Get Out of Your Mind and Into Your Life workbook for } \\
\text { continued progress }\end{array}$ \\
\hline
\end{tabular}

however, ACT-consistent exposure activities (either in- or out-of-session) occurred in $0.4 \%$ of the intervals. It should be noted that session 1 focuses heavily on assessment, and sessions 2 and 3 focus heavily on acceptance. Thus, these two areas would be expected to have higher percentages given that two incidents of sessions 1 through 3 were coded, while only one incident of sessions 4 through 10 were coded. Averaged across all coded 
sessions, "therapist competency" was rated as $M=4.7$ and "adherence to the ACT model" was rated as $M=4.8$. These means are comparable to mean ratings from previous studies in which the same treatment integrity procedure was used (competence $=4.31$, adherence $=4.94$, Twohig $\&$ Crosby, 2010; competence $=4.4$, adherence $=4.9$, Twohig, Hayes, \& Masuda, 2006a; competence $=4.4$, adherence $=3.9$, Twohig, Hayes, \& Masuda, 2006b; competence $=4.67$, adherence $=4.56$, Twohig, Hayes, et al., 2010). 


\section{CHAPTER IV}

\section{RESULTS}

\section{Outcomes}

The primary dependent variable for this investigation was the PTS-related symptoms based on self-monitoring. Total daily PTS symptom scores for all participants are presented in Figure 2. Pre- and posttreatment results from the CAPS-CA, CPSS, CDI, BSI, and objective and subjective ComQol are displayed respectively in Figures 3, 4, 5, 6,7 , and 8 .

\section{Community Participants}

Community Participant 1. During his 8-day baseline, C1 had a mean Total PTS score of $35.8(S D=6.6)$, with a range from 26 to 45 . C1's symptomology dramatically declined immediately following the start of treatment, and then increased again. $\mathrm{C} 1$ showed a high degree of variability throughout the course of treatment. $\mathrm{C} 1$ attributed this to days in which he had visitation with his father, as this was a stressful experience for him. At times, C1's attendance to treatment sessions was inconsistent, with treatment often occurring every other week rather than weekly and a 6-week gap between sessions 6 and 7. $\mathrm{C} 1$ and his mother attributed inconsistent attendance to a busy schedule, which became even more hectic during the second semester of the school year. Overall, at the time of posttreatment, $\mathrm{C} 1$ exhibited an $81.3 \%$ reduction in PTS symptomology $(M=6.7$, $S D=5.0)$ 


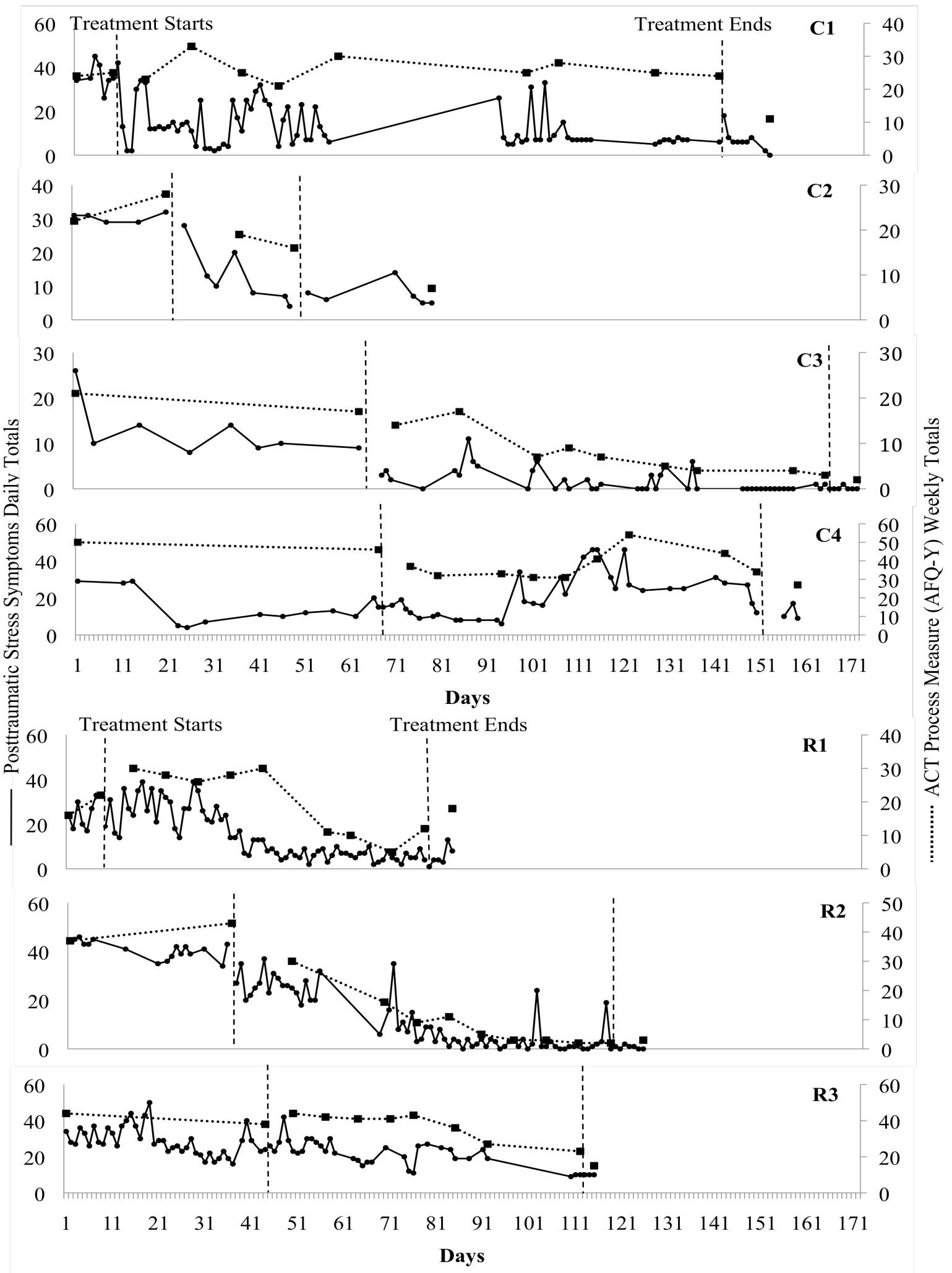

Figure 2. Daily trauma ratings (solid line) and weekly ACT process data (dotted line). 

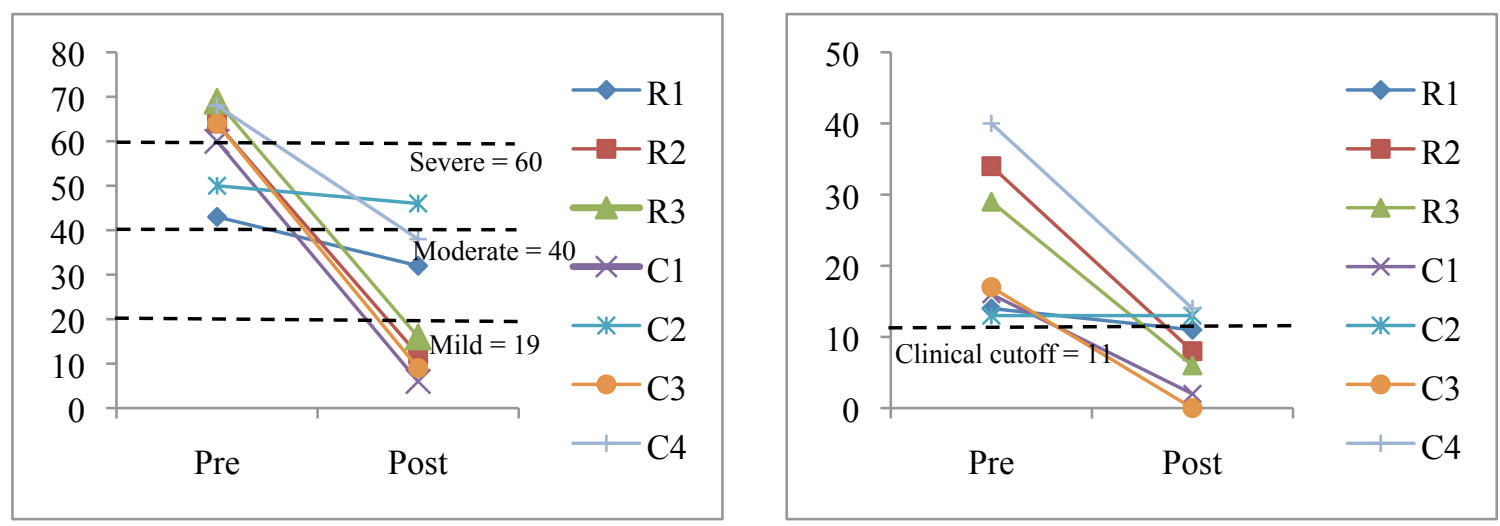

Figure 3. Clinician Administered PTSD Scale

Figure 4. Child PTSD Symptom Scale

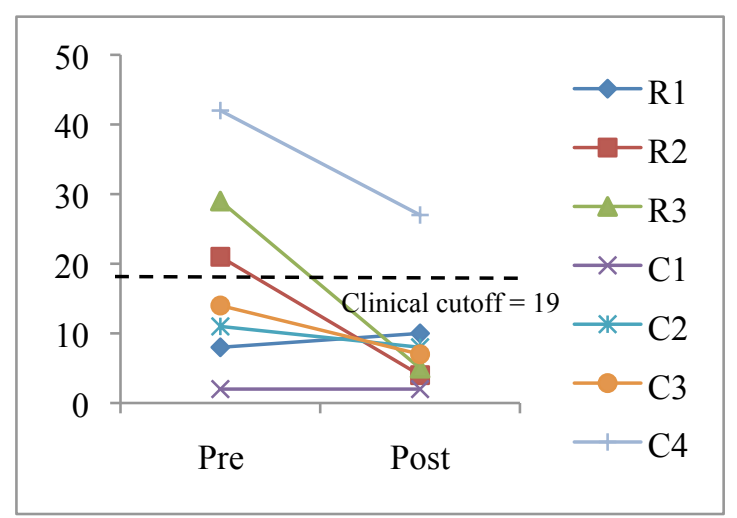

Figure 5. Children's Depression Inventory

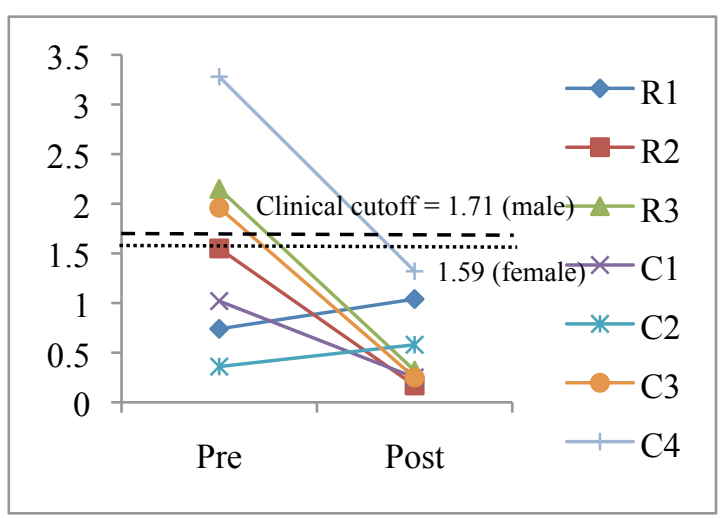

Figure 6. Brief Symptom Inventory Global Severity Index

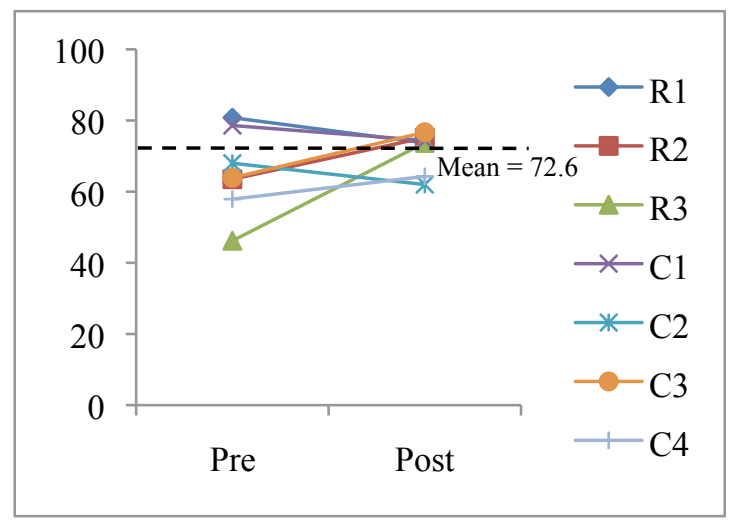

Figure 8. Comprehensive Quality of Life Subjective Scores 
C1's reduction in CAPS-CA scores between pre- and posttreatment are consistent with this significant, positive improvement. His pretreatment score of 60 fell in the severe range, while his posttreatment score of 6 fell in the asymptomatic range and represents a $90 \%$ reduction in symptomology. His CPSS scores at posttreatment (raw score $=2$ ) also represent an $87.5 \%$ decrease in symptomology compared to his score at pretreatment (raw score $=16$ ). It should be noted, however, that the validity of $\mathrm{C} 1$ 's reporting was questionable, as he seemed to have limited insight into his functioning and exhibited an extreme responding reporting style. It seemed that his self-report may have been influenced by overall distress rather than PTS symptomology per se, as well as possibly by expectancy effects of treatment.

C1's CDI scores were not in the significant range and exhibited no change between pre- (raw score $=2$ ) and posttreatment (raw score $=2$ ). His BSI scores were also both clinically insignificant at the time of pre- (raw score $=1.02)$ and posttreatment (raw score $=0.25)$. His objective ComQol score was stable between pre- (percentage scores $=$ 69.0) and posttreatment (percentage score $=69.0$ ), both of which fell more than one standard deviation above the norm. His subjective ComQol score fell within one standard deviation of the norm at both pre- (percentage scores $=78.6)$ and posttreatment (percentage scores $=74.4)$.

C1's total TEI-SF score of 35 (out of 35) indicates a high level of treatment acceptability. C1 marked "strongly agree" in response to six of the seven items, including "strongly agree" in response to the statements, "I find this treatment to be an acceptable way of dealing with posttraumatic stress," and "I believe this treatment is likely to result 
in permanent improvement." C1 marked "strongly disagree" in response to the item, "I experienced discomfort as a result of this treatment."

Community Participant 2. Baseline lasted 20 days for C2. During this time, C2's total self-reported PTS symptomology ranged from 29 to $32(M=30.4, S D=1.3)$. C2's PTS symptomology declined sharply once treatment began, which was maintained with moderate variability throughout the course of treatment. C2 opted to discontinue treatment after session 3 because she felt like she was doing better, felt as if she was too busy to continue participation, and did not believe there would be continued benefit from additional participation in treatment. $\mathrm{C} 2$ called to inform the therapist of her decision to withdraw at the time of her scheduled fourth session. She and the therapist discussed different treatment options, and C2 indicated she would like to think about these options before making a definitive decision. Two weeks after this discussion (three weeks after session 3), C2 indicated she was willing to complete a posttreatment and follow-up assessment, but was uninterested in additional treatment. C2 completed a postassessment four weeks after her final session (session 3). At the time of this assessment, C2's mean total PTS rating was $7.5(S D=3.4)$, which represents a $75 \%$ decrease in PTS symptomology compared to pretreatment.

C2's posttreatment CAPS-CA and CPSS scores, however, did not indicate any meaningful change in trauma symptomology. Her pretreatment CAPS-CA score of 50 fell in the moderate range for PTSD symptomology. Her CAPS-CA score at the time of posttreatment had decreased by only four points (raw score $=46$ ) and continued to fall in the moderate range for PTSD symptomology. Her CPSS score at the time of the 
postassessment (raw score $=13$ ) represented no change from her score at pretreatment (raw score $=13)$. Her CPSS score at the time of session 1 (raw score $=26)$, however, doubled compared to the score at the time of intake, and her lowest reported CPSS score (raw score $=6$ ) occurred at the time of session 3 .

C2's global severity score increased between pre- (raw score $=0.36)$ and posttreatment (raw score $=0.58$ ); however, both of these scores fell well below the clinical cutoff of 1.59. C2's depressive symptomology, as measured by the CDI, also fell in the clinically insignificant range at both pre- (raw score $=11)$ and posttreatment (raw score $=8$ ). C2's objective ComQol score increased between pre- (percentage score = 58.3) and posttreatment (percentage score $=67.9$ ), and both of these scores fell greater than one standard deviation above the norm. Her subjective ComQol score decreased slightly between pre- (percentage score $=68)$ and posttreatment (percentage score $=62)$. Both of these scores, however, fell within one standard deviation of the norm.

C2's total TEI-SF score of 27 (out of 35) indicates a high level of treatment acceptability. C2 marked "agree" in response to the statement, "Overall, I have a positive reaction to this treatment," and marked "strongly agree" in response to, "I find this treatment to be an acceptable way of dealing with posttraumatic stress." In response to the item, "I believe this treatment is likely to result in permanent improvement" C2 marked "strongly disagree."

Community Participant 3. C3 remained in the baseline phase for 62 days and reported a mean total PTS score of $12.5(S D=5.9$, range $=8$ to 26$)$. C3 reported a decrease in PTS symptomology following the initial intake session. His scores 
maintained at this lower level with minimal variability throughout the remainder of baseline. His PTS scores decreased again immediately following the start of treatment, with mild variability throughout the middle of treatment, and a consistent lack of symptoms throughout the later part of treatment. At the time of posttreatment, C3 exhibited a 99\% decrease in total PTS symptomolgy, with a mean score of $0.1(S D=0.4)$.

C3's pretreatment CAPS-CA score of 64 fell in the severe range. His overall posttreatment score of 9 fell in the asymptomatic range and represented an $86 \%$ reduction in PTSD symptmology. His pre- (raw score $=17)$ and posttreatment (raw score $=0)$ CPSS scores are also indicative of C3's significant improvement throughout the course of treatment, as his score at posttreatment represented a 100\% reduction in PTS symptomology compared to baseline.

C3 also showed significant reductions in general distress. His global severity BSI score at pretreatment (raw score $=1.96)$ fell above the clinical cutoff of 1.71 for adolescent males, while his posttreatment score (raw score $=0.25$ ) fell within the normal range and indicated an $87 \%$ decrease in reported distress. His pre- (raw score $=14$ ) and posttreatment (raw score $=7$ ) CDI scores both fell below the depression clinical cutoff of 19. Both C3's objective and subjective ComQol's scores increased between pre(percentage scores $=66.7$ and 63.9, respectively) and posttreatment (percentage scores $=$ 82.1 and 76.7, respectively). His objective ComQol score increased by $15.4 \%$ and fell more than one standard deviation above the norm at both time periods. His subjective ComQol score increased by $12.8 \%$ and fell within one standard deviation of the norm at both time periods. 
C3's total TEI-SF score of 27 (out of 35) indicates a high level of treatment acceptability. C3 marked "agree" in response to the items, "I find this treatment to be an acceptable way of dealing with posttraumatic stress symptomology," and "Overall, I have a positive reaction to this treatment." C3 marked "strongly agree" in response to the statement, "I believe this treatment is likely to result in permanent improvement," and marked "neutral" in response to "I like the procedures used in this treatment."

Community Participant 4. During her 66 days of baseline, C4 had a mean PTS total score of $14.8(S D=8.9)$, with ranges from 5-29. C4 inconsistently reported baseline data, with reporting occurring at a rate of about one time every six days. PTS symptomology decreased dramatically at the time of her fourth self-report, 23 days into baseline. Her reported scores remained lower throughout the rest of the baseline period. C4 attributed the decrease in her symptoms to winter break, as she said she was "less stressed out" during this time. C4 was also living with her grandmother throughout the majority of the baseline phase due to chronic behavioral problems exhibited by $\mathrm{C} 4$ while living at home and a strained relationship between $\mathrm{C} 4$ and her stepfather. After the start of treatment, C4's PTS symptomology steadily increased, and then gradually decreased following session 8 . C4's overall symptomology showed a high degree of variability throughout both baseline and treatment phases. C4's total PTS symptomology decreased by $19 \%$, for a mean of $12(S D=4.4)$ at posttreatment. At the time of posttreatment, $\mathrm{C} 4$ admitted she attempted to use her PTS daily ratings throughout the baseline and very early phases of treatment as a way to manipulate her mother, both by either refusing to complete daily rating scales and/or by intentionally underreporting her scores when both 
she and her mother knew she had had a difficult day. Retrospectively, C4 said she would have rated her overall trauma-related distress at the start of treatment at a 7.5 on a scale from 0 to 10, with 10 indicating higher levels of symptomology. At posttreatment she rated her general level of trauma-related distress at a 4. Given C4's reported manipulation of self-reported symptomology, her self-reported symptomology and functioning should be interpreted cautiously.

C4's CAPS-CA score at the time of pretreatment (raw score $=68)$ fell in the severe range for PTSD symptmology. Her score at the time of posttreatment (raw score $=$ 38) fell in the high-end of the mild range for PTSD symptomology (cut off for moderate range $=40$ ), and represented a 44\% reduction in symptomology. C4's CPSS also reflected positive change, indicated by a $65 \%$ reduction from pre- (raw score $=40)$ to posttreatment (raw score $=14$ ). Her score at the time of posttreatment, however, fell above the cutoff score of 11 and is still considered clinically significant.

C4's global severity score on the BSI at the time of intake (raw score $=3.28$ ) fell well above the clinical cutoff score of 1.59 . Her BSI score at the time of posttreatment $($ raw score $=1.32)$ was no longer clinically significant and indicated a 59.8\% decrease in overall distress. Her pre- (raw score $=42)$ and posttreatment $($ raw score $=27)$ CDI scores also reflect a $35.7 \%$ reduction in depressive symptomology; however, her scores at both time periods fell above the clinical cutoff score of 19. C4 also showed improvement in quality of life. Her objective ComQol score increased by $19 \%$ and moved from over one standard deviation below the norm at pretreatment (percentage score $=42.9$ ) to over one standard deviation above the norm at posttreatment (percentage score $=61.9$ ). Her 
subjective ComQol score increased by only $6.4 \%$ between pre- (percentage score $=$ $57.9 \%$ ) and posttreatment (percentage score $=64.3 \%$ ); however, her initial score fell over one standard deviation below the norm, while her posttreatment score fell within one standard deviation of the norm.

C4's total TEI-SF score of 30 (out of 35) indicates a high level of treatment acceptability. C4 marked "strongly agree" in response to the statements, "I believe it would be acceptable to use this treatment with individuals who cannot choose treatment for themselves," and "Overall, I have a positive reaction to this treatment."

\section{Residential Participants}

Residential Participant 1. During her seven days of baseline, R1 had a mean PTS total score of $24.1(S D=6.1)$, with ranges from 17 to 33. R1's PTS symptomology remained stable throughout the first few weeks of treatment and then sharply declined after session 4. This reduction in PTS symptomology was maintained through the end of treatment. R1's total PTS symptomology decreased by $78 \%$, for a mean of $5.3(S D=4.0)$ at posttreatment.

Improvements in R1's PTS symptomology were also reflected by her change in CAPS-CA and CPSS scores. R1 exhibited a 25.6\% reduction on her CAPS-CA score from pre- to posttreatment. Her pretreatment CAPS-CA score (raw score $=43)$ fell in the moderate range for PTSD symptomology, whereas her score at posttreatment (raw score =32) fell in the mild, subthreshold range. However, it should be noted that the CAPS-CA has identified a 15-point reduction as the required amount of change to indicate clinically meaningful change, which was not established by the time of posttreatment. R1's CPSS 
score also reflected positive change, indicated by a $21 \%$ reduction from pre- (raw score $=$ 14 ) to posttreatment (raw score $=11$ ). The CPSS was also administered at each treatment session and R1's CPSS scores ranged from 7 to 20 throughout the course of treatment. At the time of session 8, 9, and 10, R1's CPSS scores were 9, 7, and 9, respectively, which all fall below the clinical cutoff of 11 . Her score at the time of posttreatment, however, fell at the clinical cutoff and is still considered clinically significant.

R1's global severity score on the BSI, an indicator of general distress, was not clinically significant at pre- $($ raw score $=0.74)$ or posttreatment (raw score $=1.04$ ), as both of these scores fell below the recommended clinical cutoff level of 1.59 for adolescent females. R1's CDI scores at pre- (raw score $=8)$ and posttreatment (raw score $=10$ ) also both fell below the clinical depression cutoff of 19. R1's objective ComQol scores fell within one standard deviation of the normative sample at both pre- (percentage score $=53.6)$ and posttreatment (percentage score $=52.4)$. Her subjective ComQol scores also fell within one standard deviation of the norm at both pre- $($ percentage score $=80.8)$ and posttreatment (percentage score $=73.7$ ), although the direction of change is opposite of what was expected.

R1's total TEI-SF score of 28 (out of 35) indicates a high level of treatment acceptability. R1 marked "agree" in response to six of the seven items, including "agree" in response to the statements, "I liked the procedures used in this treatment," and "Overall, I have a positive reaction to this treatment." R1 marked "disagree" in response to the item, "I experienced discomfort as a result of this treatment." 
Residential Participant 2. Baseline lasted 35 days for R2. R2's total selfreported PTS symptomology ranged from 34 to $46(M=40.9, S D=3.6)$. R2's PTS symptomology declined quickly once treatment began, followed by consistent and gradual decline and moderate variability throughout treatment. R2's posttreatment mean total PTS rating was $0.7(S D=0.8)$, which represents a $98 \%$ decrease from baseline.

R2's posttreatment CAPS-CA score (raw score $=12$ ) fell in the asymptomatic range and indicates an $81 \%$ improvement compared to her pretreatment score (raw score $=64$ ), which fell in the severe range for PTSD symptomology. R2's CPSS score also reflected significant positive change, indicated by a 76.5\% reduction from pre- (raw score $=34$ ) to posttreatment (raw score $=8$ ). R2's mean CPSS score during sessions 6 through 10 was 2 . She described experiencing one difficult day during the week prior to postassessment, which is reflected in her slightly higher score at posttreatment. However, a CPSS score of 8 still falls below the clinical cutoff of 11 and represents clinically significant improvement compared to pretreatment.

At pretreatment, R2's global severity score on the BSI (raw score $=1.55)$ fell just slightly below the clinical cutoff of 1.59 . Her distress score was notably reduced at the time of posttreatment (raw score $=0.17$ ) and fell in the typical range. $\mathrm{R} 2$ also showed a decrease in depressive symptomology between pre- and posttreatment, as her pretreatment score (raw score $=21)$ fell above the clinical cutoff of 19 and her posttreatment score (raw score $=4$ ) fell in the average range. In regards to quality of life, R2's objective ComQol scores fell within one standard deviation of the norm at both pre(percentage score $=46.4)$ and posttreatment $($ percentage score $=53.6)$. Her subjective 
ComQol scores also fell within one standard deviation of the norm at both pre(percentage score $=63.5$ ) and posttreatment (percentage score $=75.2$ ). It should be noted, however, that both quality of life scores showed movement in positive directions. R2's total TEI-SF score of 27 (out of 35) indicates a high level of treatment acceptability. R2 marked "agree" on most of the items, including in response to, "I believe this treatment is likely to result in permanent improvement," and "Overall, I have a positive reaction to this treatment." On the item, "I believe this treatment is likely to be effective," R2 marked "strongly agree.” R2 marked "neutral" in response to the statements, "I experienced discomfort as a result of the treatment," and "I believe it would be acceptable to use this treatment with individuals who cannot choose treatment for themselves."

Residential Participant 3. R3 remained in the baseline phase for 43 days, and reported a mean Total PTS score of $28.9(S D=7.9$, range from 16 to 50). PTS scores increased slightly during the first part of baseline and then decreased slightly during the second half of baseline, and spiked once more immediately before treatment. During the first half of baseline, R3 was approaching the 1-year anniversary of her mother's death, which explains this increase. R3 also reported increases in symptomology around the $18^{\text {th }}$ of each month, as this is the day her mother passed away. Thus, the pattern seen during baseline is representative of this cyclical pattern, with a more dramatic increase the days leading up to the 1-year anniversary. Between sessions 8 and 9, R3 traveled home for 2 weeks as a part of the treatment plan through the residential facility. Due to R3's significant improvement with eating disordered symptomology and success on this home 
visit, residential treatment was no longer required and she discharged within a week of returning from her visit home. Thus, sessions 9 and 10 occurred within the same week, and a postassessment was administered immediately after session 10. R3's PTS symptomology decreased steadily throughout the course of treatment, and she exhibited relatively minimal variability in symptoms. At the time of the postassessment, R3 exhibited a $65.4 \%$ decrease in total PTS symptomology, with a mean score of $10(S D=$ $0)$.

R3's pretreatment CAPS-CA score of 69 fell in the severe range. Her overall score at posttrement of 16 is considered asymptomatic and represented a $76.8 \%$ reduction in PTSD symptomology. Additionally, it should be noted that the $18^{\text {th }}$ of the month fell within the week assessed by the CAPS-CA at posttreatment, a date in which R3 typically experienced a dramatic increase in symptomology. Her pre- $($ raw score $=29)$ and posttreatment (raw score $=6$ ) CPSS scores are also indicative of R3's clinically significant improvement throughout the course of treatment, as her score at postreatment represented a 79.3\% reduction in PTS symptomology compared to baseline.

R3 also showed significant reductions in general distress and depression, as well as improvements in quality of life. Her global severity BSI score at pretreatment (raw score $=2.15)$ fell above the clinical cutoff of 1.59 , while her posttreatment score (raw score $=0.32)$ fell within the normal range and indicated an $85.1 \%$ decrease in general distress. Her pretreatment CDI score (raw score $=29$ ) also fell above the depression clinical cutoff of 19. At posttreatment, R3's CDI score (raw score =5) represented an $82.8 \%$ decrease in depressive symptomology and fell in the clinically insignificant range. 
Both R3's objective and subjective ComQol's scores increased dramatically between pre(percentage scores $=41.7$ and 46.2, respectively) and posttreatment (percentage scores $=$ 60.7 and 73.7, respectively). Her objective ComQol score moved from over one standard deviation below the norm to over one standard deviation above the norm from pre- to posttreatment. Her subjective ComQol score moved from over one standard deviation below the norm to within one standard deviation of the norm.

R3's total TEI-SF score of 26 (out of 35) indicates a high level of treatment acceptability. R3 marked "agree" in response to, "Overall, I have a positive reaction to this treatment," and "I liked the procedures used in this treatment." R3 marked "neutral" in response to the statement, "I believe this treatment is likely to result in permanent improvement," and "I experienced discomfort as a result of treatment.

\section{Summary of Outcome Results}

Taken together, the mean percent reduction in total self-reported posttraumatic stress symptomology was $73.7 \%(S D=27.0)$. The mean percent reduction in trauma related symptoms according to the CPSS was $61.4 \%(S D=36.7)$. Reductions in CAPSCA scores were observed for all participants. Five participants (two from the residential sample and three from the community sample) exhibited clinically meaningful change, indicated by a reduction of 15 or more points on the CAPS-CA. Six of the participants were below the clinical range for posttraumatic stress symptomology at posttreatment; two of these participants (one residential, one community), however, fell in the subthreshold range for posttraumatic stress symptomology. One community participant 
was above the clinical range. The participant who was above the clinical range at posttreatment was the individual who discontinued treatment prematurely. Average CAPS-CA reduction was $58.8 \%(S D=32.8)$. The overall means and standard deviations from pretreatment to posttreatment for all measures are provided in Table 3.

\section{Psychological Process of Change Results}

Changes in experiential avoidance/psychological flexibility were investigated in multiple ways. Figure 2 shows weekly ratings on the measure of ACT processes (AFQY) alongside changes in PTS symptom totals. R1's AFQ-Y scores fluctuated during the treatment process. Her AFQ-Y score was 16 at pretreatment and 18 at posttreatment, with

Table 3

Means and Standard Deviations from Pretreatment to Posttreatment

\begin{tabular}{|c|c|c|c|c|}
\hline & \multicolumn{2}{|c|}{ Pretreatment } & \multicolumn{2}{|c|}{ Posttreatment } \\
\hline Measure & $M$ & $S D$ & $M$ & $S D$ \\
\hline Total PTS Symptoms & 26.8 & 10.4 & 6.0 & 4.4 \\
\hline CAPS-CA & 59.7 & 9.7 & 22.7 & 15.8 \\
\hline CPSS & 23.3 & 10.9 & 7.7 & 5.4 \\
\hline CDI & 18.1 & 13.7 & 9.0 & 8.4 \\
\hline BSI - GSI & 1.58 & 0.99 & 0.56 & 0.45 \\
\hline ComQol - Objective ${ }^{a}$ & 54.1 & 11.1 & 63.9 & 10.2 \\
\hline ComQol - Subjective $\mathrm{a}^{\mathrm{a}}$ & 65.6 & 11.9 & 71.4 & 5.8 \\
\hline TEI-SF & & & 28.6 & 3.1 \\
\hline AFQ-Y & 30.6 & 13.0 & 11.9 & 8.9 \\
\hline
\end{tabular}

Note. AFQ-Y = Avoidance and Fusion Questionnaire for Youth; BSI = Brief Symptom Inventory; CAPS-CA = Clinician Administered PTSD Scale for Children and Adolescents; CDI = Children's Depression Inventory; ComQol = Comprehensive Quality of Life Scale; CPSS = Children's PTSD Symptom Scale; GSI = Global Severity Index; PTS = Posttraumatic Stress; TEI-SF = Treatment Evaluation Inventory-Short Form ${ }^{a}$ Higher scores are indicative of better functioning or greater acceptability. 
her highest AFQ-Y score of 30 at the time of session 2 and session 6, and her lowest AFQ-Y score of 5 at the time of session 9. R2's AFQ-Y scores declined during the treatment process. Her respective AFQ-Y pre- and posttreatment scores were 37 and 3, with her highest score (raw score $=43$ ) at the time of session 1 and consistent decline throughout treatment. R3's AFQ-Y scores were 44 at pretreatment and 15 at posttreatment, with minimal fluctuation between sessions 1 and 6 and consistent decline beginning at the time of session 7. C1's AFQ-Y scores fluctuated moderately throughout treatment, with an overall decrease in process scores between pre- and posttreatment (raw scores $=24$ and 11, respectively). C2's AFQ-Y score was 22 at pretreatment, peaked at the time of session 1 (raw score $=28$ ), and declined rapidly throughout treatment, with a posttreatment score of 7. C3's process scores also declined with treatment, as his pretreatment AFQ-Y score was 21 while his posttreatment score was 2. C4's respective pre- and posttreatment AFQ-Y scores were 50 and 27, with much variability throughout treatment. Taken together, six of seven participants showed process changes in expected directions throughout the course of treatment, with an average reduction on the AFQ-Y of $57.7 \%$ from pre- to posttreatment.

A paired sample $t$ test was also conducted to investigate changes in psychological flexibility according to the AFQ-Y from pre- to posttreatment. There was a significant difference in the scores for AFQ-Y pretreatment scores $(M=30.6, S D=4.9)$ and posttreatment scores $(M=11.9, S D=8.9) ; t(6)=4.2, p=.006$. These results indicate that engagement in ACT was related to decreases in experiential avoidance and increases in psychological flexibility. 
Additionally, lag analyses across all participants were performed between weekly PTS averages and weekly AFQ-Y scores. Correlations were calculated between same week PTS and AFQ-Y scores (zero lag). Next, PTS scores were correlated with AFQ-Y scores offset by one week (lag 1), then offset by two weeks (lag 2), etc. The same analysis was then conducted between AFQ-Y and PTS at the following lags. Results of the lag analyses across all participants are displayed in Figure 9. These results generally show that decreases in experiential avoidance predict decreases in PTS severity at later time points better than changes in PTS severity predict later changes in psychological flexibility.

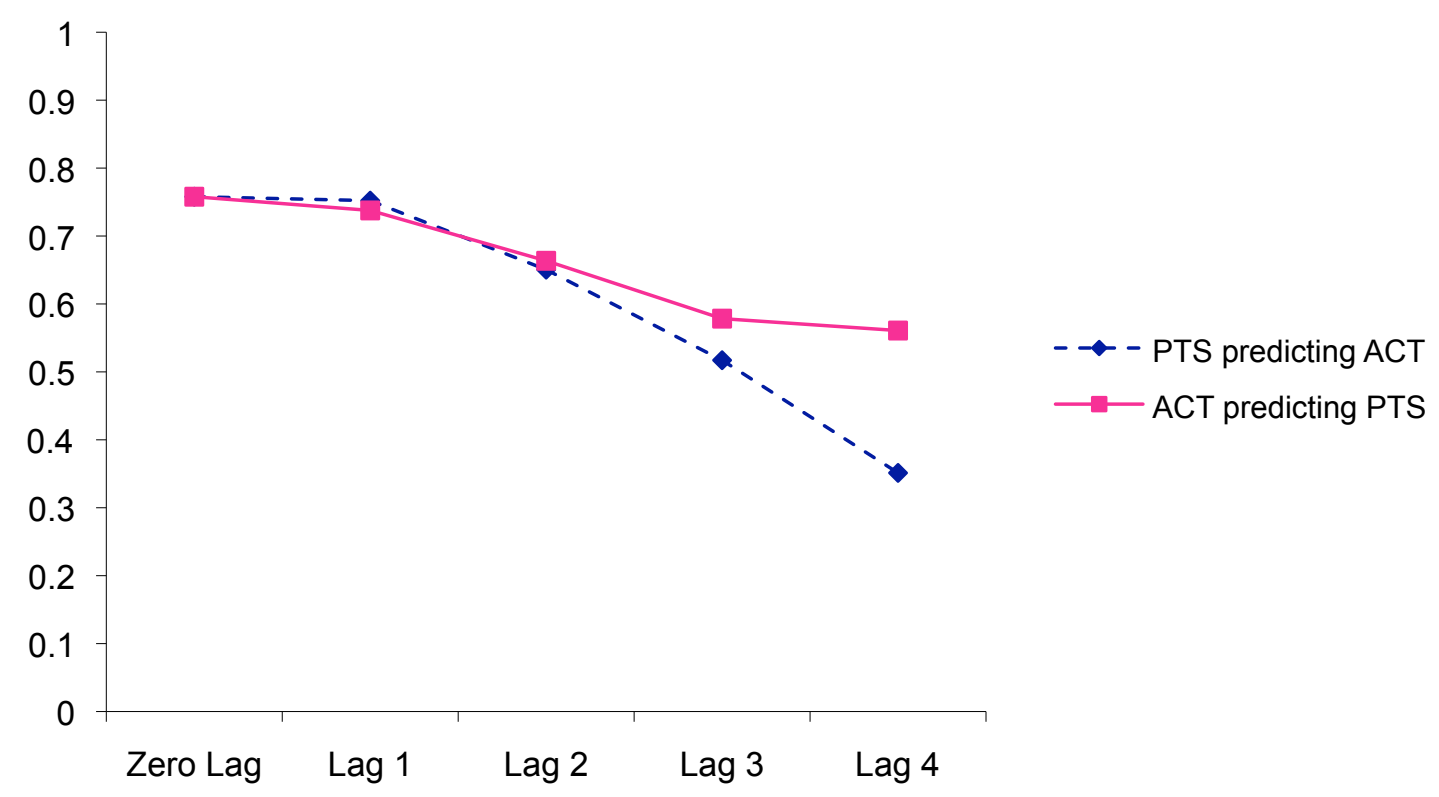

Figure 9. Lag correlations: Weekly PTS and process ratings across participants. 


\section{CHAPTER V \\ DISCUSSION}

\section{Outcomes}

This study provides preliminary support for the effectiveness of a 10-session ACT protocol to treat adolescents with posttraumatic stress. A multiple-baseline across participant design was utilized with two separate adolescent samples: a community sample $(n=4)$ and a residential sample with comorbid eating disorders $(n=3)$. All participants showed large decreases on the main dependent variable, daily ratings of posttraumatic stress symptomology $(M=73.7 \%$ reduction $)$. Pre- and posttreatment assessment data were consistent with this trend. Reductions in CAPS-CA scores were observed for all participants $(M=58.8 \%)$, indicating decreases in the frequency and severity of PTS symptoms. Only one participant continued to fall above the clinical threshold for PTSD on the CAPS-CA at the time of posttreatment. All but one participant also exhibited positive change on the CPSS $(M=61.4 \%$ reduction), further supporting a reduction in PTS symptomology. The only participant who did not exhibit change on the CPSS was the individual who discontinued treatment prematurely. This was the same participant who continued to fall in the clinical range on the CAPS-CA at posttreatment. Additionally, all participants reported that the intervention was acceptable via standardized measure. Taken together, these results suggest that ACT is a promising treatment for posttraumatic stress symptomology among adolescents. 
In addition to reductions in PTS symptomology, participants generally showed improvements on the CDI and BSI between pre- and posttreatment as well. One participant showed a slight increase in depressive symptomology according to the CDI; however, her scores fell well below the clinical cutoff for depression at both pre- and posttreatment. One participant continued to fall above the clinical cut off for depression at posttreatment; although she exhibited a notable decrease $(35.7 \%$ reduction $)$ in depression between pre- and posttreatment. No participants fell above the clinical cutoff for general distress at posttreatment according to the global severity score of the BSI, while three participants fell above this clinical cutoff at pretreatment. These results suggest that ACT was related to decreases in depression and general distress for individuals who experienced clinically significant depression and/or general distress at pretreatment, even though these concerns were not directly targeted throughout the course of treatment.

The overall impact on quality of life was also generally positive, although typically minimal. Across all participants, objective quality of life increased an average of $9.9 \%$ and subjective quality of life increased an average of $5.9 \%$ between pre- and posttreatment according to the ComQol. In regards to subjective quality of life, five of the seven participants fell within one standard deviation of the reference group mean at both pre- and posttreatment. Both participants whose subjective Qol score fell more than one standard deviation below the mean exhibited scores that fell in the normative range at posttreatment. Similarly, five of the seven participants fell within or above the normative range on objective quality of life at pretreatment and remained in their respective 
categories at posttreatment. Both participants whose objective Qol score fell more than one standard deviation below the mean at pretreatment exhibited scores that fell more than one standard deviation above the mean at posttreatment. These results suggest that ACT may only have an impact on quality of life for those who are experiencing poorer than average quality of life at pretreatment. For individuals who report normative to above average levels of subjective and objective quality of life at pretreatment, ACT may have less of an impact. It is also possible, however, that the chosen measure lacked the sensitivity to assess meaningful change in quality of life among this population, or that the time necessary to show changes in this area is longer than what was collected in this study. The ComQol does not provide cutoff scores for Qol domains and the meaning of scores that fall above or below a standard deviation of the mean is unknown. Thus, this may not be the most useful way to interpret ComQol scores for this population. Further investigation into the impact of ACT on quality of life among adolescents with posttraumatic stress is needed in order to better understand the relationship between the two. Although less change was exhibited on the ComQol than was initially expected, overall results on all outcome measures changed in expected directions.

Change on processes that ACT purports to target was assessed with the AFQ-Y. Reductions on the AFQ-Y indicate lower levels of experiential avoidance and cognitive defusion, increased levels of acceptance and psychological flexibility, and a greater degree of values-consistent behavior. Six of the seven participants showed decreases on AFQ-Y process scores between pre- and posttreatment, with one participant showing an increase of 2 points $(M=57.7 \%$ reduction). Changes in processes were observed 
alongside changes in PTS symptomology. For five of the seven participants, the changes in AFQ-Y scores correlated as expected with changes in PTS symptomology throughout the course of treatment. In other words, for these participants as AFQ-Y scores decreased, so did PTS scores. Although causal relationships cannot be inferred through this analysis, these results indicate that ACT was related to decreases in both experiential avoidance and PTS symptomology. The relationship between R1 and C1's process and PTS scores were more variable throughout the course of treatment. R1 exhibited a high degree of variability in AFQ-Y scores that did not always correlate well with changes in PTS symptomology. C1 exhibited relatively minimal variability in AFQ-Y scores throughout the course of treatment, with a notable score reduction at the time of posttreatment. These results suggest that for these participants, although positive change in PTS symptomology was observed, this change appeared to be related to factors other than reductions in experiential avoidance. As previously noted, however, C1's ability to accurately selfreport seemed questionable; and thus, his results must be interpreted with caution.

Lag correlation analyses were also conducted across all participants in order to examine the temporal connections between changes in process and changes in outcome. Lag correlations for ACT processes predicting PTS were stronger than for PTS predicting ACT processes. These results suggest that changes in processes were driving symptom changes rather than the other way around. Thus, when considering all participants together, process change and symptom change were temporally related in the manner that was expected. The finding that movement in ACT processes occurred prior to reductions in PTS symptomology is consistent with ACT's model of change. 


\section{Empirical and Clinical Implications}

Results of this study are encouraging and possess both empirical and clinical implications. The literature base of ACT as a treatment for children and adolescents is in its infancy compared to the research that has been conducted on ACT for adults. While ACT has been shown to be an effective treatment for a myriad of conditions among adults (Hayes et al., 2006; Ruiz, 2010), to date only two published randomized trials on ACT with youth exist: a pilot study for adolescents with depression (Hayes et al., 2011) and one for adolescents with chronic pain (Wicksell et al., 2009). Multiple case studies and case series support ACT as a treatment for youth in the areas of school refusal, anorexia nervosa (Heffner et al., 2002), schizophrenia (García-Montes \& Pérez-Álvarez, 2001), and obsessive compulsive disorder (Armstrong et al., in press). Empirical investigation on ACT with adolescent populations is relatively scarce, and this study represents the first in the area of ACT for adolescent posttraumatic stress.

As previously written, this is the first study to provide empirical evidence for ACT as an effective treatment for adolescent PTS. Reductions in PTS symptomology found in this study were comparable to those found in TF-CBT (e.g., Cohen et al., 2005; Vandervord Nixon, Sterk, \& Pearce, 2012) and Prolonged Exposure for adolescents exposed to a single traumatic event (e.g., Gilboa-Schechtman et al., 2010), and were better than those found in school-based group CBT (e.g., Kataoka et al., 2003; Stein et al., 2003). Further, this study supports ACT as an effective treatment not only for adolescents with PTS but also for adolescents with PTS and comorbid conditions, including comorbid eating disorders. Additionally, in this study, ACT was effective for individuals who 
experienced different types of traumatic events (i.e., exposure to violence, sexual abuse, physical abuse, traumatic loss, and natural disaster) as well as for individuals who experienced a single traumatic incident and for those who experienced multiple traumas. Much of the existing outcome research conducted with youth with PTS have focused on individuals exposed to single incidents of trauma and/or on specific types of trauma exposure (e.g., sexual abuse, exposure to domestic violence). Additionally, much of the existing literature has utilized samples that combine children and adolescents. There may be important developmental differences between these two groups that influence the effectiveness of a given treatment approach. Thus, the fact that this study was conducted solely with adolescents and found ACT to be effective across multiple trauma types is notable. Future research can help inform whether ACT is equally effective across trauma types or whether it is more effective for some types than others as well as whether ACT is more effective for youth of different age and developmental abilities.

The high rating of treatment acceptability among participants in this study is also notable. Treatment acceptability is an important issue for all treatment approaches with youth, and perhaps to an even greater degree with PTS. Given that exposure to trauma is related to a number of negative outcomes that can persist into adulthood (Flood et al., 2009), early intervention may be essential in helping to prevent long-term negative outcomes. Treatment refusal and treatment dropout have been problematic among trauma treatments for youth. The fact that participants found ACT to be an acceptable treatment is promising and may provide an avenue to help address these concerns. The exclusion of trauma narratives or repeated retellings of traumatic events may have influenced the 
positive acceptability ratings of ACT. Trauma narratives, retelling of traumatic events, and other imaginal or in vivo exposure activities are not necessarily inconsistent with an ACT approach; however, from an ACT perspective, the function and goal of these activities differ from traditional CBT and habituation models of exposure. From an ACT perspective, such activities could function as ways to practice mindful acceptance of difficult internal experiences in order to provide new learning opportunities that will allow the individual to incorporate additional, more flexible behavioral responses into his/her repertoire that will assist in values-driven behavior. In other words, exposure related activities would never be incorporated into ACT for the purpose of reducing the intensity or frequency of trauma related thoughts or feelings; rather, the purpose would be for the individual to learn that s/he can engage in previously avoided values-based behavior, even in the presence of unwanted internal experiences.

Given the centrality of avoidance in PTSD, engagement in any trauma treatment at all is a form of exposure. Thus, elements of exposure were present in this study, as it would be impossible to completely eliminate all forms of exposure from a treatment that directly targets trauma. Behavioral commitments outside of treatment sometimes placed clients in contact with previously avoided external and internal stimuli, and in-session discussions often elicited internal stimuli previously avoided by the client. However, these situations were presented as opportunities to practice ACT processes rather than opportunities to help reduce anxiety. Exposure presented from this framework may assist with treatment engagement and aid in treatment acceptability. Future research can help clarify how ACT may be able to be supplemented by other treatment approaches and/or 
how ACT can be used as an adjunct to other treatments to help with treatment engagement and compliance.

This study combined with the existing literature base of ACT with youth also provides preliminary support for the appropriateness and effectiveness of ACT's processes and procedures for this age group. As pointed out by Coyne, McHugh, and Martinez (2011), it is a common misconception that ACT is too abstract and complex to use with young people. Interestingly, the experiential techniques and metaphors presumed to be too esoteric for youth might actually be the primary treatment components that contribute to the effectiveness and appropriateness of ACT's use with children and adolescents. ACT's primary reliance on experiential learning and metaphors is less instructive than other interventions such as psychoeducation and rational arguments, and is therefore more difficult to defy, argue, or comply with (Coyne et al., 2011; Greco, Blackledge, et al., 2005). Further, because ACT emphasizes values, it may be a natural fit for adolescence because of the values exploration and increased ability for abstract thinking central to this developmental period (Greco, Blackledge, et al., 2005). Of course, developmental abilities must be taken into consideration and numerous adaptations of commonly used ACT metaphors and exercises have been created (e.g., Greco, Blackledge, et al., 2005; Murrell et al., 2005). This study provides further evidence that ACT can be effectively adapted for youth while maintaining fidelity to the ACT model. 


\section{Limitations and Future Directions}

In addition to the positive contributions of this study, there are a number of limitations that must be addressed. First, although ACT received favorable acceptability ratings, difficulty recruiting interested participants and treatment dropout in this study were comparable to those among existing treatments. Recruitment efforts were more difficult and less successful than initially expected. The original study was to be conducted with a community sample only. Low response rates to varied recruitment efforts among the community led to a broadening of the original sample. Although three to four participants is adequate for a multiple baseline design, additional participants within each sample would have further strengthened this study and would have provided stronger evidence for the effectiveness of ACT as a treatment for adolescent PTS.

Additionally, although the two separate samples provide promising support for the utility of ACT across unique groups, there are multiple complications related to conducting research with a residential population. The residential participants were receiving ongoing individual, family, and group therapy simultaneous to their participation in this study. All of these participants were receiving comprehensive residential care for severe and chronic eating disorders, and this was the primary target of treatment throughout their stay. The ACT therapist for this study was a part of the residential treatment team and worked closely with the residential therapists and team. Residential therapists reported that trauma was not being targeted in individual, family, or group sessions; however, data on this was not gathered. Taped sessions or formal assessment of TAU to confirm this report would have strengthened this study. 
Furthermore, in addition to focused treatment, residents engaged in ACT, mindfulness, dialectical behavior therapy (DBT), and recovery maintenance didactic groups, as well as equine assisted therapy as a part of the regular residential programming. Thus, participants were exposed to a variety of treatment modalities outside of the treatment of this study, including additional exposure to ACT principles. These confounding factors make it difficult to draw strong conclusions regarding the effect of 10 weeks of individual ACT alone. Although didactic groups tend to be educational and did not target trauma specifically, additional exposure to ACT principles outside of therapy may have impacted treatment effects of this study. Further, various ACT principles overlap with principles that may have been covered in mindfulness and DBT groups, and this was not controlled or assessed for. Additionally, participants were almost certainly exposed to concepts that were ACT-inconsistent through their participation in didactic groups and TAU, and the frequency of ACT-inconsistent messages as well as the impact of this exposure is unknown.

Because all residential participants engaged in TAU and regular programming throughout the baseline phase, results of this study are still indicative of positive effects of individual ACT on PTS; however, the potential impact of these additional factors must be considered. Should future research be conducted within a residential setting, greater efforts should be made to control for these variables. For example, TAU and didactic groups could be recorded and assessed for ACT consistent or inconsistent messages. Participants could also be asked to provide a self-report of what they attribute change to and how much positive and/or negative impact they believes various treatment modalities 
had on specific aspects of functioning. Additionally, research utilizing ACT as a standalone treatment should be conducted within residential environments to better understand its impact with this population. Finally, because this study was not initially intended to be conducted with adolescents with comorbid eating disorders, eating disorder behaviors alongside changes in PTS and psychological flexibility were not assessed; however, it would have been interesting to have access to this data. Although this and other studies provide support for positive changes for conditions not directly targeted in treatment (e.g., depression and general distress in this study), future research conducted with individuals with comorbid conditions should assess both behaviors directly targeted in treatment as well as comorbid symptomology not directly targeted in order to better understand ACT's impact on all conditions present for a given individual.

The ACT therapist worked within the residential facility prior to and during completion of this study, and therefore, she was familiar with participants and had interacted with them prior to their engagement in trauma treatment. These interactions likely influenced the rapport between the therapist and clients. Given the familiarity with one another, it is quite possible that the therapist had better rapport at the start of treatment with residential participants compared to community participants. This may partially explain why dropout, treatment refusal, and daily data collection were not problematic among the residential sample, while these issues were concerns among the community group. Persistent and exaggerated negative beliefs and expectations about oneself, the world, and others are so common among individuals with PTS that this has been added as a PTSD diagnostic symptom in the proposed DSM-V (APA, 2012). Given 
that mistrust of others and beliefs that the world is an unsafe place are particularly common among individuals with PTS, familiarity with the therapist prior to engagement in trauma treatment may be an important factor related to increased treatment engagement and compliance. Future research should be conducted to better understand the relationship between therapist familiarity prior to the onset of trauma treatment and treatment engagement and compliance.

In this study, individuals who completed three or more treatment sessions reported high acceptability of ACT, indicating that ACT is an acceptable treatment of adolescent PTS for those who engage in it; however, as previously noted, successfully attaining engagement of treatment and treatment dropout remained problematic in this study, particularly among the community sample. Overall dropout rates and treatment refusal of this study were comparable to that of existing trauma treatments. It should be noted that all three community participants considered treatment dropouts experienced chronic, severe sexual abuse histories, and exhibited complex trauma symptomology. This may suggest that modifications are needed to the protocol for adolescents with this history and presentation, or it may be indicative of the need for additional interventions that target treatment interfering behaviors among adolescents with complex trauma. As previously written, mistrust of others is common among individuals with PTS, particularly those with repeated interpersonal traumas such as sexual abuse. The lack of familiarity with the therapist prior to engagement in trauma treatment may have impacted participants' willingness to engage in treatment. It is possible that more time must be spent developing stronger rapport with individuals with complex trauma histories and 
presentations prior to engagement in treatment that directly targets trauma. Again, future research into this area can help answer these important questions.

Also of note regarding dropout in this study, two of the individuals who dropped out withdrew after the first session. The first session primarily focused on psychoeducation of trauma and general assessment; traditional ACT treatment did not begin until session 2 . Thus, it is likely these two participants withdrew for reasons unrelated to ACT itself. The third participant who dropped out did so after session 2 and was siblings with one of the other dropout participants. Although she indicated she felt as if she was "too busy" to participate after she was selected for participation on a school sports team, she and her sister also possessed a highly enmeshed relationship and had previously expressed only being interested in participation if the other agreed to participate. Thus, refusal from one sibling likely influenced withdrawal of the other sibling.

Consistent daily PTS data collection was also more challenging than initially expected, particularly during the baseline phase and among the community sample. Given that avoidance is a primary component of PTS, simply tracking the frequency and distress of PTS symptoms is a form of exposure and directly challenges the avoidance agenda central to the pathology itself. In hindsight, a multiple baseline design may not be the best design for trauma interventions because of the exposure that occurs through data collection prior to engagement in treatment. In this study, inconsistent daily data collection was conceptualized as a form of avoidance of trauma reminders. Therefore, it would be expected that data collection would be more inconsistent among the baseline 
phase compared to the treatment phase, as avoidance was directly targeted throughout the course of treatment. If regular symptom monitoring functions as an exposure activity, it is quite possible this had an impact on the effects seen throughout the course of treatment. Thus, future research utilizing alternative treatment designs that do not include daily symptom tracking can help isolate effects related to ACT itself versus effects related to regular symptom monitoring. Daily symptom monitoring, particularly during the baseline phase, may have also impacted potential participants' decision whether or not to engage in this study, as potential participants may have been deterred upon discovering that regular symptom tracking would be required. It is possible the initial explanation of the study, including the description of regular symptom tracking as well as the description of the selected intervention could account for acceptance or decline of participation. Future research investigating factors related to treatment seeking behavior and acceptance or refusal of psychological treatment can help us better understand this phenomenon.

Another limitation of this study was that the therapist, instead of another researcher, conducted pre- and posttreatment assessments. Pre- and postassessments were conducted by the treating therapist for logistical reasons; however, utilization of an independent assessor for the CAPS-CA would have strengthened this study and future research should use independent assessors in order to reduce the likelihood of interviewer bias and socially desirable responding. Further, this study relied on self-report data and a semi-structured interview conducted by the therapist and did not include data provided by the parent/guardian. It is unknown how the findings of this study may have been impacted had additional information been collected from parents. Similarly, best practice 
recommends parental involvement throughout the course of treatment, and this study utilized some, but minimal involvement with parents. Involvement primarily consisted of periodic updates of what had been covered in sessions and what the individual was working on between sessions. Future research should control for parental involvement and investigate its impact on outcomes.

Finally, inclusion of follow-up data is needed in order to determine the long-term impacts of treatment gains. As of July 2012, over half of the participants from this study had completed a 3-month follow-up assessment in which they provided the same data that they reported at pre- and posttreatment, and the results thus far are positive and encouraging. Upon completion of follow-up assessments for the remaining three participants, results will be synthesized and reported in a future publication. A logical next step to help confirm the findings of this study as well as the long-term effectiveness of ACT for adolescent PTS would be a randomized controlled trial with assessments conducted at pre-, posttreatment, and successive follow-up periods up to a year or longer by independent assessors blind to time and condition. Such a study would help draw stronger conclusions about the effectiveness of ACT as a treatment for PTS among youth.

\section{Conclusions}

In summary, a brief course of individual ACT was successfully implemented with seven adolescents with PTS across two separate samples: a community sample and a residential sample with comorbid eating disorders. Six of seven participants completed the entire course of treatment and one withdrew early because of reported early 
improvement. All participants exhibited notable reductions in self-reported PTS symptomology and endorsed high acceptability of treatment procedures. All treatment completers also exhibited notable reductions on additional clinician administered and self-report PTSD measures. Results provide preliminary support for ACT as an effective stand-alone treatment for adolescent PTS. Future research is needed in order to confirm these findings and to explore the long-term effectiveness of ACT as a treatment for youth with PTS. 


\section{REFERENCES}

Aaron, J., Zaglul, H., \& Emery, R. E. (1999). Posttraumatic in children following acute physical injury. Journal of Pediatric Psychology 24, 335-343.

Ahmad, A., \& Sundelin-Wahlsten, V. (2008). Applying EMDR on children with PTSD. European Child and Adolescent Psychiatry, 17, 127-132.

Alonso, J., Angermeyer, M. C., Bernet, S., Bruffaerts, R., Brugha, T. S., Bryson, H., ... Vollebergh, W. A. (2004). Disability and quality of life impact of mental disorders in Europe: Results from the European Study of the Epidemiology of Mental Disorders (ESEMeD) project. Acta Psychiatrica Scandinavica, Supplement, 109, 38-46.

Amaya-Jackson, L., \& DeRosa, R. R. (2007). Treatment considerations for clinicians in applying evidence-based practice to complex presentations in child trauma. Journal of Traumatic Stress, 20, 379-390.

American Academy of Child and Adolescent Psychiatry. (2010). Practice parameter for the assessment and treatment of children and adolescents with posttraumatic stress disorder. Journal of the American Academy of Child and Adolescent Psychiatry, 49(4), 414-430.

American Psychological Association, Division 12: Society of Clinical Psychology. (n.d.). Psychological treatments. Retrieved from (September 17, 2012) http://www.div12.org/PsychologicalTreatments/treatments.html.

American Psychiatric Association. (2000). Diagnostic and Statistical Manual of Mental Disorders ( $4^{\text {th }}$ ed., text rev.). Washington, DC: Author.

American Psychiatric Association. (2004). Practice guidelines for the treatment of acute stress and posttraumatic stress disorder. American Journal of Psychiatry, 161, 131.

American Psychiatric Association. (2012). American Psychiatric Association DSM V development. Retrieved from http://www.dsm5.org/ProposedRevision/Pages/proposedrevision.aspx?rid=165

Anthony, J. L., Lonigan, C. J., \& Hecht, S. A. (1999). Dimensionality of posttraumatic stress disorder symptoms in children exposed to disaster: Results from confirmatory factor analyses. Journal of Abnormal Psychology, 108, 326-336. 
Anthony, J. L., Lonigan, C. J., Vernberg, E. M., La Greca, A. M., Silverman, W. K., \& Prinstein, M. J. (2005). Multisample cross validation of a model of childhood posttraumatic stress disorder symptomology. Journal of Traumatic Stress, 18, 667-676.

Armstrong, A. B., Morrison, K. L., \& Twohig, M. P. (in press). Acceptance and commitment therapy for adolescent obsessive-compulsive disorder. Journal of Cognitive Psychotherapy.

Asmundson, G. J., Coons, M. J., Taylor, S., \& Katz, J. (2002). PTSD and the experience of pain: Research and clinical implications of shared vulnerability and mutual maintenance models. Canadian Journal of Psychiatry, 47(10), 930-937.

Batten, S. V., \& Hayes, S. C. (2005). Acceptance and Commitment Therapy in the treatment of comorbid substance abuse and post-traumatic stress disorder: A case study. Clinical Case Studies, 4(3), 246-262.

Berman, S. L., Kurtines, W. M., Silverman, W. K., \& Serafini, L. T. (1996). The impact of exposure to crime and violence on urban youth. American Journal of Orthopsychiatry, 66, 329-336.

Blackledge, J. T. (2004). Functional contextual processes in posttraumatic stress. International Journal of Psychology and Psychological Therapy, 4, 443-467.

Boney-McCoy, S., \& Finkelhor, D. (1995). Psychosocial sequelae of violent cictimization in a national youth sample. Journal of Consulting and Clinical Psychology, 63, 726-736.

Boscarino, J. A. (2004). Posttraumatic stress disorder and physical illness: Results from clinical and epidemiologic studies. Annals of the New York Academy of Sciences, 1032, 141-153.

Brady, S. S. (2006). Lifetime community violence exposure and health risk behavior among young adults in college. Journal of Adolescent Health, 39, 610-613.

Breslau, N., Kessler, R. C., Chilcoat, H. D., Schultz, L. R., Davis, G. C., \& Andreski, P. (1998). Trauma and posttraumatic stress disorder in the community: The 1996 Detroit Area Survey of Trauma. Archives of General Psychiatry, 60(3), 289-294.

Cameron, A., Palm, K., \& Follette, V. (2010). Reaction to stressful life events: What predicts symptom severity? Journal of Anxiety Disorders, 24, 645-649.

Carrion, V. G., Weems, C. F., Ray, R., \& Reiss, A. L. (2002). Toward an empirical definition of pediatric PTSD: The phenomenology of PTSD in youth. Journal of the American Academy of Child \& Adolescent Psychiatry, 41, 166-173. 
Celano, M., Hazzard, A., Webb, C., \& McCall, C. (1996). Treatment of traumagenic beliefs among sexually abused girls and their mothers: An evaluation study. Journal of Abnormal Child Psychology, 24, 1-16.

Chambless, D. L., Baker, M. J., Baucom, D. H., Beutler, L. E., Calhoun, K. S., CritsChristoph, P., ... Woody, S. R. (1998). Update on empirically validated therapies, II. The Clinical Psychologist, 51, 3-16.

Chemtob, C. M., Nakashima, J., \& Carlson, J. G. (2002). Brief treatment for elementary school children with disaster-related posttraumatic stress disorder: A field study. Journal of Clinical Psychology, 58, 99-112.

Classen, C. C., Palesh, O. G., \& Aggarwal, R. (2005). Sexual revictimization: A review of the empirical literature. Trauma, Violence, and Abuse: A Review Journal, 6, 103-129.

Codd, R. T., Twohig, M. P., Crosby, J. M., \& Enno, A. (2011). Treatment of three anxiety disorder cases with acceptance and commitment therapy in a private practice. Journal of Cognitive Psychotherapy: An International Quarterly, 25, 203-217.

Cohen, J. A., Deblinger, E. Mannarino, A. P., \& Steer, R. A. (2004). A multisite randomized controlled trial for children with sexual abuse related PTSD symptoms. Journal of the American Academy of Child and Adolescent Psychiatry, 43, 393-402.

Cohen, J. A., \& Mannarino, A. P. (1996). A treatment outcome study for sexually abused children: Initial findings. Journal of the American Academy of Child and Adolescent Psychiatry, 35, 42-50.

Cohen, J. A., \& Mannarino, A. P. (1997). A treatment study for sexually abused preschool children: Outcome during a one-year follow-up. Journal of the American Academy of Child and Adolescent Psychiatry, 36, 1228-1235.

Cohen, J. A., \& Mannarino, A. P. (1998). Interventions for sexually abused children: Initial treatment outcome findings. Child Maltreatment, 3, 17-26.

Cohen, J. A., Mannarino, A. P., \& Deblinger, E. (2006). Treating Trauma and Traumatic Grief in Children and Adolescents. New York, NY: Guilford Press.

Cohen, J. A., Mannarino, A. P., \& Knudsen, K. (2005). Treating sexually abused children: 1-year follow-up of a randomized controlled trial. Child Abuse and Neglect, 29, 135-145. 
Cooper, J. O., Heron, T. E., \& Heward, W. L. (2007). Applied behavior analysis (2nd ed.). Upper Saddle River, NJ: Merrill/Prentice Hall.

Copeland, W. E., Keeler, G., Angold, A., \& Costello, E. J. (2007). Traumatic events and posttraumatic stress in childhood. Archives of General Psychiatry, 64(5), 577-584.

Costello, E. J., Erkanali, A., Fairbank, J. A., \& Angold, A. (2002). The prevalence of potentially traumatic events in childhood and adolescence. Journal of Traumatic Stress, 15(2), 99-112.

Cougle, J. R., Resnick, H., \& Kilpatrick, D. G. (2009). Does prior exposure to interpersonal violence increase risk of PTSD following subsequent exposure? Behaviour Research and Therapy, 47(12), 1012-1017.

Cox, B. J., Clara, I. P., \& Enns, M. W. (2002). Posttraumatic stress disorder and the structure of common mental disorders. Depression and Anxiety, 15, 168-171.

Coyne, L. W., McHugh, L., \& Martinez, E. R. (2011) Acceptance and commitment therapy (ACT): Advances and applications with children, adolescents, and families. Child and Adolescent Psychiatric Clinics of North America, 20, 379-399.

Cummins, R. A. (1997). Manual for the Comprehensive Quality of Life Scale-Student (Grades 7-12): $5^{\text {th }}$ ed. (ComQol-15). Melbourne, Australia: Melbourne School of Psychology, Deakin University.

Deblinger, E., Lippmann, J., \& Steer, R. (1996). Sexually abused children suffering posttraumatic stress symptoms: Initial treatment outcome findings. Child Maltreatment, 1, 310-321.

Dempsey, M. (2002). Negative coping as mediator in the relation between violence and outcomes: Inner-city African-American youth. American Journal of Orthopsychiatry, 72, 102-109.

Derogatis, L. R. (1993). Brief Symptom Inventory: Administration, scoring, and procedures manual. Minneapolis, MN: National Computer Systems.

Doerfler, L. A., Felner, R. D., Rawlinson, R. T., Raley, P. A., \& Evans, E. (1988). Depression in children and adolescents: A comparative analysis of the utility and construct validity of two assessment measures. Journal of Consulting and Clinical Psychology, 56, 769-772.

Dohrenwend, B. P., Turner, J. B., Turse, N. A., Adams, B. G., Koenen, K. C., \& Marshall, R. (2006). The psychological risks of Vietnam for U.S. veterans: A revisit with new data and methods. Science, 313, 979-982. 
Fairbanks, J. A., Ebert, L., \& Caddell, J. M. (2001). Posttraumatic stress disorder. In P. B. Sutker \& H. E. Adams (Eds.), Comprehensive handbook of psychopathology $\left(3^{\text {rd }}\right.$ ed., pp. 183-209). New York, NY: Kluwer.

Fergusson, D. M., Lynskey, M. T., \& Horwood, L. J. (1996). Childhood sexual abuse and psychiatric disorder in young adulthood: I. Prevalence of sexual abuse and factors associated with sexual abuse. Journal of the American Academy of Child and Adolescent Psychiatry, 34, 1355-1364.

Finch, A. J., Saylor, C. F., Edwards G. L., \& McIntosh, J. A. (1987). Children's depression inventory: Reliability over repeated administrations. Journal of Clinical Child Psychology, 16, 339-341.

Flannery, D. J., Wester, K. L., \& Singer, M. I. (2004). Impact of exposure to violence in school on child and adolescent mental health and behavior. Journal of Community Psychology, 32, 559-573.

Flood, A. M., McDevitt-Murphy, M. E., Weathers, F. W., Eakin, D. E., \& Benson, T. A. (2009). Substance use behaviors as a mediator between posttraumatic stress disorder and physical health in trauma-exposed college students. Journal of Behavioral Medicine, 32, 234-243.

Foa, E., Johnson, K., Feeny, N., \& Treadwell, K. R. (2001). The child PTSD symptom scale: A preliminary examination of its psychometric properties. Journal of Clinical Child Psychology, 30(3), 376-384.

Foa, E. B., Keane, T. M., Friedman, M. J., \& Cohen, J. A. (2009). Effective treatments for PTSD: Practice guidelines from the International Society of Traumatic Stress Studies $\left(2^{\text {nd }}\right.$ ed.). New York, NY: Guilford Press.

Frewen, P. A., Lanius, R. A., Dozois, D. J. A., Neufeld, R. W. J., Pain, C., Hooper, J. W., ... Stevens, T. K. (2008). Clinical and neural correlates of alexithymia in posttraumatic stress disorder. Journal of Abnormal Psychology, 117, 171-181.

Fukunishi, I., Tsuruta, T., Hirabayashi, N., \& Asukai, N. (2001). Association of alexithymic characteristics and posttraumatic stress responses following medical treatment for children with refractory hematological diseases. Psychological Reports, 89, 527-534.

Gabbay, V., Oatis, M. D., Silva, R. R., \& Hirsch, G. (2004). Epidemiological aspects of PTSD in children and adolescents. In R. R. Silva (Ed.), Posttraumatic stress disorder in children and adolescents: Handbook (pp. 1-17). New York, NY: Norton. 
Galovski, T., \& Lyons, J. A. (2004). Psychological sequelae of combat violence: A review of the impact of PTSD on the veteran's family and possible interventions. Aggression and Violent Behavior, 9(5), 477-501.

Galea, S., Ahern, J., Resnick, H. S., Kilpatrick, D. G., Bucuvalas, M. J., Gold, J., \& Vlahov, D. (2002). Psychological sequelae of the September 11 terrosit attacks in New York City. New England Journal of Medicine, 346, 982-987.

García-Montes, J. M., \& Pérez-Álvarez, M. (2001). ACT como tratamiento de síntomas psicóticos. El caso de las alucinaciones auditivas [ACT as a treatment for psychotic symptoms: The case of auditory hallucinations]. Análisis $y$ Modificación de Conducta, 27, 455-472.

Giaconia, R., Reinherz, H., Silverman, A., Bilge, P., Frost, A., \& Cohen, E. (1995). Traumas and posttraumatic stress disorder in a community population of older adolescents. Journal of the American Academy of Child and Adolescent Psychiatry, 34, 1369-1380.

Giboa-Schechtman, E., Foa, E. B., Shafran, N., Aderka, I. M., Powers, M. B., Rachamim, L., ... Apter, A. (2010). Prolonged exposure versus dynamic therapy for adolescent PTSD: A pilot randomized controlled trial. Journal of the American Academy of Child \& Adolescent Psychiatry, 49, 1034-1042.

Gorman-Smith, D., \& Tolan, P. H. (1998). The role of exposure to violence and developmental problems among inter-city youth. Development and Psychopathology, 10, 101-116.

Gray, M. J., Litz, B. T., Hsu, J. L., \& Lombardo, T. W. (2004). The psychometric properties of the Life Events Checklist. Assessment, 11, 330-341.

Greco, L. A. (2002, November). Creating a context of acceptance in child clinical and pediatric settings. In G. H. Eifert (Chair), Balancing acceptance and change in the treatment of anxiety disorders. Symposium presented at the Association for the Advancement of Behavior Therapy, Reno, NV.

Greco, L. A., Blackledge, J. T., Coyne, L. W., \& Ehrnreich, J. (2005). Integrating acceptance and mindfulness into treatments for child and adolescent anxiety disorders: Acceptance and commitment therapy as an example. In S. M. Orsillo \& L. Romer (Eds.), Acceptance and mindfulness approaches to anxiety: Conceptualization and treatment (pp. 301-322). New York, NY: Springer Science \& Business Media.

Greco, L. A., \& Hayes, S. C. (Eds). (2008). Acceptance and mindfulness treatments for children and adolescents: A practitioner's guide. Oakland, CA: New Harbinger and Context Press. 
Greco, L. A., Lambert, W., \& Baer, R. A. (2008). Psychological inflexibility in childhood and adolescence: Development and evaluation of the avoidance and fusion questionnaire for youth. Psychological Assessment, 20, 93-102.

Greco, L. A., Murrell, A. R., \& Coyne, L. W. (2005). Avoidance and fusion questionnaire for youth. Available from the first author at Department of Psychology, University of Missouri, St. Louis, and online at www.contextualpsychology.org.

Greenberg, P. E., Sisitsky, T., Kessler, R. C., Finkelstein, S. N., Berndt, E. R., Davidson, J. R., ... Fyer, A. J. (1999). The economic burden of anxiety disorders in the 1990s. Journal of Clinical Psychiatry, 60(7), 427-435.

Harrington, T. L. (2009). The Clinician Administered PTSD Scale for Children and Adolescents: A validation study. Dissertation Abstracts International: Section B. Sciences and Engineering, 69(8-B), 5028.

Hamblen, J. L., Schnurr, P. P., Rosenberg, A., \& Eftekhari, A. (2009). A guide to the literature on psychotherapy for PTSD. Psychiatric Annals, 39, 348-354.

Hayes, S. C. (2004). Acceptance and commitment therapy, relational frame theory, and the third wave of behavior therapy. Behavior Therapy, 35, 639-665.

Hayes, L., Boyd, C. P., \& Sewell, J. (2011). Acceptance and commitment therapy for the treatment of adolescent depression: A pilot study in a psychiatric outpatient setting. Mindfulness, 2, 86-94.

Hayes, S. C., Luoma, J. B., Bond, F. W., Masuda, A., \& Lillis, J. (2006). Acceptance and commitment therapy: Model, processes, and outcomes. Behaviour Research and Therapy, 44, 1-25.

Hayes, S. C., Strosahl, K. D., \& Wilson, K. G. (1999). Acceptance and commitment therapy: An experiential approach to behavior change. New York, NY: Guilford Press.

Hayes, S. C., Strosahl, K., Wilson, K. G., Bissett, R. T., Pistorello, J., Toarmino, D., ... McCurry, S. M. (2004). Measuring experiential avoidance: A preliminary test of a working model. The Psychological Record, 54, 553-578.

Heffner, M., Sperry, J., \& Eifert, G. H. (2002). Acceptance and commitment therapy in the treatment of an adolescent female with anorexia nervosa: A case example. Cognitive and Behavioral Practice, 9, 232-236.

Humphrey, J. A., \& White, J.W. (2000).Women's vulnerability to sexual assault from adolescence to young adulthood. Journal of Adolescent Health, 27, 419-424. 
Kang, H. K., Bullman, T. A., \& Taylor, J. W. (2006). Risk of selected cardiovascular diseases and posttraumatic stress disorder among former World War II prisoners of war. Annals of Epidemiology, 16(5), 381-386.

Kataoka, S. H., Stein, B. D., Jaycox, L. H., Wong, M., Escudero, P., Tu, W., ... Fink, A. (2003). A school-based mental health program for traumatized Latino immigrant children. Journal of the American Academy of Child and Adolescent Psychiatry, 42, 311-318

Kazdin, A. (1992). Research design in clinical psychology (2nd ed.). Boston, MA: Allyn and Bacon.

Kelley, M. L., Heffer, R. W., Gresham, F. M., \& Elliot, S. N. (1989). Development of a modified treatment evaluation inventory. Journal of Psychopathology and Behavioral Assessment, 11, 235-247.

Kessler, R. C., Berglund, P., Demler, O., Jin, R., \& Walters, E. E. (2005). Lifetime prevalence and age-of-onset distributions of DSM-IV disorders in the National Comorbidity Survey Replication. Archives of General Psychiatry, 62(6), 593-602.

Kessler, R. C., Sonnega, A., Bromet, E., Hughes, M., \& Nelson, C. B. (1995). Posttraumatic stress disorder in the National Comorbidity Survey. Archives of General Psychiatry, 52, 1048-1060.

King, N. J., Tonge, B. J., Mullen, P., Myerson, N., Heyne, D., Rollings, S., ... Ollendick, T. H. (2000). Treating sexually abused children with posttraumatic stress symptoms: A randomized clinical trial. Journal of the American Academy of Child and Adolescent Psychiatry, 39, 1347-1355.

Kilpatrick, D. G., Ruggiero, K. J., Acierno, R., Saunders, B. E., Resnick, H. S., \& Best, C. L. (2003). Violence and risk of PTSD, major depression, substance abuse/dependence, and comorbidity: Results from the National Survey of Adolescents. Journal of Consulting and Clinical Psychology, 71(4), 692-700.

Kilpatrick, D. G., Resnick, H. S., Freedy, J. R., Pelcovitz, D., Resick, P. A., Roth, S., \& van der Kolk, B. (1998). Posttraumatic stress disorder field trial: Evaluation of the PTSD construct: Criteria A through E. In T. A. Widiger, A. J. Frances, H. A. Pincus, R. Ross, M. B. First, R. Ross, \& W. Davis. (Eds.), DSM-IV sourcebook (Vol. 4, pp. 803-844). Washington, DC: American Psychiatric Press.

Kilpatrick, D. G., \& Saunders, B. E. (1999). Prevalence and consequences of child victimization: Results from the national survey of adolescents. Charleston, SC: Medical University of South Carolina, National Crime Victims Center. 
Kovacs, M. (1985). The Children's Depression Inventory. Psychopharmacology Bulletin, 21, 995-998.

Leichsenring, F., Hiller, W., Weissberg, M., \& Leibing, E. (2006). Cognitive-behavioral therapy and psychodynamic psychotherapy: Techniques, efficacy, and indications. American Journal of Psychotherapy, 60, 233-259.

Levin, M., \& Hayes, S. C. (2009). Is acceptance and commitment therapy superior to established treatment comparisons? Psychotherapy and Psychosomatics, 78, 380.

Mayou, R. A., Ehlers, A., \& Bryant, B. (2002). Posttraumatic stress disorder after motor vehicle accidents: 3-Year follow-up of a prospective longitudinal study. Behavior Research and Therapy, 40, 665-675.

McGloin, J. M., \& Widom, C. S. (2001). Resilience among abused and neglected children grown up. Development and Psychopathology, 13, 1021-1038.

Murrell, A. R., Coyne, L. W., \& Wilson, K. G. (2005). ACT with children, adolescents, and their parents. In S. C. Hayes \& K. D. Strosahl (Eds.). A practical guide to acceptance and commitment therapy (pp. 249-273). New York, NY: Springer Science \& Business Media.

Murrell, A. R., \& Scherbarth, A. J. (2006). State of the research and literature address: ACT with children, adolescents, and parents. International Journal of Behavioral Consultation and Therapy, 2, 531-543.

Nader, K., Pynoos, R., Fairbanks, L., \& Fredrick, C. (1990). Childhood PTSD reactions one year after sniper attack at their school. American Journal of Psychiatry, 147, 1526-1530.

Newman, E., Weathers, F. W., Nader, K. O., Kaloupek, D. G., Pynoos, R., Blake, D. D., \& Kriegler, J. A. (2004). Clinician-Administered PTSD Scale for Children and Adolescents for DSM-IV Manual. Los Angeles, CA: Western Psychological Services.

Orsillo, S. M., \& Batten, S. V. (2005). Acceptance and commitment therapy in the treatment of posttraumatic stress disorder. Behavior Modification, 29(1), 95-129.

Osofsky, J., Wewers, S., Hann, D., \& Fick, A. (1993). Chronic community violence: What is happening to our children? Psychiatry: Interpersonal \& Biological Processes, 56, 35-45.

Powers, M. B., Zum Vorde Sive Vording, M. B., \& Emmelkamp, M. P. (2009). Acceptance and commitment therapy: A meta-analytic review. Psychotherapy and Psychosomatics, 78, 73-80. 
Ramchandani, P., \& Jones, D. P. H. (2003). Treating psychological symptoms in sexually abused children. British Journal of Psychiatry, 183, 484-490.

Roy-Byrne, P. P., Noonan, C., Afari, N., Buchwald, D., \& Goldberg, J. (2006). Is the association between posttraumatic stress disorder symptoms and poor health due to a common familial or genetic factor? General Hospital Psychiatry, 28(5), 408413.

Roy-Byrne, P. P., Smith, W., Goldberg, J., Afari, N., \& Buchwald, D. (2004). Posttraumatic stress disorder among patients with chronic pain and chronic fatigue. Psychological Medicine, 34(2), 363-368.

Ruiz, F. J. (2010). A review of Acceptance and Commitment Therapy (ACT) empirical evidence: Correlational, experimental, psychopathology, component, and outcome studies. International Journal of Psychology and Psychological Therapy, 10, 125162.

Sack, W. H., Seeley, J. R., \& Gregory, M. (1997). Does PTSD transcend cultural barriers? A study from the Khmer adolescent refugee project. Journal of American Academy of Child and Adolescent Psychiatry, 36, 49-55.

Sareen, J., Cox, B. J., Stein, M. B., Afifi, T. O., Fleet, C., \& Asmundson, G. J. (2007). Physical and mental comorbidity, disability, and suicidal behavior associated with posttraumatic stress disorder in a large community sample. Psychosomatic Medicine, 69(3), 242-248.

Saul, A. L., Grant, K. E., \& Carter, J. S. (2008). Post-traumatic reactions in adolescents: How well do the DSM-IV PTSD criteria fit the real life experience of trauma exposed youth? Journal of Abnormal Child Psychology, 36, 915-925.

Scarpa, A., Fikretoglu, D., Bowser, F., Hurley, J. D., Pappert, C. A., Romero, N., \& Van Voorhees, E. (2002). Community violence exposure in university students: A replication and extension. Journal of Interpersonal Violence, 17, 253-272.

Scarpa, A., Haden, S. C., \& Hurley, J. (2006). Community violence victimization and symptoms of posttraumatic stress disorder. Journal of Interpersonal Violence, 21, 446-469.

Scheeringa, M. S., Zeanah, C. H., \& Cohen, J. A. (2010). PTSD in children and adolescents: Toward an empirically based algorithm. Depression and Anxiety, 28, 770-782.

Schwab-Stone, M., Chen, C., Greenberger, E., Silver, D., Lichtman, J., \& Voyce, C. (1999). No safe haven: The effects of violence exposure on urban youth. Journal of the American Academy of Child and Adolescent Psychiatry, 38, 359-367. 
Schwartz, D., \& Gorman, A. H. (2003). Community violence exposure and children's academic functioning. Journal of Educational Psychology, 95, 163-173.

Shalev, A. Y., Freedman, S. A., Peri, T., Brandes, D., Sahar, T., Orr, S. P., \& Pitman, R. K. (1998). Prospective study of posttraumatic stress disorder and depression following trauma. American Journal of Psychiatry, 155, 630-637.

Shipherd, J. C., \& Beck, J. G. (2005). The role of thought suppression in posttraumatic stress disorder. Behavior Therapy, 36, 277-287.

Silverman, W. K., Ortiz, C. D., Chockalingham, V., Burns, B. J., Kolko, D. J., Putnam, F. W., \& Amaya-Jackson, L. (2008). Evidence-based psychosocial treatments for children and adolescents exposed to traumatic events. Journal of Clinical Child \& Adolescent Psychology, 37, 156-183.

Singer, M. I., Anglin, T. M., Song, L. Y., \& Lunghofer, L. (1995). Adolescents exposure to violence and associated symptoms of psychological trauma. Journal of the American Medical Association, 273, 477-482.

Sledjeski, E. M., Speisman, B., \& Dierker, L. C. (2008). Does number of lifetime traumas explain the relationship between PTSD and chronic medical conditions? Answers from the National Comorbidity Survey-Replication (NCS-R). Journal of Behavioral Medicine, 31, 341-349.

Smith, M. W., Schnurr, P. P., \& Rosenheck, R. A. (2005). Employment outcomes and PTSD symptom severity. Mental Health Services Research, 7(2), 89-101.

Stallard, P. (2006). Psychological intervention for post-traumativ reactions in children and young people: A review of randomized controlled trials. Clinical Psychology Review, 26, 895-911.

Stein, B. D., Jaycox, L. H., Kataoka, S. H., Wong, M., Tu, W., Elliott, M. N., \& Fink, A. (2003). A mental health intervention for schoolchildren exposed to violence: A randomized controlled trial. Journal of the American Medical Association, 290, 603-611.

Thompson, B. L., \& Waltz, J. (2010). Mindfulness and experiential avoidance as predictors of posttraumatic stress disorder avoidance symptom severity. Journal of Anxiety Disorders, 24, 409-415.

Trowell, J., Klovin, I., Weeramanthri, T., Sadowski, H., Berelowitz, M., Glaser, D., \& Leitch, I. (2002). Psychotherapy for sexually abused girls: Psychopathological outcome findings and patterns of change. British Journal of Psychiatry, 180, 234247. 
Tull, M. T., Gratz, K. L., Salters, K., \& Roemer, L. (2004). The role of experiential avoidance in posttraumatic stress symptoms and symptoms of depression, anxiety, and somatization. Journal of Nervous and Mental Disease, 192, 754-761.

Twohig, M. P. (2009). Acceptance and commitment therapy for treatment-resistant posttraumatic stress disorder: A case study. Cognitive and Behavioral Practice, $16,243-252$.

Twohig, M. P., \& Crosby, J. M. (2010). Acceptance and commitment therapy as a treatment for problematic internet pornography viewing. Behavior Therapy, 41, 285-295.

Twohig, M. P., Field, C., Armstrong, A., \& Dahl, A. (2010). Acceptance and mindfulness as mechanisms of change in mindfulness-based interventions for children and adolescents.(pp. 225-250). In R. Baer (Ed.), Assessing mindfulness and acceptance: Illuminating the process of change. Oakland, CA: New Harbinger.

Twohig, M. P., Hayes, S. C., \& Berens, N. M. (2007). A contemporary behavioral analysis of childhood behavior problems. In D. W. Woods \& J. Kantor (Eds.), $A$ modern behavioral analysis of clinical problems (pp. 417-444). Reno, NV: Context Press.

Twohig, M. P., Hayes, S. C., \& Berlin, K. S. (2008). A behavioral approach to cognitions: Acceptance and commitment therapy for childhood externalizing disorders. In L.A. Greco \& S. C. Hayes (Eds.), Acceptance and Mindfulness Interventions for Children, Adolescents, and Families. Oakland, CA: New Harbinger.

Twohig, M. P., Hayes, S. C., \& Masuda, A. (2006a). Increasing willingness to experience obsessions: Acceptance and Commitment Therapy as a treatment for obsessive compulsive disorder. Behavior Therapy, 37, 3-13.

Twohig, M. P., Hayes, S. C., \& Masuda, A. (2006b). A preliminary investigation of acceptance and commitment therapy as a treatment for chronic skin picking. Behavior Research and Therapy, 44, 1513-1522.

Twohig, M. P., Hayes, S. C., Plumb, J. C., Pruitt, L. D., Collins, A. B., Hazlett-Stevens, H., \& Woidneck, M. R. (2010). A randomized clinical trial of acceptance and commitment therapy versus progressive relaxation training for obsessivecompulsive disorder. Journal of Consulting and Clinical Psychology, 78, 705-716.

United States Department of Health and Human Services. (2001). Report of the Surgeon General's conference on children's mental health: A national action agenda. Washington, DC: U.S. Department of Health and Human Services. 
Vandervord Nixon, R. D., Sterk, J., \& Pearce, A. (2012). A randomized trial of cognitive behaviour therapy and cognitive therapy for children with posttraumatic stress disorder following single-incident trauma. Journal of Abnormal Child Psychology, 40, 327-337.

Walser, R. D., \& Hayes, S. C. (2006). Acceptance and commitment therapy in the treatment of posttraumatic stress disorder: Theoretical and applied issues. In V. M. Follette \& J. I. Ruzek (Eds.), Cognitive-behavioral therapies for trauma $\left(2^{\text {nd }} \mathrm{ed}\right.$; pp. 146-172). New York, NY: Guilford Press.

Walser, R. D., \& Westrup, D. (2007). Acceptance and commitment therapy for the treatment of post-traumatic stress disorder and trauma related problems: $A$ practitioner's guide to using mindfulness and acceptance strategies. Oakland, CA: New Harbinger Publications.

Wicksell, R. K., Melin, L., Lekander, M., \& Olsson, G. L. (2009). Evaluating the effectiveness of exposure and acceptance to improve functioning and quality of life in longstanding pediatric pain: A randomized controlled trial. Pain, 141, 248257.

Wilson, K. G., \& Coyne, L. W. (2003, May). Treatment of refractory school refusal using a values-centered ACT approach. Paper presented at the Applied Behavioral Analysis Conference, San Francisco, CA.

Zehnder, D., Meuli, M., \& Landolt, M. A. (2010). Effectiveness of a single-session early psychological intervention for children after road traffic accidents: A randomised controlled trial. Child and Adolescent Psychiatry and Mental Health, 4(7), 1-10. doi: $10.1186 / 1753-2000-4-7$ 


\section{APPENDICES}


Appendix A

Recruiting Materials 


\section{Newspaper Ad}

\section{Research Study}

The Psychology Department at Utah State University is seeking individuals ages 12 to 17 experiencing distress related to a past traumatic experience(s) (e.g., witness or victim of events such as abuse, assault, domestic violence, natural disasters, accidents or other events in which physical safety and/or life was in danger) to participate in a study assessing the effectiveness of a psychological treatment for problems related to these events. The study will involve 13 hours of your time over 6 to 9 months. There will be no compensation for participation, but you will receive free psychological treatment. You will need your parents' or legal guardian's permission to participate. If you are interested or have questions please contact Michelle Woidneck at (435) 797-8303 or michelle.woidneck@aggiemail.usu.edu. 
Flyer

\section{Treatment for Trauma}

The Psychology Department at Utah State University is seeking individuals between the ages of 12 and 17 who have witnessed or experienced a traumatic event. Traumatic events may include abuse, assault, domestic violence, natural disasters, accidents, or other events in which physical safety was in danger. Common reactions to these events include re-experiencing the event through nightmares or flashbacks; attempting to avoid memories, people, places, or other things that remind you of the experience; feeling numb or dethatched from others; always feeling on edge or nervous; or other experiences that cause distress and/or impairment in your life.

If you experience stress related to a traumatic event and are between the ages of 12 and 17 , you may be eligible for participation in a study assessing the effectiveness of a psychological intervention. The study will involve 13 hours of your time over 6 to 9 months. There will be no compensation for participation, but you will receive free psychological treatment. Parental or legal guardian's permission is required for participation. If you and/or your child are interested or have questions please contact Michelle Woidneck at (435) 797-8303 or michelle.woidneck@aggiemail.usu.edu. 


\section{Script for Initial Contact}

This study is assessing the effectiveness of a psychological treatment for distress related to exposure to past traumatic events. The purpose of this study is to see if this particular treatment is effective at helping people with trauma-related distress. The study will involve 13 hours of your time over 6 to 9 months. There will be no compensation for participation, but you will receive free psychological treatment.

If you agree to participate, you will be asked to come to a lab on campus for an initial introductory session where you will be informed of the study procedures, asked for your consent to participate, and complete a package of questionnaires about the nature of your problems. You will begin the treatment phase within 1 to 10 weeks after this initial session. Treatment will involve 10 therapy sessions over 10 weeks. You will be asked to return for a post assessment one week after the final session and for a follow-up session 12 weeks after the completion of treatment to complete the same packet of questionnaires.

The treatment sessions will involve meeting with a trained therapist and discussing your trauma related symptoms and concerns. The therapy will only involve talking and verbal exercises. No medication or other devices are used in this treatment. All sessions will be recorded by video to ensure that the treatment is being provided correctly. The only persons who will view the recordings are the principal investigator and the graduate research assistants monitoring the study. Complete confidentiality will be respected in this study. All data that will be collected from you will be protected and stored in a locked file cabinet at the university. No personal information will appear in any reports or publications that may result from the study. 
Appendix B

Informed Consent/Assent 


\section{PARENT PERMISSION / YOUTH ASSENT \\ Acceptance and Commitment Therapy as a Treatment for Posttraumatic Stress}

Introduction/ Purpose: Dr. Michael P. Twohig, Ph.D. and Michelle Woidneck, M.A. in the Department of Psychology at Utah State University are running a study to find out more about the treatment of distress related to exposure to past traumatic events. The goal of this study is to look at a specific type of therapy for trauma-related problems. The therapy sessions will involve talking about symptoms and problems and doing exercises aimed at helping your child gain greater control over this problem. There will be no medication or other devices used in this treatment.

We are asking your permission to allow your child to take part in this study your child has shown an interest in receiving treatment for posttraumatic stress. There will be up to 12 participants enrolled in this study.

Procedures: If you agree to participate, the following will happen:

1) Your child will attend a pretreatment interview and be asked to complete a packet of paper/pencil surveys to help us understand the problem and to track how well the treatment works.

2) Your child will begin treatment within 1 to 10 weeks. Your child will be asked to track a number of trauma-related symptoms and behaviors using a daily tracking system throughout the pretreatment and treatment phase of this study.

3) When treatment begins, your child will be asked to attend 10 weekly sessions ( 1 hour each) of therapy that targets these issues. Therapy will be about the way that your child responds to trauma symptoms and will use some exercises aimed at helping your child respond differently to these symptoms. Your child will be asked to complete a short survey during each therapy session to help pay attention to how well he/she is doing in treatment. Your child will also complete a daily self-monitoring form to track changes throughout his/her participation in this study.

4) All of the treatment sessions will be video recorded to allow us to make sure that the treatment is being done well. These videotapes will be stored in locked filing cabinet which only the investigators will have access to. Only the investigator and graduate research assistant will ever view these tapes.

5) Your child will be asked to complete the same assessments that he/she completed during the initial assessment session at a post assessment 1 week after the last treatment session.

6) Your child will be asked to return and complete these assessments again, 3 months after he/she has completed the treatment.

New Findings: You and your child will be told of any important new findings (either good or bad), such as changes in the risks or benefits of being part of this study, or if 
there are different options to participating in this study that might cause you or your child to change your mind about continuing in the study. If we learn new things about the study that are useful to you or your child, or if the study changes at any time, you both will be informed and we will ask you both to complete a new consent form that will include the new information.

Risks: Every effort will be made to keep physical, medical, psychological, social, legal, or other risks as low as possible. Your child could possibly feel mild discomfort from answering some of the questions or discussing the problem. Your child is welcome to stop being part of the study at any time or to not do any part of the study that he/she chooses not to. You are also welcome to withdrawal your consent to allow your child participate in this study at any time or can choose to not allow your child to complete any part of the study you do not want him/her to complete. There are no penalties for stopping or choosing to not do any part of the study. There is a possibility that data could be lost or revealed to others; however, every effort has been made to protect you and your child's privacy and maintain you and your child's confidentiality.

Benefits: It is possible that this treatment may help reduce trauma-related symptoms and decrease your child's distress, and the findings from this study may help us treat other people with similar problems who are not part of this study.

Explanation \& offer to answer questions: The research assistant has explained this research study to you and your child and answered any questions. If you have other questions or research-related problems, you may reach Dr. Michael Twohig at (435) 7971402 or Michelle Woidenck at (435) 797-8303.

Extra $\operatorname{Cost}(\mathbf{s}):$ There are no extra costs to participating in this study.

Voluntary nature of participation and right to withdraw without consequence: Participation in research is completely up to you and your child. You or your child may stop at any time you want, or you or your child may skip any part of the study that you don't want to do. Stopping early or not completing part of the study will not affect your child's ability to participate in the study. Alternate procedures to treat trauma-related concerns are available and include other forms of psychosocial therapies and/or medication. If you are interested in alternate procedures, Dr. Twohig or Michelle Woidneck can provide you with referral information for nearby resources.

Confidentiality: Research records will be kept confidential, consistent with federal and state regulations. Only the investigator and the graduate research assistant will have access to the data. Any information that could be used to identify your child will be kept separate from his/her survey material. To protect your child's privacy his/her name will be replaced with a code number and stored in a locked file cabinet in a locked room of Dr. Twohig. To maintain your child's confidentiality, all data will also be kept in a locked room in a locked file cabinet. Any personal identifiable information will be kept for three years after the study is completed and then destroyed, including the video recordings. 
There are a few limits of confidentiality. If at any time the therapist becomes aware that you or your child are at risk of harming yourself or someone else, or becomes aware of current child abuse, abuse to the elderly, or if you report physical or sexual abuse that has not been previously reported to authorities, the therapist has a legal and ethical obligation to report this information to appropriate authorities and must also report this to the child's legal guardian.

IRB Approval Statement: The Institutional Review Board for the protection of human participants at USU has approved this research study. If you have any pertinent questions or concerns about your rights or a research-related injury, you may contact the IRB Administrator at (435) 797-0567 or email irb@usu.edu If you have a concern or complaint about the research and you would like to contact someone other than the research team, you may contact the IRB Administrator to obtain information or to offer input.

Copy of consent: You have been given two copies of this Informed Consent. Please sign both copies and keep one copy for your files.

Investigator Statement: "I certify that the research study has been explained to the individual, by me or my research staff, and that the individual understands the nature and purpose, the possible risks and benefits associated with taking part in this research study. Any questions that have been raised have been answered."

Michael P. Twohig, Ph.D.

Principal Investigator

(435) 797-1402
Michelle R. Woidneck

Student Researcher

(435) 797-8303

Signature of Parent / Guardian: My signature below indicates that I am willing to have my son/daughter participate in this study. I have read this form and I understand the purpose of this project. I also understand the potential risks and benefits involved, what to do and whom to contact if I have any concerns. If I have other questions, I understand that I may contact the researchers at the phone numbers listed above.

Printed name of Parent/Guardian

Parent/Guardian's signature
Printed Name of Child

Date

Participant Assent: I understand that my parent(s) know about my participation in this treatment study and that they have given permission for me to participate. I understand that it is my decision if I want to be in this study. If I do not want to be in this study or if I 
change my mind later and want to stop, no one will be upset. I can ask any questions anytime about this study. By signing below, I agree to participate. 
Appendix C

Measures 


\section{Background Information}

1. What is your sex?

$1=$ female

$2=$ male

2. What is your date of birth?

What is your age?

3. What is the highest grade of school you have completed?

4. What is your ethnicity/race?

1=African American

2=Asian American

$3=$ Caucasian

4=Latino/Hispanic

$5=$ Native American

$6=$ Other

5. At what age(s) did the traumatic event(s) occur?

6. How long have trauma-related symptoms been a problem for you?

7. Have you ever sought treatment or tried other procedures? If yes, what did you try?

8. Have you ever been diagnosed with any psychological disorders? If yes, please list.

9. Are you on any psychotropic medications or have you been on any in the last 6 months? If yes please list and tell me when you started your most recent dosage. 


\section{Daily Tracking Form}

\section{Avoidance}

Rate how often you deliberately avoided things associated with your past traumatic experience(s) of avoided doing things that may remind you of your past trauma(s).

None 0 1

\section{Reexperiencing}

Rate how frequently you experienced recurring, unwanted, and/or upsetting thoughts or memories of your past traumatic experience(s). This includes upsetting dreams/nightmares related to the events and/or feeling as if you were reliving the event.

None

$\begin{array}{lllllllllll}0 & 1 & 2 & 3 & 4 & 5 & 6 & 7 & 8 & 9 & 10\end{array}$

\section{Arousal}

Rate how frequently you experienced any of the following today: feeling on edge or as if you were expecting danger; had difficulty falling or staying asleep; had anger outbursts or were irritable; being very jumpy; had difficulty concentraining.

None

$\begin{array}{lllllllllll}0 & 1 & 2 & 3 & 4 & 5 & 6 & 7 & 8 & 9 & 10\end{array}$

\section{Distress}

Think about ALL of the experiences you rated above. Rate how distressing these experiences were for you today.

None

0

1

2

34

$\begin{array}{llll} & & \text { Extremely upsetting }\end{array}$

\section{Interference}

Think about ALL of the experiences you rated above. Rate how much these experiences interfered with areas of your life. (i.e., Today did the thoughts, feelings, sensations, and avoidance get in the way of things you want in your life? How much?)

None

0

0

1

2

3

4

5

6

Extreme interference 


\section{Child PTSD Symptom Scale (CPSS)}

Below is a list of problems that kids sometimes have after experiencing a trauma. Read each one carefully and circle the number (0-3) that best describes how often that problem has bothered you IN THE PAST TWO WEEKS.

\section{Part I}
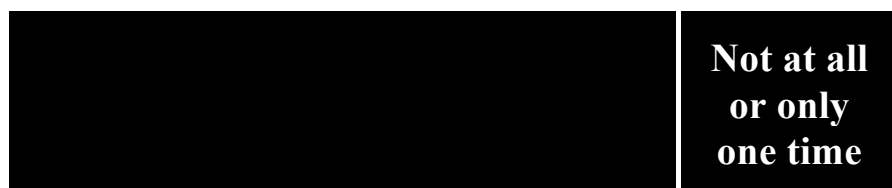

Once a
week or
less/once in
a while

\begin{tabular}{|c|}
\hline 2 to 4 \\
times a \\
week/half \\
the time
\end{tabular}

5 or more times per

1. Having upsetting thoughts or images about the trauma that came into your head when you didn't want them to

2. Having bad dreams or nightmares

3. Acting or feeling as if the trauma was happening again (hearing something or seeing a picture about it and feeling as if I am there again)

4. Feeling upset when you think about or hear about the trauma (for example, feeling scared, angry, sad, guilty, etc.)

5. Having feelings in your body when you think about or hear about the trauma (for example, breaking out in a sweat, heart beating fast)

6. Trying not to think about, talk about, or have feelings about the trauma

7. Trying to avoid activities, people, or places that remind you of the traumatic event

8. Not being able to remember an important part of the trauma

9. Having much less interest or not doing things you used to do

10. Not feeling close to people around you

11. Not being able to have strong feelings (for example, being unable to cry or unable to feel very happy)

one time

week/almost always 


\begin{tabular}{|c|c|c|c|c|}
\hline $\begin{array}{l}\text { 12. Feeling as if your future plans or } \\
\text { hopes will not come true (for } \\
\text { example, you will not have a job or } \\
\text { getting married or having kids) }\end{array}$ & 0 & 1 & 2 & 3 \\
\hline $\begin{array}{l}\text { 13. Having trouble falling or staying } \\
\text { asleep }\end{array}$ & 0 & 1 & 2 & 3 \\
\hline $\begin{array}{l}\text { 14. Feeling irritable or having fits of } \\
\text { anger }\end{array}$ & 0 & 1 & 2 & 3 \\
\hline $\begin{array}{l}\text { 15. Having trouble concentrating (for } \\
\text { example, losing track of a story on } \\
\text { television, forgetting what you } \\
\text { read, not paying attention in class) }\end{array}$ & 0 & 1 & 2 & 3 \\
\hline $\begin{array}{l}\text { 16. Being overly careful (for example, } \\
\text { checking to see who is around you } \\
\text { and what is around you) }\end{array}$ & 0 & 1 & 2 & 3 \\
\hline $\begin{array}{l}\text { 17. Being jumpy or easily startled (for } \\
\text { example, when someone walks up } \\
\text { behind you) }\end{array}$ & 0 & 1 & 2 & 3 \\
\hline
\end{tabular}

\section{Part II}

Indicate below if the problems you rated in Part I have gotten in the way with any of the following areas of your life DURING THE PAST TWO WEEKS. Circle ' $Y$ ' for yes or ' $\mathrm{N}$ ' for no.

18. $\mathrm{Y} \quad \mathrm{N}$ Doing your prayers

19. Y N Chores and duties at home

20. $\mathrm{Y}$ N Relationships with friends

21. $\mathrm{Y}$ N Fun and hobby activities

22. $\mathrm{Y}$ N Schoolwork

23. $\mathrm{Y} N$ Relationships with your family

24. $\mathrm{Y}$ N General hopes with your life 


\section{Acceptance and Fusion Questionnaire for Youth (AFQ-Y)}

We want to know more about what you think, how you feel, and what you do. Read each sentence. Then, circle a number between 0-4 that tells how true each sentence is for you.

\begin{tabular}{|c|c|c|c|c|c|c|}
\hline & & $\begin{array}{l}\text { Not at } \\
\text { all True }\end{array}$ & $\begin{array}{l}\text { A little } \\
\text { True }\end{array}$ & $\begin{array}{c}\text { Pretty } \\
\text { True }\end{array}$ & True & $\begin{array}{l}\text { Very } \\
\text { True }\end{array}$ \\
\hline & $\begin{array}{l}\text { My life won’t be good until I } \\
\text { feel happy. }\end{array}$ & 0 & 1 & 2 & 3 & 4 \\
\hline 2. & $\begin{array}{l}\text { My thoughts and feelings } \\
\text { mess up my life. }\end{array}$ & 0 & 1 & 2 & 3 & 4 \\
\hline & $\begin{array}{l}\text { If I feel sad or afraid, then } \\
\text { something must be wrong } \\
\text { with me. }\end{array}$ & 0 & 1 & 2 & 3 & 4 \\
\hline & $\begin{array}{l}\text { The bad things I think about } \\
\text { myself must be true. }\end{array}$ & 0 & 1 & 2 & 3 & 4 \\
\hline & $\begin{array}{l}\text { I don't try out new things if } \\
\text { I'm afraid of messing up. }\end{array}$ & 0 & 1 & 2 & 3 & 4 \\
\hline & $\begin{array}{l}\text { I must get rid of my worries } \\
\text { and fears so I can have a good } \\
\text { life. }\end{array}$ & 0 & 1 & 2 & 3 & 4 \\
\hline & $\begin{array}{l}\text { I do all I can to make sure I } \\
\text { don't look dumb in front of } \\
\text { other people. }\end{array}$ & 0 & 1 & 2 & 3 & 4 \\
\hline & $\begin{array}{l}\text { I try hard to erase hurtful } \\
\text { memories from my mind. }\end{array}$ & 0 & 1 & 2 & 3 & 4 \\
\hline & $\begin{array}{l}\text { I can't stand to feel pain or } \\
\text { hurt in my body. }\end{array}$ & 0 & 1 & 2 & 3 & 4 \\
\hline & $\begin{array}{l}\text { If my heart beats fast, there } \\
\text { must be something wrong } \\
\text { with me. }\end{array}$ & 0 & 1 & 2 & 3 & 4 \\
\hline & $\begin{array}{l}\text { I push away thoughts and } \\
\text { feelings that I don't like. }\end{array}$ & 0 & 1 & 2 & 3 & 4 \\
\hline & $\begin{array}{l}\text { I stop doing things that are } \\
\text { important to me whenever I } \\
\text { feel bad. }\end{array}$ & 0 & 1 & 2 & 3 & 4 \\
\hline & $\begin{array}{l}\text { I do worse in school when I } \\
\text { have thoughts that make me } \\
\text { feel sad. }\end{array}$ & 0 & 1 & 2 & 3 & 4 \\
\hline & $\begin{array}{l}\text { I say things to make me sound } \\
\text { cool. }\end{array}$ & 0 & 1 & 2 & 3 & 4 \\
\hline & $\begin{array}{l}\text { I wish I could wave a magic } \\
\text { wand to make all my sadness } \\
\text { go away. }\end{array}$ & 0 & 1 & 2 & 3 & 4 \\
\hline & I am afraid of my feelings. & 0 & 1 & 2 & 3 & 4 \\
\hline & $\begin{array}{l}\text { I can't be a good friend when } \\
\text { I feel upset. }\end{array}$ & 0 & 1 & 2 & 3 & 4 \\
\hline
\end{tabular}




\section{Comprehensive Quality of Life Scale-Student Version (ComQol)}

\section{Section 1}

This section asks for information about various aspects of your life. Please circle the response that most accurately describes your situation.

1 (a) Where do you live?
A house
Trailer
Other:
An apartment
Dormitory

Do you live with your parents or primary guardian? YES NO

Do you or your parents own the place where you live or do you/your parents pay rent? OWN RENT

(b) How many clothes and toys do you have compared with people of your age?

$\begin{array}{ccccc}\text { More than } & \text { More than } & \text { About } & \text { Less than } & \text { Less than } \\ \text { almost anyone } & \text { most people } & \text { average } & \text { most people } & \text { almost anyone }\end{array}$

(c) If either of your parents has paid work, please give the name of their job.

Father

Mother

2 (a) How many times have you seen a doctor over the past 3 months?

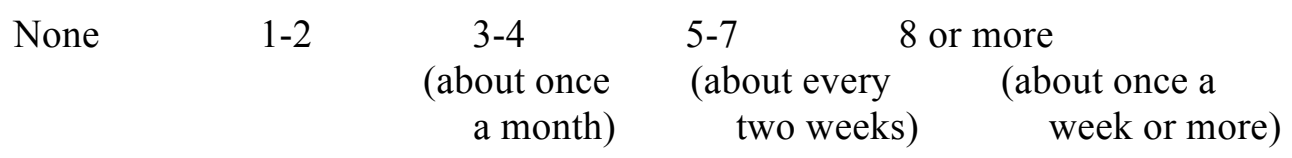

(b) Do you have any on-going medical problems? (e.g. visual, hearing, physical, health, etc).

YES NO

If yes, please specify the name and extent of the medical condition.
e.g. Visual
Diabetes
Requires glasses for reading
Epilepsy
Requires daily injections
Requires daily medication 
(c) Do you take regular medication each day? YES NO

Please list name(s) of medication if yes:

3 (a) How many hours do you spend on the following each week? (circle one)

$\begin{array}{lccccc}\text { Hours of work for pay } & 0 & 1-10 & 11-20 & 21-30 & 31-40+ \\ \text { Hours at school or college } & 0 & 1-10 & 11-20 & 21-30 & 31-40+\end{array}$

(b) In your spare time, how often do you have nothing much to do? (circle one) Almost always Usually Sometimes Not usually Almost never

(c) On average, how many hours TV do you watch each day? (circle one)

$$
\text { None } \quad 1-2 \quad 3-5 \quad 6-9 \quad 10 \text { or more }
$$

4 (a) How often do you talk with a close friend? (circle one)

$\begin{gathered}\text { Several times } \\ \text { a week }\end{gathered}$
Once a week Once a month $\begin{gathered}\text { Less than } \\ \text { once a month }\end{gathered}$

(b) If you feel sad or depressed, how often does someone show they care for you?(circle one)
Almost always
Usually Sometimes
Not usually
Almost never

(c) If you want to do something special, how often does someone else want to do it with you? (circle one)

Almost always Usually Sometimes Not usually Almost never

5 (a) How often do you sleep well? (circle one)

Almost always Usually Sometimes Not usually Almost never

(b) Are you safe at home? (circle one)

Almost always Usually Sometimes Not usually Almost never 
(c) How often are you worried or anxious during the day? (circle one)
Almost always
Usually
Sometimes
Not usually
Almost never

6 (a) Below is a list of leisure activities. Indicate how often in an average month you attend or do each activity for your enjoyment (not employment). Activity Number of times per month

Go to a club/group/society

Meet with friend(s)

Watch live sporting events (not on TV)

Go to a place of worship

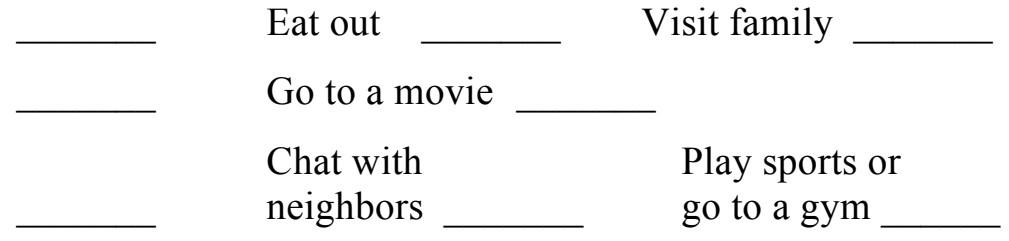

Other (describe)

(b) Do you hold an unpaid position of responsibility in relation to any team, club, group, or society? YES NO

If 'YES', please indicate the highest level of responsibility held: (circle one)

Committee Member Secretary/Treasurer/Team Vice-Captain

Committee Chairperson Captain, Group President, Chairperson

(c) How often do people outside your home ask for your help or advice? (circle one) Almost always Usually Sometimes Not usually Almost never

7 (a) How often can you do the things you really want to do? (circle one)

Almost always Usually Sometimes Not usually Almost never

(b) When you wake up in the morning, how often do you wish you could stay in bed all day?

Almost always Usually Sometimes Not usually Almost never

(c) How often do you have wishes that cannot come true?

Almost always Usually Sometimes Not usually Almost never


ComQol Section 2

How important are each of the following areas to you? There are no right or wrong answers. Please circle the response that best describes how important each area is to you. Do not spend too much time on any one question.

1. How important to you ARE THE THINGS YOU OWN?

Could not be Very important Somewhat Slightly Not important more important important important at all

2. How important to you is YOUR HEALTH?

Could not be Very important Somewhat Slightly Not important more important important important all

3. How important to you is WHAT YOU ACHIEVE IN LIFE?

Could not be Very important Somewhat Slightly Not important more important important important at all

\section{How important to you are CLOSE RELATIONSHIPS WITH YOUR FAMILY OR} FRIENDS?

Could not be Very important Somewhat Slightly Not important more important important important all

\section{How important to you is HOW SAFE YOU FEEL?}

Could not be

Very important

Somewhat

more important

important

Slightly

important

Not important

at all

\section{How important to you is DOING THINGS WITH PEOPLE OUTSIDE YOUR}

\section{HOME?}

\begin{tabular}{|c|c|c|c|}
\hline $\begin{array}{l}\text { Could not be } \\
\text { more important }\end{array}$ & Very important & $\begin{array}{l}\text { Somewhat } \\
\text { important }\end{array}$ & $\begin{array}{l}\text { Slightly } \\
\text { important }\end{array}$ \\
\hline
\end{tabular}

\section{How important to you is YOUR OWN HAPPINESS?}

Could not be

more important
Very important

Somewhat

important
Slightly

important
Not important at all 
ComQol Section 3

How satisfied are each of the following areas to you? There are no right or wrong answers. Please circle the response that best describes how satisfied you are with each area.

\section{How satisfied are you with the THINGS YOU OWN?}

Delighted Pleased Mostly Mixed Mostly Unhappy Terrible

$$
\text { satisfied dissatisfied }
$$

2. How satisfied are you with your HEALTH?

Delighted Pleased Mostly Mixed Mostly Unhappy Terrible satisfied dissatisfied

3. How satisfied are you with what you ACHIEVE IN LIFE?

\begin{tabular}{|c|c|}
\hline elighted & $\mathrm{Pl}$ \\
\hline
\end{tabular}

4. How satisfied are you with your CLOSE RELATIONSHIPS WITH YOUR FAMILY OR FRIENDS?

Delighted Pleased $\begin{gathered}\text { Mostly } \\ \text { satisfied }\end{gathered} \quad$ Mixed $\begin{gathered}\text { Mostly } \\ \text { dissatisfied }\end{gathered}$ Unhappy $\quad$ Terrible

\section{How satisfied are you with HOW SAFE YOU FEEL?}

Delighted Pleased Mostly Mixed Mostly Unhappy Terrible satisfied dissatisfied

6. How satisfied are you with DOING THINGS WITH PEOPLE OUTSIDE YOUR HOME?

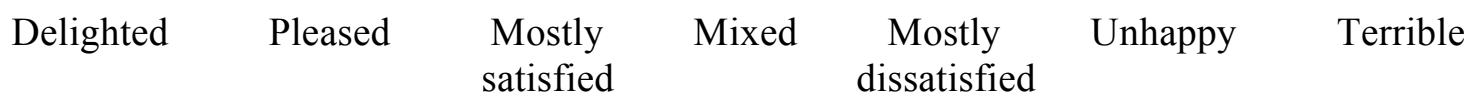

\section{How satisfied are you with YOUR OWN HAPPINESS?}

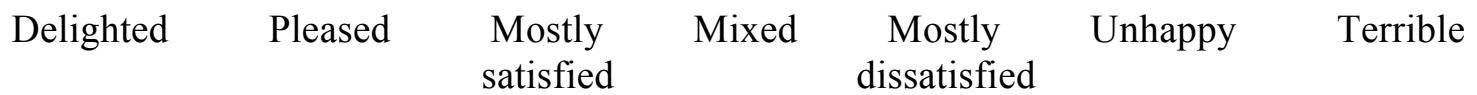




\section{The Treatment Evaluation Inventory-Short Form (TEI-SF)}

Please complete the items listed below by placing a checkmark on the line next to each question that best indicates how you feel about the treatment. Please read the items over carefully because to make sure you place the checkmark where you intend.

1. I find this treatment to be an acceptable way of dealing with my posttraumatic stress symptoms.

\begin{tabular}{|c|c|c|c|}
\hline $\begin{array}{l}\overline{\text { strongly }} \\
\text { disagree }\end{array}$ & $\overline{\text { disagree }}$ & neutral & agree \\
\hline
\end{tabular}

2. I liked the procedures used in this treatment.

\begin{tabular}{|c|c|c|c|}
\hline $\begin{array}{l}\overline{\text { strongly }} \\
\text { disagree }\end{array}$ & $\overline{\text { disagree }}$ & neutral & agree \\
\hline
\end{tabular}

3. I believe this treatment is likely to be effective.

\begin{tabular}{|c|c|c|c|}
\hline $\begin{array}{l}\overline{\text { strongly }} \\
\text { disagree }\end{array}$ & $\overline{\text { disagree }}$ & neutral & agree \\
\hline
\end{tabular}

4. I experienced discomfort as a result of the treatment.

\begin{tabular}{|c|c|c|c|}
\hline $\begin{array}{l}\overline{\text { strongly }} \\
\text { disagree }\end{array}$ & $\overline{\text { disagree }}$ & neutral & agree \\
\hline
\end{tabular}

5. I believe this treatment is likely to result in permanent improvement.

\begin{tabular}{|c|c|c|c|}
\hline $\begin{array}{l}\overline{\text { strongly }} \\
\text { disagree }\end{array}$ & $\overline{\text { disagree }}$ & neutral & agree \\
\hline
\end{tabular}

6. I believe it would be acceptable to use this treatment with individuals who cannot choose treatment for themselves.

\begin{tabular}{|c|c|c|c|}
\hline $\begin{array}{l}\overline{\text { strongly }} \\
\text { disagree }\end{array}$ & $\overline{\text { disagree }}$ & neutral & agree \\
\hline
\end{tabular}

7. Overall, I have a positive reaction to this treatment.

\begin{tabular}{|c|c|c|c|}
\hline $\begin{array}{l}\text { strongly } \\
\text { disagree }\end{array}$ & disagree & neutral & agree \\
\hline
\end{tabular}


Appendix D

Treatment Adherence 
Treatment Adherence: Definitions of ACT Processes

\begin{tabular}{|c|c|c|}
\hline Process & Definitions & Therapist Behavior (examples) \\
\hline Acceptance & $\begin{array}{l}\text { "The active and aware } \\
\text { embrace of private events } \\
\text { that are occasioned by our } \\
\text { history, without unnecessary } \\
\text { attempts to change their } \\
\text { frequency or form, } \\
\text { especially when doing so } \\
\text { would cause psychological } \\
\text { harm" (Luoma et al., 2007). } \\
\text { "Actively embracing private } \\
\text { events (thoughts, feelings, } \\
\text { bodily sensations), while } \\
\text { they are presently occurring, } \\
\text { as ongoing private } \\
\text { experiences" (Twohig \& } \\
\text { Hayes, 2008). }\end{array}$ & $\begin{array}{l}\text { Encourages sticking with difficult thoughts, feelings, } \\
\text { memories, and/or bodily sensations^ } \\
\text { - } \quad \text { Engages client in exposure exercises* } \\
\text { - Talks about doing things just to do them or doing } \\
\text { things for the experience* } \\
\text { - Encourages behaviors that are new or have not been } \\
\text { done for a long time* } \\
\text { - Reinforces client for saying "I would usually not talk } \\
\text { about this" or the like* } \\
\text { Encourages the client to engage in any of the above } \\
\text { outside the session }\end{array}$ \\
\hline $\begin{array}{l}\text { Creative } \\
\text { Hopelessness } \\
\text { (coded as } \\
\text { Acceptance) }\end{array}$ & $\begin{array}{l}\text { Undermining ineffective } \\
\text { change strategies } \\
\text { and emphasizing the negative } \\
\text { consequences of the } \\
\text { strategies. }^{\wedge}\end{array}$ & $\begin{array}{l}\text { - Asks the client for specific instances of efforts to } \\
\text { control or change thoughts or feelings^ } \\
\text { - Asks about workability of control attempts^} \\
\text { - Uses "control as the problem" techniques (e.g., } \\
\text { polygraph^, man in the hole^, chocolate cake, wedge } \\
\text { of lemon, mind reading). } \\
\text { - Reminds the client of historical control attempts^ } \\
\text { Encourages the client to engage in any of the above } \\
\text { outside the session }\end{array}$ \\
\hline Defusion & $\begin{array}{l}\text { "Seeing thoughts and } \\
\text { feelings for what they are } \\
\text { (i.e., a verbally entangeled } \\
\text { process of minding) rather } \\
\text { than what they advertise } \\
\text { themselves to be (e.g., the } \\
\text { world understood; structured } \\
\text { reality)" (Hayes et al., 1999). } \\
\text { "The process of creating } \\
\text { nonliteral contexts in which } \\
\text { language can be seen as an } \\
\text { active, ongoing, relational } \\
\text { process that is historical in } \\
\text { nature and present in the } \\
\text { current moment" (Luoma et } \\
\text { al., 2007). }\end{array}$ & 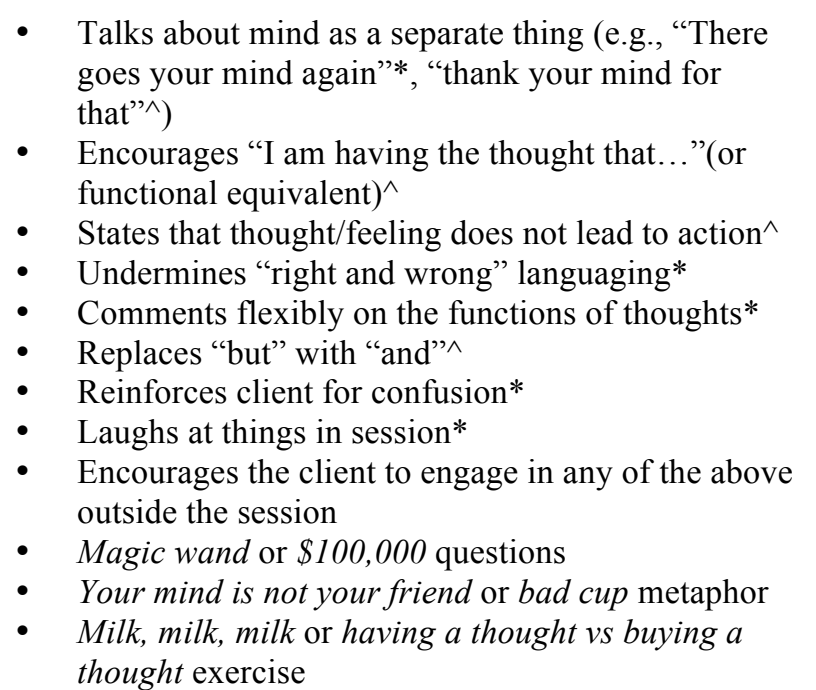 \\
\hline
\end{tabular}


Self-as- "A continuous and secure 'I' Context from which events are experienced, but that is also distinct from those events" (Luoma et al., 2007).

"Seeing that observations are being made from a consistent locus:

I/here/now - the "you" aware of the experiences, not the experiences themselves" (Twohig \& Hayes, 2008).

"The locus from which a person's experience unfolds" (Bach \& Moran, 2008).

Being "Ongoing, nonjudgmental Present contact with psychological and environmental events as they occur" (Luoma et al., 2007).

"Consciously experiencing internal and external events as they are occurring, without attachment to evaluation or judgment" (Twohig \& Hayes, 2008).

Values "Chosen actions that can never be obtained as an object, but can be instantiated moment by moment" (Luoma et al., 2007).

"Areas of importance that we recognize and embrace as guides of our patterns of action" (Twohig \& Hayes, 2008).
- Reinforces client's perspective-taking (e.g. expression of empathy for others)*

- Discusses private events as ongoing processes that do not define client*

- Says "you are the place/container/context"...

- Uses chessboard metaphor ${ }^{\wedge}$

- Uses observer exercise

- Encourages the client to engage in any of the above outside the session
- Helps client focus on bodily sensations, thoughts, and/or feelings in present ${ }^{\wedge}$

- Describes own (therapist's) sensory experience of present

- Models flexibility related to what the current environment affords*

- Notes small events that transpire, or features of the room, with appreciation.*

- Makes process comments about client (e.g., body language, affect)

- Encourages the client to engage in any of the above outside the session

- $\quad$ Engages in activities because of their intrinsic value and the vitality they bring*

- Asks for clarity about what client wants*

- Links previous pain to present purposes*

- Reminds client of stated values ${ }^{\wedge}$

- Encourages the client to engage in any of the above outside the session 
Committed "The development of larger

Action and larger patterns of effective action linked to chosen values" (Luoma et al., 2007).

"Behaving in the service of chosen values" (Bach \& Moran, 2008).
- Assigns homework linked to short-, medium-, and long-term behavior change goals.

- Asks client to generate behavioral goals ${ }^{\wedge}$

- Encourages client to follow through on behavioral goals $^{\wedge}$

- Reinforces completion of homework and keeping of commitments*

- Reinforces spontaneous engagement in new behaviors *

- Encourages behavioral generalization to new domains*

- Encourages flexibility, responsibility, and empowerment related to actions*

- Encourages the client to engage in any of the above outside the session

Bach, P., \& Moran, D. (2008). ACT in practice: Case conceptualization in Acceptance and Commitment Therapy. Oakland, CA: New Harbinger.

Crosby, J. M. (2011). ACT for treatment of compulsive pornography use adherence manual. Unpublished. Luoma, J. B., Hayes, S. C., \& Walser, R. D. (2007). Learning ACT: An Acceptance and Commitment Therapy skills-training manual for therapist. Oakland, CA: New Harbinger.

Twohig, M. P., Hayes, S. C. (2008). ACT verbatim for depression and anxiety. Oakland, CA: New Harbinger.

Twohig, M. P., \& Plumb, J. (2008). ACT for OCD adherence manual. Unpublished.

$\wedge$ adapted from ACT for OCD Adherence Manual (Twohig \& Plumb, 2008)

*adapted from ACT Verbatim (Twohig \& Hayes, 2008) 
CURRICULUM VITAE

\section{MICHELLE R. WOIDNECK, Ph.D.}

Boys Town Center for Behavioral Health

13603 Flanagan Blvd

Boys Town, NE 68010

(w) 402-498-3068 (c) 303-596-1427

michelle.woidneck@boystown.org

\section{EDUCATION}

\section{Ph.D.}

(anticipated 8/13)

accredited)
Utah State University, Logan, UT

Combined Clinical/Counseling/School Psychology (APA

Dissertation: Acceptance and Commitment Therapy for the treatment of posttraumatic stress among adolescents

Chair: Michael Twohig, Ph.D.

Ed.S.

Utah State University, Logan, UT

2011

School Psychology (NASP approved)

Thesis: Exploring the relation between office discipline referrals and reinforcement rates in school-based positive behavior support programs

Chair: Donna Gilbertson, Ph.D.

M.A.

2007

University of Northern Colorado, Greeley, CO

Special Education: Generalist Program

Endorsement

2004

University of Denver Teacher Education Program, Denver, CO

B.S. Elementary Education

2004

University of Denver, Denver, CO

Psychology; Minors: Biology, Education

Graduated with Honors; Magna Cum Laude

\section{LICENSURE}

08/12 - 08/17 State of Nebraska Provisional Mental Health Practitioner, License: 9727

11/11 - 11/14 Nationally Certified School Psychologist, License: 41485 


\section{CLINICAL EXPERIENCE}

08/12 - Present Predoctoral Psychology Intern - Nebraska Internship Consortium in Professional Psychology (APA accredited) Boys Town Behavioral Health Clinic, Omaha, NE Individual and family therapy for adolescents and children in a treatment group home setting; co-lead psychoeducational skills group for chemical use program; co-lead social skills group; consultation with on-campus family treatment homes, high school, middle school, and day school.

Supervisors: Kimberly Haugen, Ph.D., Connie Schnoes, Ph.D.

06/11 - 06/12 Graduate Assistant Therapist - Clinical Assistantship Avalon Hills Residential Eating Disorders Program, Petersboro, UT Individual therapy for adolescents and adults in a residential setting; led experiential and didactic groups including acceptance and commitment therapy (ACT), mindfulness, and recovery maintenance; led and co-led process and body image groups; collaboration with multidisciplinary treatment team. Supervisor: Tera Lensegrav-Benson, Ph.D. Total Hours: 1010, Direct Contact Hours: 425

06/11 - 05/12 Graduate Student Therapist - Clinical Psychology Practicum Anxiety Specialty Clinic, Logan, UT

Intake interviewing, individual therapy, and psychodiagnostic assessment with adolescents and adults with anxiety and anxietyrelated disorders supported by weekly supervision and didactic training. Supervisors: Michael P. Twohig, Ph.D., Melanie DomenechRodríguez, Ph.D.

Total Hours: 271, Direct Contact Hours: 79

06/09-04/12 Graduate Student Therapist

Utah State University Community Clinic, Logan, UT

Provided continued individual and family psychotherapy services for two children; provide continued individual psychotherapy for one adult client.

Supervisors: Susan Crowly, Ph.D.; Melanie Domenech-Rodreiguez, Ph.D.

Total Hours: 68.5, Direct Contact Hours: 29.5

08/10 - 06/11 School Psychologist Intern - School Psychology Internship Davis School District, Farmington, UT 
Conducted thorough school evaluations, including the administration and interpretation of psychoeducational, cognitive, adaptive, and behavioral assessments; developed and implemented individualized, small group, and classwide behavioral and academic interventions; consulted with teachers and parents; participated on interdisciplinary team meetings.

Supervisors: Donna Gilbertson, Ph.D.; Lorene Newbold, Ph.D.

Total Hours: 795, Direct Contact Hours: 349

08/09-05/10 Mental Health Specialist - Clinical Assistantship

Bear River Head Start, Logan, UT

Provided individual psychotherapy services to adults, children, and families; provided parent training; conducted functional behavioral assessments and classroom observations; provided outreach services and staff trainings to paraprofessionals working with at-risk children and their families.

Supervisor: David Stein, Ph.D.

Total Hours: 254, Direct Contact Hours: 107

08/09 - 05/10 Graduate Student Therapist - School Psychology Practicum Logan School District, Logan, UT

Participated in a variety of aspects of school psychology in a high school and elementary school setting, including the following: thorough student psychoeducational evaluations; teacher and parent consultation; development and implementation of individualized academic and behavioral interventions; individual therapy; IEP meetings; program development of social-emotional curriculum for multicultural high school students; provided outreach services to multicultural families.

Supervisors: Donna Gilbertson, Ph.D.; Travis Loosli, Ph.D.

Total Hours: 320.5, Direct Contact Hours: 120

08/08 - 05/09 Graduate Student Therapist - Counseling Psychology Practicum Utah State University Community Clinic, Logan, UT

Mental health services for children, adolescents, and adults in the community; intake assessments; individual and family psychotherapy services; parent training; comprehensive psychological and psychoeducational evaluations; report writing; treatment planning; clinical case presentations.

Supervisors: Melanie Domenech-Rodreiguez, Ph.D.; Susan Crowly, Ph.D.

Total Hours: 649, Direct Contact Hours: 116

05/08 - 08/08 Graduate Student Therapist - Practicum in Psychology 
Utah State University Community Clinic, Logan, UT

Mental health services for children, adolescents, and adults in the community; intake assessments; individual and family psychotherapy services; parent training; comprehensive psychological evaluations; report writing.

Supervisors: Susan Crowly, Ph.D.; Gretchen Gimpel-Peacock, Ph.D. Total Hours: 100.5, Direct Contact Hours: 38

01/08 - 05/08 Graduate Student Therapist - Introductory Practicum Utah State University Community Clinic, Logan, UT

Conducted intake assessments; parent management training; provided psychotherapy for children and adults in a co-therapy setting. Supervisor: Melanie Domenech-Rodreiguez, Ph.D.

Total Hours: 145, Direct Contact Hours: 22

\section{PROFESSIONAL EXPERIENCE}

05/10 - 08/10 Summer Program Special Education Teacher Mount Saint Vincent Home, Denver, CO

Taught $4^{\text {th }}-7^{\text {th }}$ grade students during a summer program at a residential treatment facility for children with emotional and behavioral difficulties; engaged in lesson planning and provided daily instruction in mathematics and literacy; implemented various behavior management techniques, behavior intervention plans, and crisis management plans; led daily progressive muscle relaxation and guided imagery interventions.

Supervisor: Lori McClurg, M.A.

\section{7/04- 08/07 Special Education Teacher}

Mount Saint Vincent Home, Denver, CO

Taught $2^{\text {nd }}-3^{\text {rd }}$ grade during 2004-2005 school year, $1^{\text {st }}-2^{\text {nd }}$ grade during 2005-2006 school year, and K-2 during 2006-2007 school year. Taught at a residential and day treatment facility for students with severe emotional and behavioral difficulties; provided daily instruction in all academic areas for children with a wide range of educational needs; assessed students' academic and behavioral functioning using traditional and alternative methods; implemented various behavior management techniques, behavior intervention plans, and crisis management plans; wrote and implemented individualized education plans. Trained in Therapeutic Crisis Intervention (TCI). Supervisor: Lori McClurg, M.A.

\section{6/03 - 08/03 Clinical Research Assistant}


SUNY Buffalo: Center for Children \& Families, Summer Treatment Program, Buffalo, NY

Implemented three levels of behavior modification as part of a research/treatment program for children ages 5-12 with AttentionDeficit/Hyperactivity Disorder, Oppositional Defiant Disorder, and/or Conduct Disorder; recorded frequencies of various behaviors, completed daily surveys on children's behavior and affect, and tracked children's progress throughout each treatment level of the 9-week program.

Supervisors: Anil Chacko, Ph.D.; William Pelham, Ph.D.

\section{RESEARCH EXPERIENCE}

$01 / 09-11 / 09$

Research Project Coordinator and Clinical Research Assistant Center for Clinical Research, Utah State University, Logan, UT Administered intake interviews, diagnostic assessments, and psychotherapy as part of a NIMH funded project assessing the effectiveness of Acceptance and Commitment Therapy versus Progressive Muscle Relaxation for Obsessive Compulsive Disorder among adults.

Supervisors: Michael Twohig, Ph.D.; Melanie Domenech-Rodriguez, Ph.D.

Total Hours: 119, Direct Contact Hours: 68

05/09 - 08/09 Research Co-Investigator

Center for Clinical Research, Utah State University, Logan, UT

Helped design and evaluate the effectiveness of an acceptance- and mindfulness-based training for elementary educators and administrators experiencing workplace discord.

Supervisor: Michael Twohig, Ph.D.

\section{1/03 - 01/04 Undergraduate Research Assistant}

University of Denver Family Stress and Coping Lab, Denver, CO Studied family stress and coping in poverty-stricken families; collected and entered data; administered adolescent/preadolescent interviews; assisted with data analysis and grant writing.

Supervisor: Martha Wadsworth, Ph.D. 


\section{INVITED CHAPTERS}

Twohig, M. P., Woidneck, M. R., \& Crosby, J. M. (in press). Newer generations of CBT for Anxiety Disorders. In. G. Simos \& S. Hoofmann (Eds.). Textbook of CBT for Anxiety Disorders. Wiley-Blackwell.

Twohig, M. P., Bluett, E. J., Morrison, K. M., \& Woidneck, M. R. (in press). Habit reversal. In S. Hofmann (Ed.). Cognitive behavioral therapy: A complete reference guide. Wiley-Blackwell.

\section{MANUSCRIPTS IN PREPARATION}

Woidneck, M. R., \& Gilbertson, D. (in preparation). Exploring the relation between office discipline referrals and reinforcement rates in schoolwide positive behavior support programs.

Pratt, K.M., Woidneck, M. R., \& Twohig, M. P. (in preparation). Progressive relaxation training and Acceptance and Commitment Therapy for the treatment of hoarding: A case study.

\section{PEER REVIEWED PUBLICATIONS}

Woidneck, M. R., Pratt, K. M., Gundy, J. M., Nelson, C., \& Twohig, M. P. (in press). Exploring cultural competence in acceptance and commitment therapy outcomes. Professional Psychology: Research and Practice.

Gundy, J. M., Woidneck, M. R., Pratt, K. M., Christian, A. W., \& Twohig, M. P. (2011). Acceptance and commitment therapy: The state of the evidence in the field of health psychology. Scientific Review of Mental Health Practice, 8, 23-35.

Twohig, M. P., Hayes, S. C., Plumb, J. C., Pruitt, L. D., Collins, A. B., Hazlett-Stevens, H., \& Woidneck, M. R. (2010). A randomized clinical trial of Acceptance and Commitment Therapy vs. Progressive Relaxation Training in the treatment of obsessive compulsive disorder. Journal of Consulting and Clinical Psychology, 78, 705-716.

\section{PROFESSIONAL PRESENTATIONS}

Woidneck, M. R., \& Twohig, M. P. (2012, November). Acceptance and commitment therapy for the treatment of posttraumatic stress among adolescents. In P. Chan \& 
C. Kerns (Chairs), Developmentally informed applications of mindfulness, $A C T$, and DBT for internalizing disorders in youth. Symposium to be conducted the Association for Behavioral and Cognitive Therapies $46^{\text {th }}$ Annual Convention, National Harbor, MD.

Woidneck, M. R., Gilbertson, D., \& Nelson, C. (2011, May). Exploring ratios of reinforcement rates to office referral rates in schoolwide programs. Poster to be presented at the $37^{\text {th }}$ Association for Behavior Analysis International Annual Convention, Denver, CO.

Woidneck, M. R., Gilbertson, D., \& Nelson, C. (2011, February). Exploring office referral and reinforcement rates in schoolwide programs. Poster to be presented at the National Associations for School Psychologists Annual Convention, San Francisco, CA.

Twohig, M. P., Hayes, S. C., Plumb, J., Pruitt, L., Collins, A., Hazlett-Stevens, H. H., \& Woidneck, M. R. (2010, November). Final results of ACT versus relaxation control in the treatment of adult OCD. Paper presented at the Association for Behavioral and Cognitive Therapies Annual Convention, San Francisco, CA.

Woidneck, M. R., Pratt, K. M., Gundy, J. M., Nelson, C., \& Twohig, M. P. (2010, June). An investigation of the potential utility of Acceptance and Commitment Therapy to treat diverse populations. Poster presented at the Association for Contextual Behavioral Science World Conference VIII, Reno, NV.

Woidneck, M. R., Twohig, M. P., Gilbertson, D., \& Crosby, J. (2010, June). Evaluation of an acceptance and mindfulness training for elementary staff, educators, and administrators. In M. R. Woidneck (Chair), ACT with students and educators: A review of successes and challenges. Symposium conducted at the Association for Contextual Behavioral Science World Conference VIII, Reno, NV.

Woidneck, M. R. \& Gilbertson, D. (2008, June). Functionally based classwide interventions. Presentation presented at the annual statewide Effective Practices in Special Education and Rehabilitation Conference, Logan, UT.

\section{TEACHING EXPERIENCE}

Summer 2011

Spring 2010

Summer 2009

\section{Course Instructor}

PSY 1010: General Psychology, Utah State University, Logan, UT Independent instructor; responsible for all aspects of introductory level undergraduate psychology courses including lecturing, providing student support, and creation of course-related materials; 
supervised graduate and undergraduate teaching assistants. Summer 2011, interactive broadcast.

Supervisor: Gretchen Gimpel-Peacock, Ph.D.

Fall 2007, 2008 Graduate Teaching Assistant

Spring 2008, 2009 PSY 1010: General Psychology, Utah State University, Logan, UT Planned, taught, and managed lab sections; held regular office hours; graded tests and written assignments; designed class webpage through Blackboard; collaborated with professor and other teaching assistants; lectured in professors' absence; provided additional support for students as necessary.

Supervisors: Kerry Jordan, Ph.D.; Scott Bates, Ph.D.; Jared Cox, M.A.

\section{INVITED WORKSHOPS AND TRAININGS}

Woidneck, M. R. (2012, May). Acceptance and Commitment Therapy in the Treatment of Eating Disorders. Presentation for Avalon Hills Residential Eating Disorders Program's biannual Family Week, Logan, UT.

Woidneck, M. R. (2010, December). ACT for supervisors: What you need to know. Presentation for Utah State University's Counseling and Psychological Services, Logan, UT.

Woidneck, M. R., \& Morrison, K. (2010, November). ACT Overview and Basic Techniques. Workshop at Utah State University's Department of Psychology monthly student meeting, Logan, UT.

Woidneck, M. R., Tafoya, M., \& Mendiola, H. (2010, March). Depression: What is it and how can I help? Presentation presented at a Logan High School meeting for Latino parents, Logan, UT.

Woidneck, M. R. (2010, February). Premenstrual Dysphoric Disorder: Symptoms and treatment. Workshop conducted at Bear River Head Start Staff Management Training, Logan, UT.

Woidneck, M. R. (2010, January). What is psychology and why should I care? Presentation presented to Logan High School's Latinos in Action class, Logan, UT.

Woidneck, M. R. (2010, January). I'm cooking for five, the baby needs a diaper change, the dog won't stop barking, I haven't sat down all day, and I think I'm going to 
lose my mind! Stress management 101. Workshop conducted at Bear River Head Start Mother's Group, Logan, UT.

Woidneck, M. R., Jones, M., \& Mendiola, H. (2009, December). Effective strategies for parenting your teenager. Presentation presented at a Logan High School meeting for Latino parents, Logan, UT.

Woidneck, M. R. (2009, December). Step back from stress: Learn how to cope with the holiday season. Workshop conducted at Bear River Head Start Parent Committee Meeting, Logan, UT.

Woidneck, M. R. (2009, May). Mental Health in the Schools. Systematic Screening of Behavior Disorders training for J.A. Taylor Elementary in Davis School District, Centerville, UT.

Woidneck, M. R. \& Pratt, K. (2009, March). ADHD: Navigating the Evaluation Process and Working with the School System. Workshop conducted at Bear River Head Start Staff Management Training, Logan, UT.

Woidneck, M. R. \& Pratt, K. (2007, November). Strategies for Effective Parenting. Workshop conducted at the annual USU Counseling Center REACH Program Parenting and Marriage Skills Seminar, Logan, UT.

\section{PROFESSIONAL DEVELOPMENT TRAINING}

September 2012 ADHD From A to Z: Advances in the Understanding and Management of ADHD in Children and Adolescents (6.5 CEUs)

Presenter: Russell Barkley, Ph.D.

Nebraska Psychological Association, Omaha, NE

September 2012 The Impact of Trauma and Neglect on the Developing Child (4.5 hour training)

Presenter: Bruce Perry, M.D., Ph.D.

Boys Town National Research Institute, Omaha, NE

April 2012 The How, What and Why of Happiness: The Science of Interventions Aimed at Increasing Well-Being -- $18^{\text {th }}$ Annual Conference of Utah State University Counseling \& Psychological Services (5.0 CEUs) Presenter: Sonja Lyubomirsky, Ph.D. Utah State University Counseling Center, Logan, UT

October 2010 Prolonged Exposure for the Treatment of PTSD (6.0 CEUs) Presenter: Tom Mullin, Ph.D. 
Utah Psychological Association, Salt Lake City, UT

June 2010

Association for Contextual Behavioral Science World Conference VIII, Reno, NV

ACT with Challenging Patients (3 hour training)

Presenter: Kirk Stroshal, Ph.D.

ACT for Anxious Children, Adolescents, and Families (3 hour training)

Presenters: Lisa Coyne, Ph.D. \& Elizabeth Davis, M.A.

ACT with Young People (3 hour training)

Presenter: Louise Hayes, Ph.D.

April 2010

An Integrated Approach to Complex Psychological Trauma -- $16^{\text {th }}$

Annual Conference of Utah State University Counseling \&

Psychological Services (8 hour training)

Presenter: John Briere, Ph.D.

Utah State University Counseling Center, Logan, UT

April 2009 Two Day Experiential workshop on Acceptance and Commitment Therapy (16 hour training)

Presenter: Steven C. Hayes, Ph.D.

Utah State University, Logan, UT

April $2009 \quad$ An Introduction to Acceptance and Commitment Therapy -- $15^{\text {th }}$

Annual Utah State University Counseling \& Psychological Services Conference (8 hour training)

Presenter: Steven C. Hayes, Ph.D.

Utah State University Counseling Center, Logan, UT

April $2009 \quad$ Using Motivational Interviewing and Behavior Change (2 hour training)

Presenters: Jason Burrow-Sanchez, Ph.D. \& Megan Call, M.S. Utah State University, Logan, UT

February 2009 Scaling Up Innovation in Utah Schools (8 hour training)

Utah's Academic, Behavior \& Coaching Initiative (ABC-UBI), Salt Lake City, UT

October 2008 Acceptance- and Values- Based Multicultural Training to Increase Multicultural Competency and Engagement in Faculty Members in Graduate Students (4.5 hour training) 
Presenters: Michael P. Twohig, Ph.D. \& Melanie DomenechRodriguez, Ph.D.

Utah State University, Logan, UT

September 2008 WAIS-IV Training (3.0 CEUs)

Utah Psychological Association, Salt Lake City, UT

\section{PROFESSIONAL ASSOCIATIONS}

Association for Contextual Behavioral Science (ACBS), Student Member ACBS Children, Adolescents and Families Special Interest Group, Acting Secretary/Treasurer American Psychological Association of Graduate Students (APAGS), Student Member Association for Behavior Analysis International (ABAI), Student Member National Association of School Psychologists (NASP), Student Member Utah Psychological Association (UPA), Student Member

Golden Key International Honour Society

Psi Chi National Honor Society in Psychology

\section{HONORS AND AWARDS}

2011

2011

2011

2010

2010

2009-2012

2005-2007

2000-2004

2000-2004

2000
Graduate Student Senate Research \& Project Grant (\$400), Utah State University

Borg Applied Practice and Research Scholarship (\$2100), Utah State University, Department of Psychology

Graduate Student Senate Travel Awards (\$600), Utah State University

Department of Psychology Travel Awards (\$600), Utah State

University

Elwin Nielsen Scholarship (\$1000), Utah State University, Department of Psychology

Krantz Research Award (\$1504), Utah State University, Department of Psychology

Dean's list

Provost's Academic Merit-Based Scholarship $(\$ 21,000)$, University of Denver

Dean's list, University of Denver

Scholar Athlete, University of Denver 